\title{
On the flexural strength and stiffness of cast glass
}

\author{
Telesilla Bristogianni • \\ Faidra Oikonomopoulou - Fred A. Veer
}

Received: 14 December 2020 / Accepted: 14 April 2021 / Published online: 9 June 2021

(C) The Author(s) 2021

\begin{abstract}
Cast glass has great potential for diverse load-bearing, architectural applications; through casting, volumetric glass components can be made that take full advantage of glass's stated compressive strength. However, the lack of engineering, production and quality control standards for cast glass and the intertwined ambiguities over its mechanical properties-particularly due to the variety in chemical compositions and the lack of understanding of the influence of flaws occurring in the glass bulk-act as an impediment to its wide-spread application. Addressing the above uncertainties, this work studies a total of 64 silicate-based glass specimens, prepared in $20 * 30 * 350 \mathrm{~mm}$ beam size, either by kiln-casting at relatively low forming temperatures (970-1120 ${ }^{\circ} \mathrm{C}$ ), or by modification of industrially produced glass. For the kiln-casting of the specimens, pure and contaminated recycled cullet are used, either individually or in combination (composite glasses). The defects introduced in the glass specimens during the casting process are identified with digital microscopy and qualitative stress analysis using cross polarized light, and are categorized as stress-inducing, strengthreducing or harmless. The Impulse Excitation Technique is employed to measure the Young's modulus
\end{abstract}

T. Bristogianni $(\varangle)$

Faculty of Civil Engineering and Geosciences, TU Delft,

Delft, The Netherlands

e-mail: t.bristogianni@tudelft.nl

F. Oikonomopoulou · F. A. Veer

Faculty of Architecture and the Built Environment, TU Delft, Delft, The Netherlands and internal friction of the different glasses. Differential Scanning Calorimetry is used on a selection of glasses, to investigate changes in the glass transition range and fictive temperature of the kiln-cast glasses due to the slower cooling and prolonged annealing. The four-point bending experiments are shedding light upon the flexural strength and stiffness of the different glasses, while the fractographic analysis pinpoints the most critical defects per glass category. The experiments show the flexural strength of cast glass ranging between 30-73 MPa, according to the level of contamination and the chemical composition. The measured $\mathrm{E}$ moduli by both methods are in close agreement, ranging between $60-79 \mathrm{GPa}$. The comparison of the flexural strength with prior testing of cast glass involving shorter span fixtures showed a decreasing strength with increasing size for the contaminated specimens, but similar strengths for pure compositions. The results highlight the versatile role of defects in determining the glass strength and the complexity that arises in creating statistical prediction models and performing quality control.

Keywords Cast glass - Glass flexural strength · Glass defects $\cdot$ Recycling of glass waste $\cdot$ Mechanical properties of glass - Glass contamination

\section{Introduction}

Only within the last two decades, have we seen architectural projects exploring the structural potential of 
cast glass components, such as the Atocha Memorial (Paech and Göppert 2008) and the Crystal Houses (Oikonomopoulou et al. 2018a,b). Recent research by the authors has further shown that casting glass components for architectural applications can be a promising upcycling approach for currently discarded glass of a variety of chemical compositions (Oikonomopoulou et al. 2018c; Bristogianni et al. 2018, 2019). Volumetric glass components are anticipated to tolerate a far higher contamination rate than thin-walled glass, allowing for the closed-loop recycling of different glass types in their as-received condition (e.g. coated glass), reducing in this manner the need for treatment and purification.

Yet, despite the rising interest on cast glass from architects, designers and engineers, the lack of a standardized production method, quality control process and relevant engineering data and thus, the intertwined knowledge gaps on the strength of such components, hinder the upscaling of its application. Added complexity is introduced in the case of the aforementioned environmental aspirations, where recycled glass cullet and lower casting temperatures are employed to reduce the carbon footprint of cast glass components. The presence of impurities in the batch and the high forming viscosities introduce inhomogeneities in the cast glass, creating unique identities of mechanical and aesthetical properties, closely related to glass composition and inherent defects.

This study addresses the uncertainties surrounding the design strength and stiffness of cast silicatebased glasses, and the quality control procedure to be followed, as a continuation of previously published research by Bristogianni et al. (2020). ${ }^{1}$ For this purpose, $20 * 30 * 350 \mathrm{~mm}$ glass beams are kiln-cast at relatively low forming temperatures $\left(970-1120^{\circ} \mathrm{C}\right)$, using pure and contaminated silicate-based cullet, either individually or in combination. Reference specimens made from industrially produced glass are employed for com-

\footnotetext{
1 This work explores the flexural strength and stiffness of $30 * 30 * 240 \mathrm{~mm}$ recycled glass beams. The specimens are kilncast at $820-1120^{\circ} \mathrm{C}$ using different types of pure and contaminated silicate-based glasses. The occurring glass defects are documented and correlated to the used casting parameters. The fourpoint bending experiments on the pure and contaminated specimens show a flexural strength range of 9-72 MPa. The Young's modulus of the more homogeneous glass beams ranges between 65-79 GPa. The test results are analysed according to the role of the chemical composition, level of contamination and followed casting parameters, in determining the flexural strength, the Young's modulus and the prevailing strength-limiting flaw.
}

parison. The beams are tested by Impulse Excitation and in four-point bending (4PB), to derive their stiffness and flexural strength. Purpose of this work is to (i) verify the previously obtained stiffness and flexural strength data while improving the accuracy of the four-point bending experiments, (ii) investigate if a longer fixture span affects the flexural strength, (iii) cross-check the E moduli resulting from the 4PB measurements with values obtained from non-destructive testing methodologies such as Impulse Excitation, (iv) examine changes in the glass nano-structure due to a longer cooling and annealing scheme, and how this thermal history affects the macro-properties, (v) further analyse the profile of the different casting defects and investigate how critical they are, and (vi) experiment with the concept of improving the glass strength by engineering composite glasses.

\section{Experimental work}

\subsection{Specimen preparation and analysis}

For the purposes of the four-point bending experiments, beams of $20 * 30 * 350 \mathrm{~mm}$ size are kiln-cast from different pure or contaminated silicate-based glasses, in triplets per glass type. To achieve comparable data to preceding research (Bristogianni et al. 2020), the study focuses on the same characteristic commercial silicate glasses as the ones used before, and adopts the same casting process and thermal history for the majority of the samples (unless otherwise stated). The chemical composition of the glass cullet types is defined by Xray fluorescence (XRF) analyses conducted with a Panalytical Axios Max WDXRF spectrometer. The beams are kiln-cast in silica-plaster investment moulds (Crystalcast M248 ${ }^{2}$ ) using an ROHDE ELS 200S or ELS 1000S electric kiln (Fig. 1). The forming temperatures range from 970 to $1120^{\circ} \mathrm{C}$, corresponding to viscosities between $10^{6}-10^{3.5} \mathrm{dPa}$ s. The moulds containing the glass cullet are heated up to the selected forming temperature per glass type with a rate of $50^{\circ} \mathrm{C} / \mathrm{h}$, kept at that temperature for $10 \mathrm{~h}$, and then cooled in the same kiln with a rate of $-160{ }^{\circ} \mathrm{C} / \mathrm{h}$ to a temperature $20^{\circ} \mathrm{C}$ above the annealing point. There a dwell of $5 \mathrm{~h}$ takes place before cooling down to the annealing point with

\footnotetext{
${ }^{2}$ Crystalcast M248 is an investment powder made of $73 \%$ silica powder (cristobalite, quartz), 23\% calcium sulphate (gypsum) and $1 \%$ organics (Goodwin Refractory Services 2003, 2019).
} 
a rate of $-3{ }^{\circ} \mathrm{C} / \mathrm{h}$, annealing there for $10 \mathrm{~h}$, and then controllably going down to the strain point with the same rate before cooling down to room temperature in a faster pace. Information on the chemical composition of the selected glasses, and on the forming and annealing temperatures used per glass type can be found in Table 1 . The only exception to the above described firing schedule is the sample type "FT ${ }^{3}$ Float $1120^{\circ} \mathrm{C}$, $2 \mathrm{~h},-50^{\circ} \mathrm{C} / \mathrm{h}$ ". In this case, a shorter dwell time of $2 \mathrm{~h}$ is kept at forming temperature, and a slower cooling rate of $-50{ }^{\circ} \mathrm{C} / \mathrm{h}$ instead of $-160{ }^{\circ} \mathrm{C} / \mathrm{h}$ is used for the cooling segment to the $20{ }^{\circ} \mathrm{C}$ above annealing point temperature. The different firing schedule is selected, in this case, to investigate the effect of the thermal history to the mechanical properties of the glass sample. For the same reason, several glass types are kiln-cast at several top temperatures (e.g. Poesia kiln-cast $970{ }^{\circ} \mathrm{C}$ vs $\left.1070{ }^{\circ} \mathrm{C}\right)$.

Apart from the beams produced by a single cullet type, two different composite glasses are engineered. The selection of the glasses to be mixed is based on the purity of the cullet, and the stiffness and flexural strength of the individual cast glasses (as defined by (Bristogianni et al. 2020)). Goal of this mixing is to either locally (e.g. bottom beam surface subjected to maximum tension during bending) or globally reinforce a beam made from a weak/contaminated glass with a small percentage of stronger/purer compatible glass. The used ratio of pure to contaminated/weak glass is 1:3. The two produced combinations involve float glass of:

(i) AGC Blue cullet (pure, $\mathrm{E}$ modulus $=76.5 \mathrm{GPa}$, Flexural strength $=63 \mathrm{MPa}$, density $\approx 2.548 \mathrm{~g} / \mathrm{cm}^{3}$ ) mixed with FT Float (pure but prone to crystallization, E modulus $=72.7 \mathrm{GPa}$, Flexural strength $=44 \mathrm{MPa}$, density $\approx 2.508 \mathrm{~g} / \mathrm{cm}^{3}$ ). In this combination, a localized reinforcement at the beam's bottom surface is achieved. Additional specimens are produced with localized reinforcement at the beam's side surface, exposing in this manner both the pure and weak glass qualities to the zone of maximum tensile stress. These additional specimens serve to investigate if the pure/weak glass

\footnotetext{
${ }^{3}$ FT refers to glass shards collected from Fully Tempered float glass panes. The heat-treatment history of the shards is erased during casting and the final kiln-cast components are simply annealed.

${ }^{4}$ Density measured with the Archimedes' Principle.
}

interface is a stress inducing factor that can lead to component failure.

(ii) AGC Clear pure cullet mixed with contaminated Maltha Car windshields cullet (Flexural strength $=41 \mathrm{MPa}$ ). The clear glass in this case diffuses throughout the beam's mass, leading to a global improvement of the properties.

Prior to arranging the different cullet types inside the mould, a simple two step test showing the viscosity and density differential between the mixed glasses is made at the selected top temperature, as seen in Fig. 2. The information derived from this test are used in combination with the selection of cullet size, in order to engineer the desired composite glasses. More specifically, in the first scenario (i), the AGC blue glass will soften faster at the selected top temperature, and flow to the bottom of the mould due to its higher density. A localized reinforced surface out of AGC blue glass can be produced, either by placing the coarse (as received) blue shards at the bottom of the mould and then placing on top the FT shards, or by arranging the blue cullet sideways, parallel to an FT float part precast into one piece, which due to its size will take longer to melt (confining thus the blue glass in its specified region). For the second scenario (ii), given that the two glasses have very similar melting behavior-with the contaminated one being slightly heavier and the pure one less viscous-an arrangement of the pure cullet at the bottom of the mould in combination with a long dwell time of $10 \mathrm{~h}$ at top temperature, will promote the diffusion and intermixing of the two glasses leading to a more global reinforcement (Figs. 3, 4).

All kiln-cast specimens are cast with their side surfaces $(20 * 350 \mathrm{~mm})$ oriented at the bottom and top of the mould. The beams are produced at a $40 \mathrm{~mm}$ height, and then cut to size $(30 \mathrm{~mm})$ with a water-cooled rotary diamond wheel cutter. This step is necessary to remove compositional inhomogeneities, seeds, stones and crazing often occurring at the top cast surface. Then, the specimens are ground and polished using a Provetro flat grinder and diamond abrasive discs in sequence of 60, 120, 200, 400 and 600 grit.

Moreover, a series of tack-fused float glass specimens is produced. Two $10 \mathrm{~mm}$ float plies are placed on thin kiln paper above the kiln's base and heated up to $650{ }^{\circ} \mathrm{C}$ for $1 \mathrm{~h}$. Upon annealing and cooling, the fused plate is cut and polished to beam size. As the fusing temperature and dwell are not sufficient for a complete 

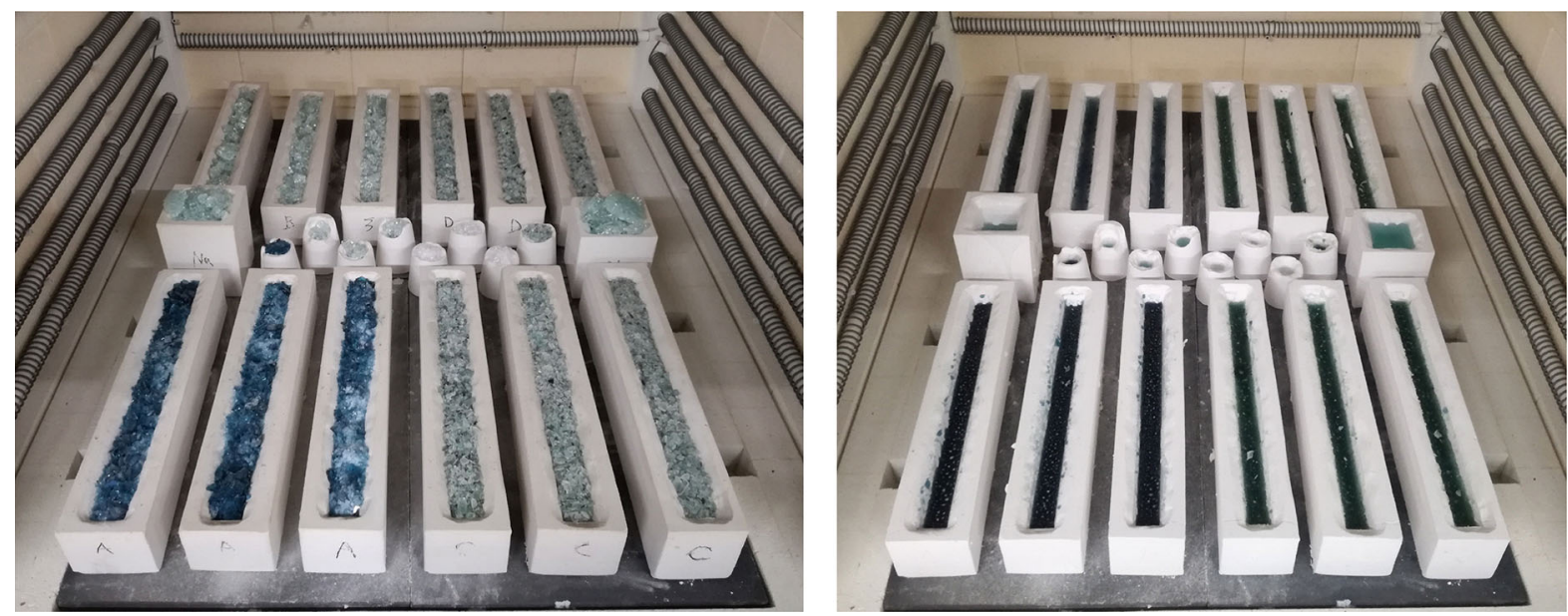

Fig. 1 Arrangement of the investment moulds and glass cullet inside the ROHDE ELS 1000S kiln (left) and final kiln-cast components after a complete heating and cooling cycle
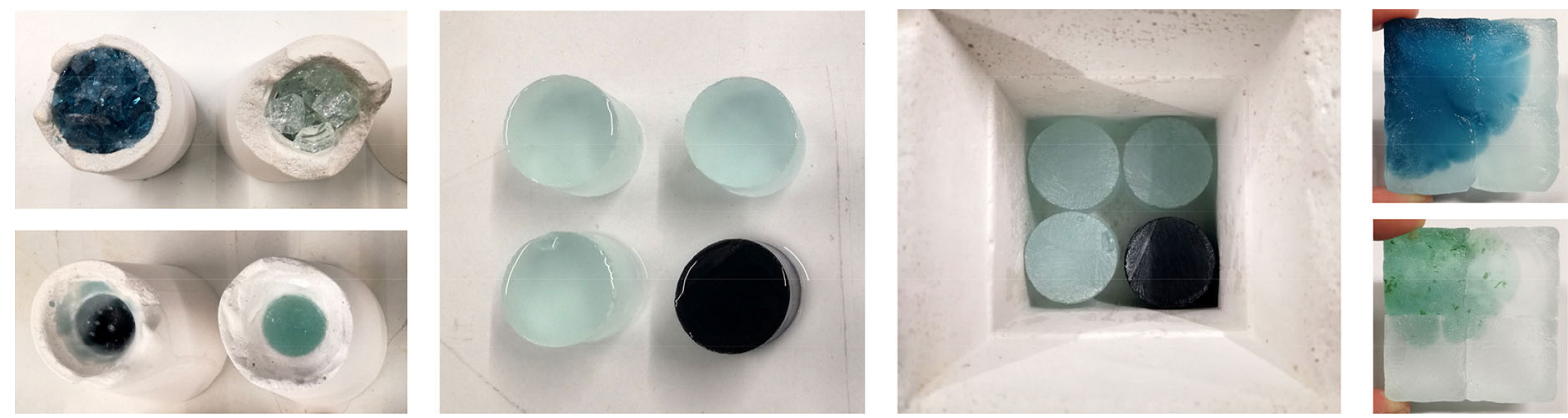

Fig. 2 Two-step viscosity test from left to right: kiln-casting of $\varnothing 24 \mathrm{~mm}$ rods out of FT Float and AGC Blue cullet at $1120^{\circ} \mathrm{C}$, polishing of the rods, kiln-casting of the rods in $50 * 50 \mathrm{~mm}$ area investment moulds at $1120^{\circ} \mathrm{C}$, and studying of the compatibility and mixing gradient of the two glasses. In the images on the right,

bonding between the two panes, a dominant weak zone is introduced at the longitudinal middle of these beams.

In addition to the kiln-cast and tack-fused specimens, industrially produced specimens are prepared to serve as a reference. The specimens are cut in size and the damaged cut surfaces are polished in the same procedure as previously described, while the rest of the surfaces are left in the as received condition (fine glossy polishing, occasional scratches). The reference specimens are divided in the categories below:

- Beams cut out in $20 * 30 * 350 \mathrm{~mm}$ size from Poesia cast glass frames. ${ }^{5}$

\footnotetext{
5 The specific cast glass frames were produced as test pieces for the Crystal Houses façade (Oikonomopoulou et al. 2018a), in a $65 * 150 * 790 \mathrm{~mm}$ size.
}

a comparison can be seen between the FT Float-AGC Blue combination (top) and the Car glass-AGC Clear mix (bottom). These relationships help determine the positioning of the different cullet types in the mould in order to achieve the desired composite glass

- Single float glass panes of $10 * 30 * 350 \mathrm{~mm}$ size.

- Double float glass panes of $8 * 30 * 350 \mathrm{~mm}$ size, laminated (thickness of interlayer $\approx 700 \mu \mathrm{m}$ ). Total beam height approx. $16.6 \mathrm{~mm}$.

- Double float glass panes of $10 * 30 * 350 \mathrm{~mm}$ size, glued with UV-curing acrylate DELO 4468 (adhesive thickness varies from $30-235 \mu \mathrm{m}$ ). Total beam height approx. $19.9 \mathrm{~mm}$.

The dimensions of all the produced samples are measured with a digital caliper, and the density of a selection of samples is defined using the Archimedes' Principle. A Keyence VHX-7000 digital microscope with a $20-200 \times$ zoom lens is used for analyzing characteristic defects in the cast samples under standard and polarized illumination. The cross-polarization of the filters 
Fig. 3 Positioning of the cullet in a vertical layering (left, AGC Blue shards and FT Float precast in a single slab) or horizontal (right, AGC clear shards at the bottom of the mould and Car glass shards on top)

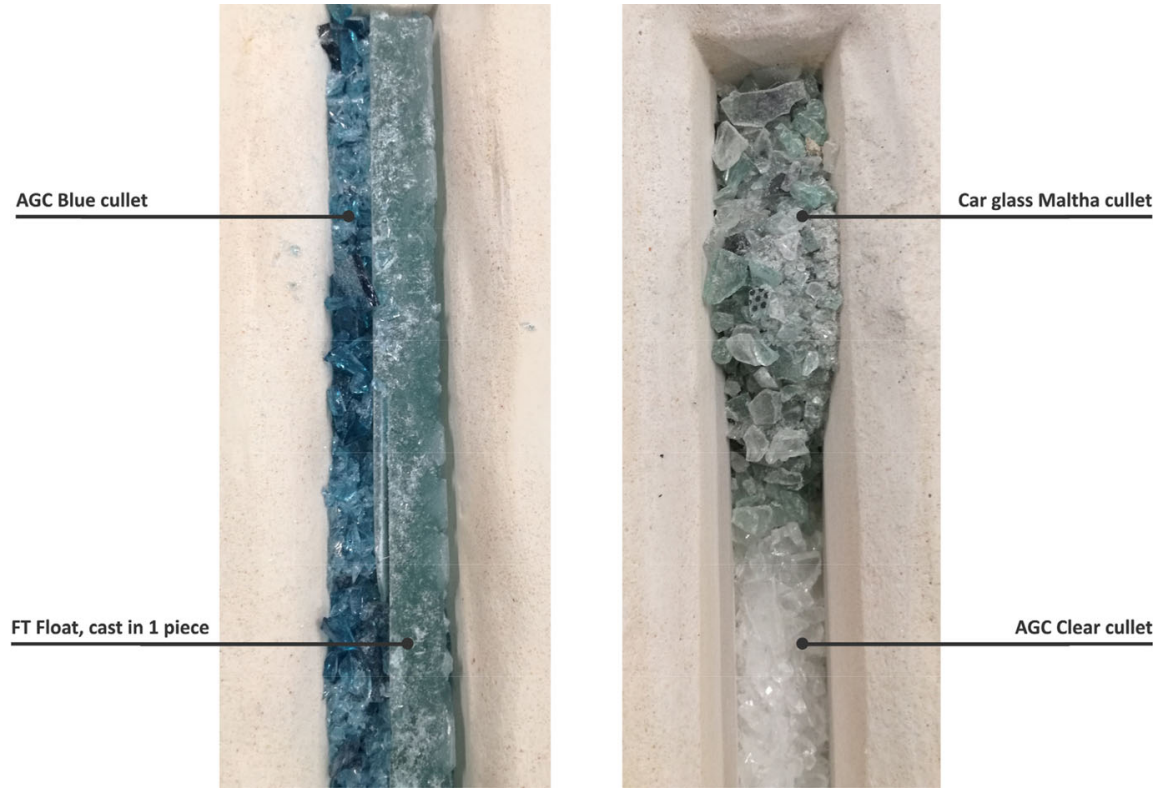

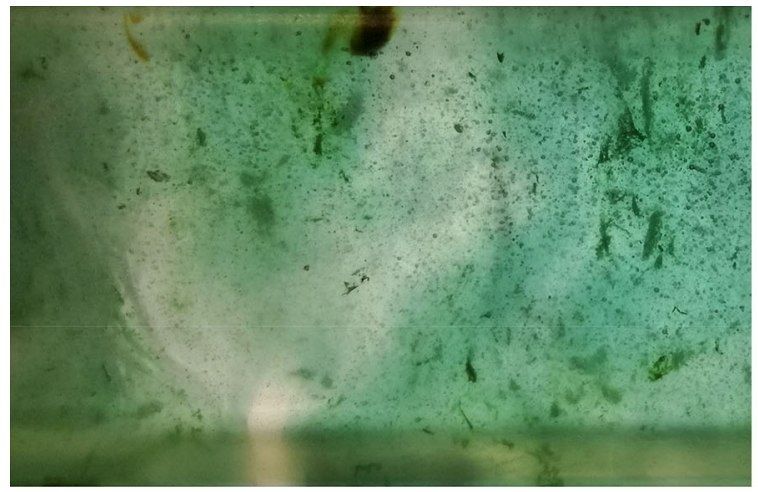

Fig. 4 Global (left, AGC Clear and Car glass) versus local (right, AGC Blue and FT Float) reinforcement. Both specimens were produced by adding the purer cullet at the bottom of the mould, so AGC clear and AGC Blue respectively. Considering however the

allows for the qualitative detection of internal stresses in the glass induced by the defects. Upon inspection of the samples, a white/black speckle pattern is sprayed on one side of the beams, to be used for the Digital Image Correlation (DIC) measurement.

\subsection{Impulse excitation test set-up and Differential Scanning Calorimetry test}

Measurements employing the Impulse Excitation Technique (IET) are performed at room temperature accord-

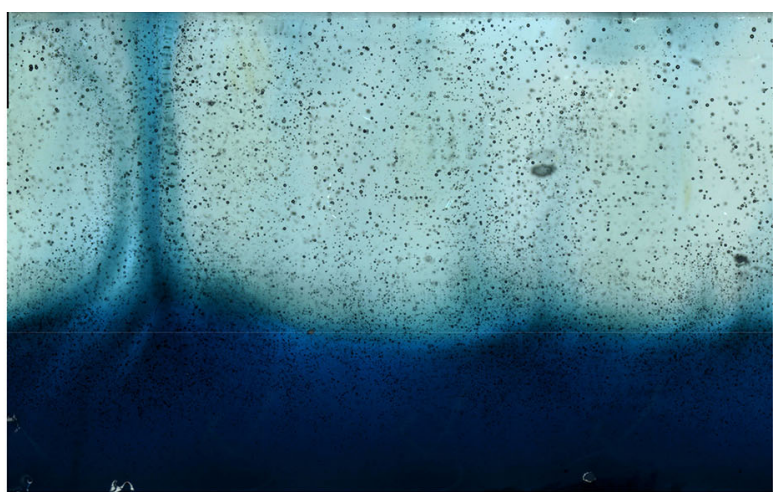

viscosity differential between the chosen pure and contaminated glasses (Fig. 2), the car glass flowed to the bottom, evoking the diffusion between the two glasses, while the AGC glass remained to its position promoting a functional layering

ing to the ASTM E1876-15 standards. Goal is to measure the elastic properties and internal friction of the glasses-using a non-destructive method-prior to the four point bending experiment, and compare the resulting E moduli from both tests. For this measurement, a Resonant Frequency and Damping Analyser (RFDA) Professional system developed by IMCE NV is used (Fig. 5). One cast specimen per cast glass triplet is selected, as well as one float glass pane to be used as reference. The samples are placed on a wire support frame and are gently tapped with a manual excitation tool at the middle of the top surface (flexural vibration 
mode). The induced vibration signal is detected by a microphone placed above the middle of the beam, and is amplified and sent to a computer for analysis. The test is repeated ten times per specimen.

The captured resonant frequency of each beam is related to its mass, dimensions and elastic properties. For rectangular beam sections ${ }^{6}$ of a homogeneous, isotropic material, the $\mathrm{E}$ modulus can be calculated from the following equation (ASTM 2002):

$$
E=0.9465\left(\frac{m \cdot f_{f}^{2}}{w}\right)\left(\frac{L^{3}}{h^{3}}\right) T
$$

where $\mathrm{m}$ is mass, $\mathrm{f}_{\mathrm{f}}$ is flexural frequency, $\mathrm{L}, \mathrm{h}, \mathrm{w}$ the length, height and width of the beam, and T is a correction factor. ${ }^{7}$ Based on the amplitude decay of the free vibration, the internal friction $\mathrm{Q}^{-1}$ is also calculated by the IMCE software.

To identify possible alterations in the glass transition region of float glass after casting, a Differential Scanning Calorimetry (DSC) analysis is conducted for a selection of glasses before and after forming, ${ }^{8}$ using a Netzsch STA 449 F3 Jupiter ${ }^{\circledR}$ apparatus. The measurements are performed in inert atmosphere (Argon) together with a correction blank sample. Pure (99.99\%)

\footnotetext{
${ }^{6}$ ASTM advises rectangular beams without chamfered or round edges to avoid calculation errors. In this study the edges are rounded to eliminate post-processing damage, so a minor error is to be expected in the calculations.

7 The correction factor $\mathrm{T}$ accounts for the finite thickness of the beam and the Poisson's ratio. For beams of $\mathrm{L} / \mathrm{h}=20$ ratio, then:

$T=1+6.858\left(\frac{h}{L}\right)^{2}$

While for $\mathrm{L} / \mathrm{h}<20$ the following formula can be used, with $v$ being the Poisson's ratio:

$$
\begin{aligned}
T & =1+6.585\left(1+0.0752 v+0.8109 v^{2}\right)\left(\frac{h}{L}\right)^{2}-0.868\left(\frac{h}{L}\right)^{4} \\
& -\left[\frac{8.340\left(1+0.2023 v+2.173 v^{2}\right)\left(\frac{h}{L}\right)^{4}}{1+6.338\left(1+0.1408 v+1.536 v^{2}\right)\left(\frac{h}{L}\right)^{2}}\right]
\end{aligned}
$$

In this study, the $\mathrm{L} / \mathrm{h}$ ratio for the float panes is 35 so the simplified formula can be used, while for the cast beams this ratio is approximately 17.5 and requires the second equation for the $\mathrm{E}$ modulus calculation. However, it is found that for the given beam dimensions and a hypothetical $\mathrm{v}=0.22$ that corresponds to typical float soda lime compositions, the difference in the E modulus deriving from the use of the simple and the elaborate formula is in the order of $0.015 \mathrm{GPa}$, thus for simplification purposes, the shorter equation can be used.

8 The samples referring to the cast specimens are collected after the 4-point bending test. alumina crucibles are used, closed with a lid that allows for gas release, and the used glass sample mass is approximately $60 \mathrm{mg}$. A heating rate of $10 \mathrm{~K} / \mathrm{min}$ is used until the samples reach $1120{ }^{\circ} \mathrm{C}$. The obtained data are analysed via the Proteus Software.

\subsection{Four-point bending experiment set-up}

A total of 64 beam specimens of $350 \mathrm{~mm}$ length, $30 \mathrm{~mm}$ width and $20 \mathrm{~mm}$ height (with the reference beams varying from 8 to $20 \mathrm{~mm}$ height) are tested in four point bending, in room temperature conditions. An Instron $1251(100 \mathrm{KN})$ Universal Testing hydraulic machine is used, set to a displacement controlled loading rate of $0.6 \mathrm{~mm} / \mathrm{min} .^{9}$ The four-point bending fixtures have a span of $140 \mathrm{~mm}$ for the loading rollers and $280 \mathrm{~mm}^{10}$ for the support rollers, and articulate in pairs. To allow for minor adjustments and rotational movements, a semi-circular pin is placed below the support fixture, while the loading fixture has a loose connection to the machine's head. The rollers are made from S355J2 (St52-3) steel, have a $14 \mathrm{~mm}$ diameter $^{11}$ and are free to roll sideways to relieve frictional constraints (free movement outwards for the support rollers, and inwards for the loading rollers). Silicone rubber strips of $1 \mathrm{~mm}$ thickness are placed between the beam and the loading cylinders to correct minor deviations in the beam's height (Fig. 6).

The displacement during loading is measured ${ }^{12}$ with the 2D-DIC technique, using a high-resolution (50.6 MP) Canon EOS 5Ds camera that captures a picture per second of the deformed speckled surface of the

9 According to the glass stiffness, the loading rate corresponds to a stress increase of $0.4-0.7 \mathrm{MPa} / \mathrm{s}$, which is below the $1.1 \pm 0.2 \mathrm{MPa} / \mathrm{s}$ rate indicated by ASTM C158-02 (2002).

10 The beam size and fixture spans are adapted from the suggested ASTM C1161-13 dimensioning. As a basis the $1.5 * 2 * 25 \mathrm{~mm}$ specimen size is used that corresponds to a 10:20 mm load span to support span.

11 The bearing's diameter is adjusted from the ASTM C158-02 (2002) suggestion for testing glass plates. For a $250 \mathrm{~mm}$ long glass beam, a $3 \mathrm{~mm}$ radius is advised.

12 A Linear Variable Differential Transformer (LVDT) displacement sensor (Solartron AX 2.5 Spring Push Probe calibrated to a $0.5 \mu \mathrm{m}$ accuracy) that reports the displacement under the middle of the beam was also used. However, since the sensor was fixed with a bolt, the full body (thus not only the spring), would move downwards during bending, resulting in a slightly higher deformation. The results of the LVDT were therefore not used in this paper. 

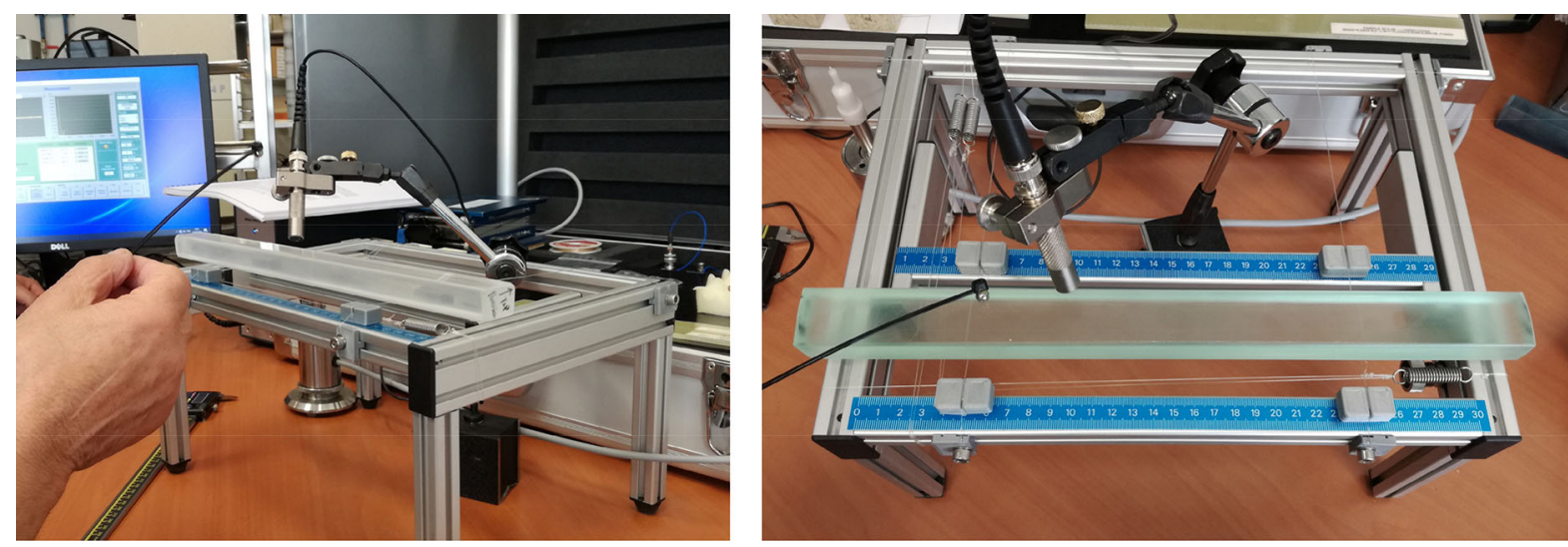

Fig. 5 Impulse Excitation experiments at IMCE NV, employing a Resonant Frequency and Damping Analyser (RFDA) Professional system
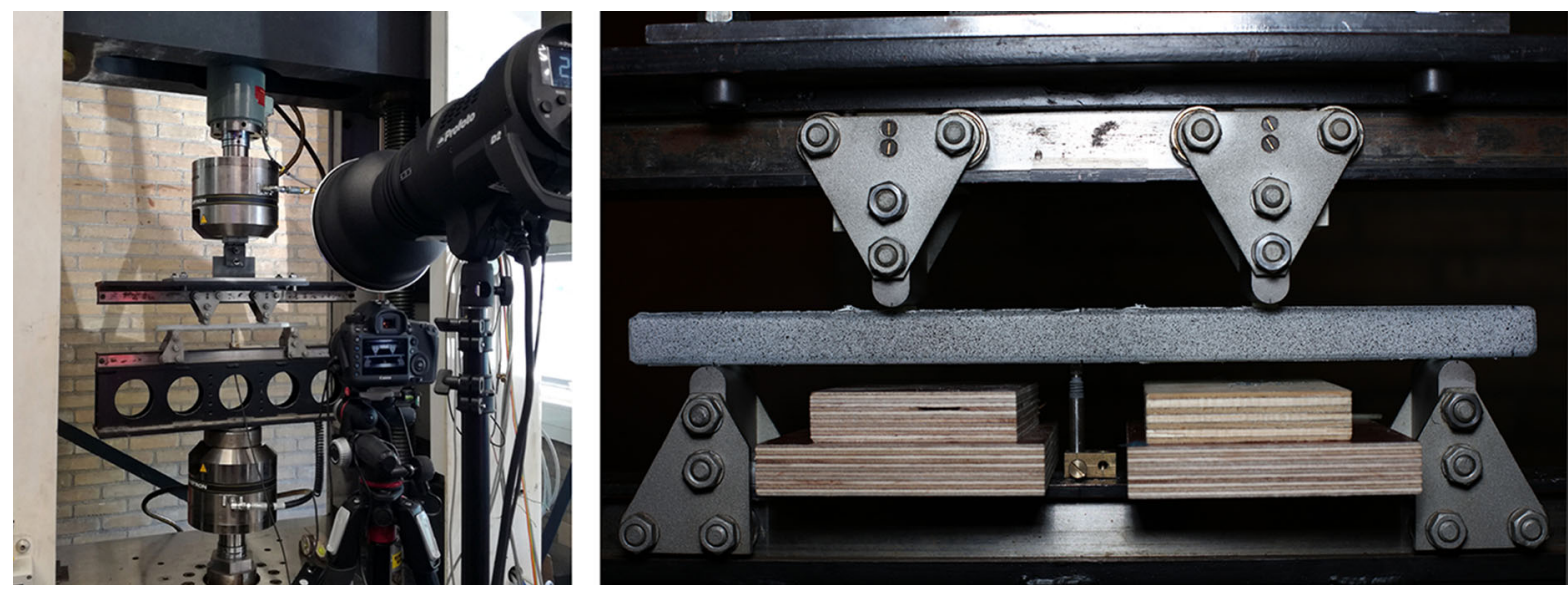

Fig. 6 Four-point bending set-up (left) and image of the beam's side surface containing the speckle pattern to be used for the DIC analysis (right)

Fig. 7 Measurement of displacement in y direction, by analyzing the captured images using the GOM Correlate software. The maximum displacement due to bending at the middle, is calculated by subtracting the total displacement at the middle from the average displacement at the beam points above the supports (displacement marked in dark yellow)

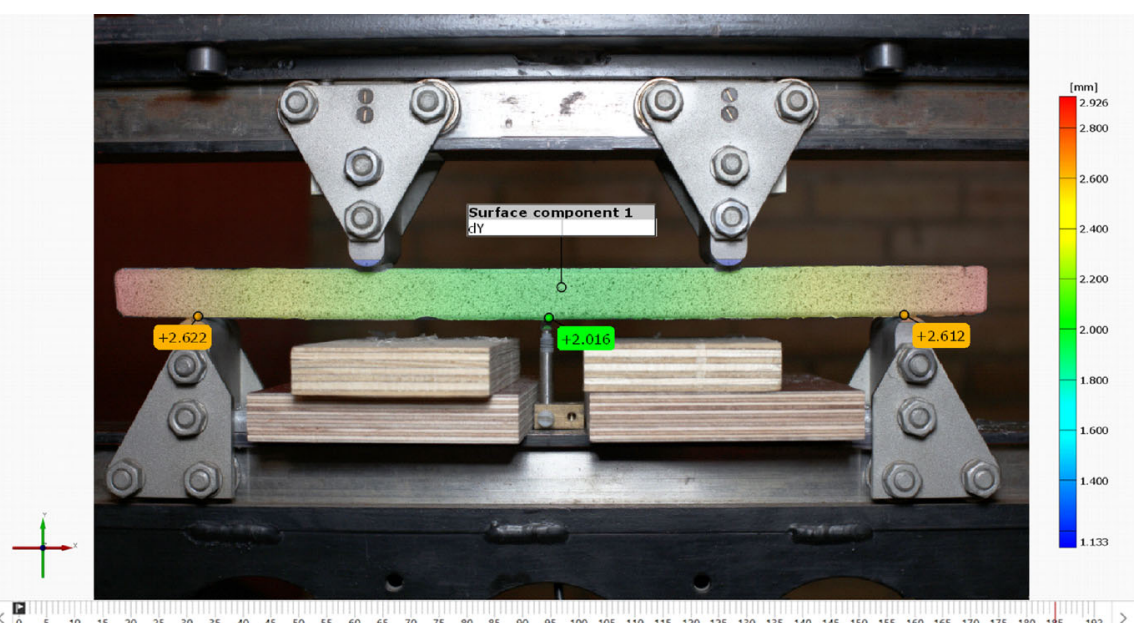


beam. The pictures are consequently analysed using the GOM Correlate software ${ }^{13}$ (Fig. 7).

For the flexural strength $(\sigma)$ calculation, the following formula is applied:

$\sigma=\frac{3 \cdot F \cdot\left(L_{s}-L_{l}\right)}{2 \cdot w \cdot h^{2}}$

where $\mathrm{F}$ the maximum load, $\mathrm{L}_{\mathrm{s}}$ the support span, $\mathrm{L}_{\mathrm{l}}$ the load span, w the beam's width and h the beam's height. The calculation of Young's (E) modulus is performed by correlating the force data obtained from the Instron machine with the maximum displacement at the bottom middle of the beam as reported by the DIC analysis. Equation 5 is applied for calculating the E modulus:

$E=\frac{\Delta F}{\Delta l_{\max }} \cdot \frac{\left(\frac{L_{s}-L_{l}}{2}\right)\left(3 L_{s}^{2}-4\left(\frac{L_{s}-L_{l}}{2}\right)^{2}\right)}{4 \cdot w \cdot h^{3}}$

Considering the beam proportion, the shear contribution to the maximum deformation is negligible and thus excluded from the E modulus calculation.

\section{Results}

\subsection{Glass casting defect evaluation}

A variety of defects are encountered in the kiln-cast glass specimens, which are formed during:

a. Casting: these flaws (e.g. stones, bubbles) are linked to the chosen casting parameters and can be situated both in the bulk and at the surface of the glass beams.

b. Post-processing and handling: these are surface flaws (e.g. scratches, chippage) that are caused during the grinding, polishing and handling of the glass beams. In this case, the quality of the diamond discs, machinery, and polishing work, act together with the predisposition of each glass type to get easily damaged (for example due to low hardness or the presence of surface stones).

In this chapter, first the casting related defects (a) will be discussed, linking them to the casting parameters responsible for their formation. Thereafter, both casting (a) and post processing (b) defects will be evaluated, according to the effect they have on the glass, based on the characterization proposed by Aldinger and de Haan (2019) in:

\footnotetext{
13 One image pixel equals to $31.5 \mu \mathrm{m}$, therefore given the software accuracy of 0.05 pixel, displacements larger than $1.57 \mu \mathrm{m}$ are detected.
}

- Stress increasing: these are defects that introduce stress in the glass that adds to a stress created by an applied load. Such defects can be situated in the bulk or/and at the surface of the glass.

- Strength reducing: these defects reduce the strength of glass and are mainly concerning surface flaws in this research work.

The effect of the different flaws will be further evaluated by analyzing the results of the four-point bending experiments. Understanding the cause and the effect of the different encountered flaws will contribute to distinguishing the tolerable from the critical defects, and will indicate how the occurrence of the later can be avoided.

\subsubsection{Defects due to the casting process}

Table 1 presents an overview of the defects found in the kiln-cast beams which form during the casting process at the chosen high viscosities. The documentation of and the reasoning behind the occurring defects are required to understand the structural performance of the specimens in the succeeding sections.

The majority of the specimens are made from pure cullet of a single glass composition, either manually selected and cleaned in the laboratory (e.g. FT float shards, Poesia glass), or gathered at the rejection point of float line production ${ }^{14}$ (e.g. ACG blue, AGC clear). In this category of more pure samples, the defects occurring due to the casting process (e.g. cullet shape and size, mould material) and thermal history (forming temperature, dwell times, cooling scheme) are highlighted. In comparison, two series of samples are made from contaminated "Car glass Matlha" cullet, highlighting the contribution of contaminants in the formation of defects during casting. Specifically, the cullet is characterized by minor compositional variations (float glass from various producers), the presence of various anti-glare and sun-blocking coatings, and of several external contaminants such as lamination foil, traces of metal and ceramic-stone-porcelain (CSP). Lastly, the defects occurring in the composite glass series are addressed.

The glass defects occurring from the selected casting parameters-from the quality and characteristics of the cullet and the type of mould to the imposed thermal history-can be categorized in three groups

$\overline{14}$ In this case, minor traces of metal contaminants may appear in the cullet. 


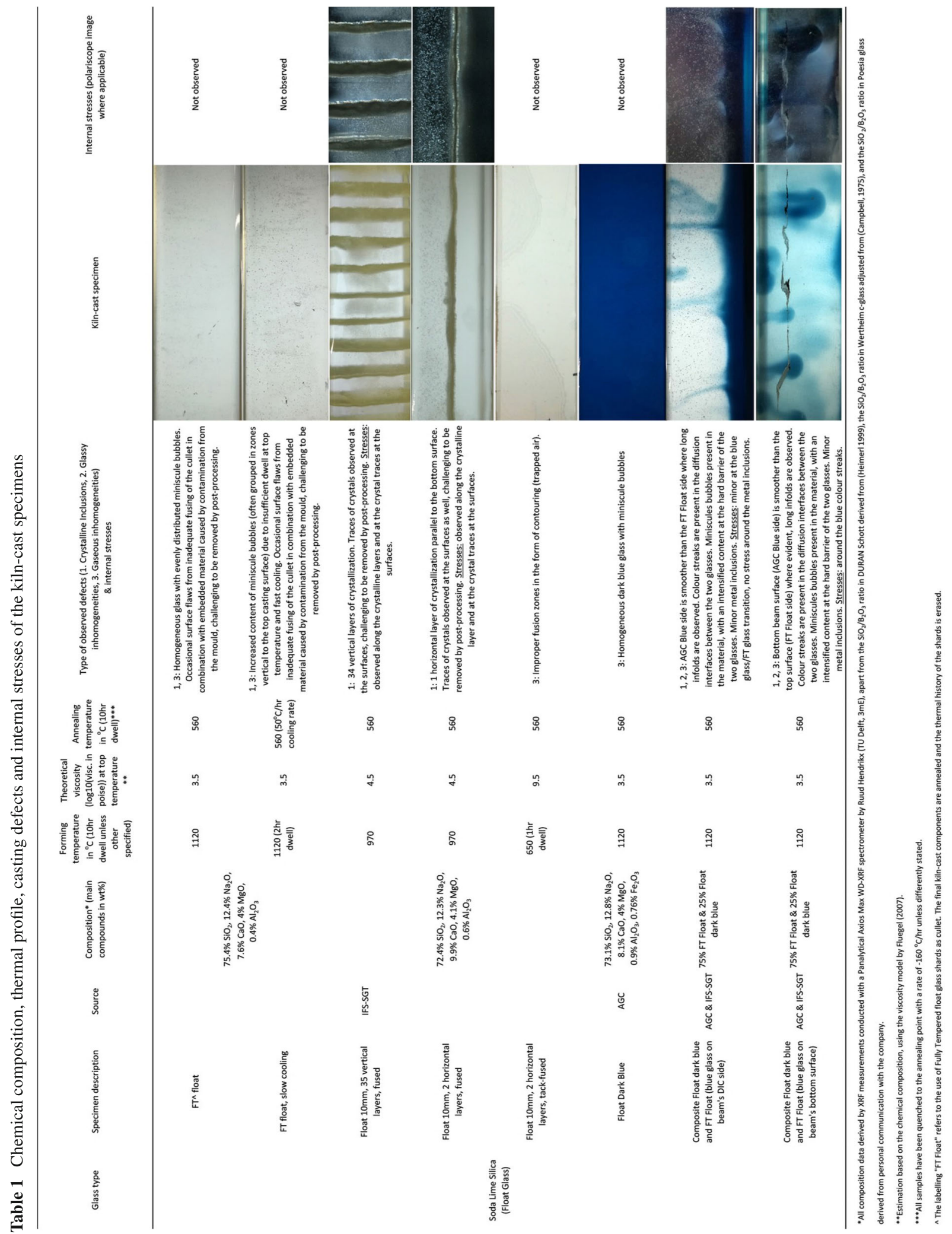




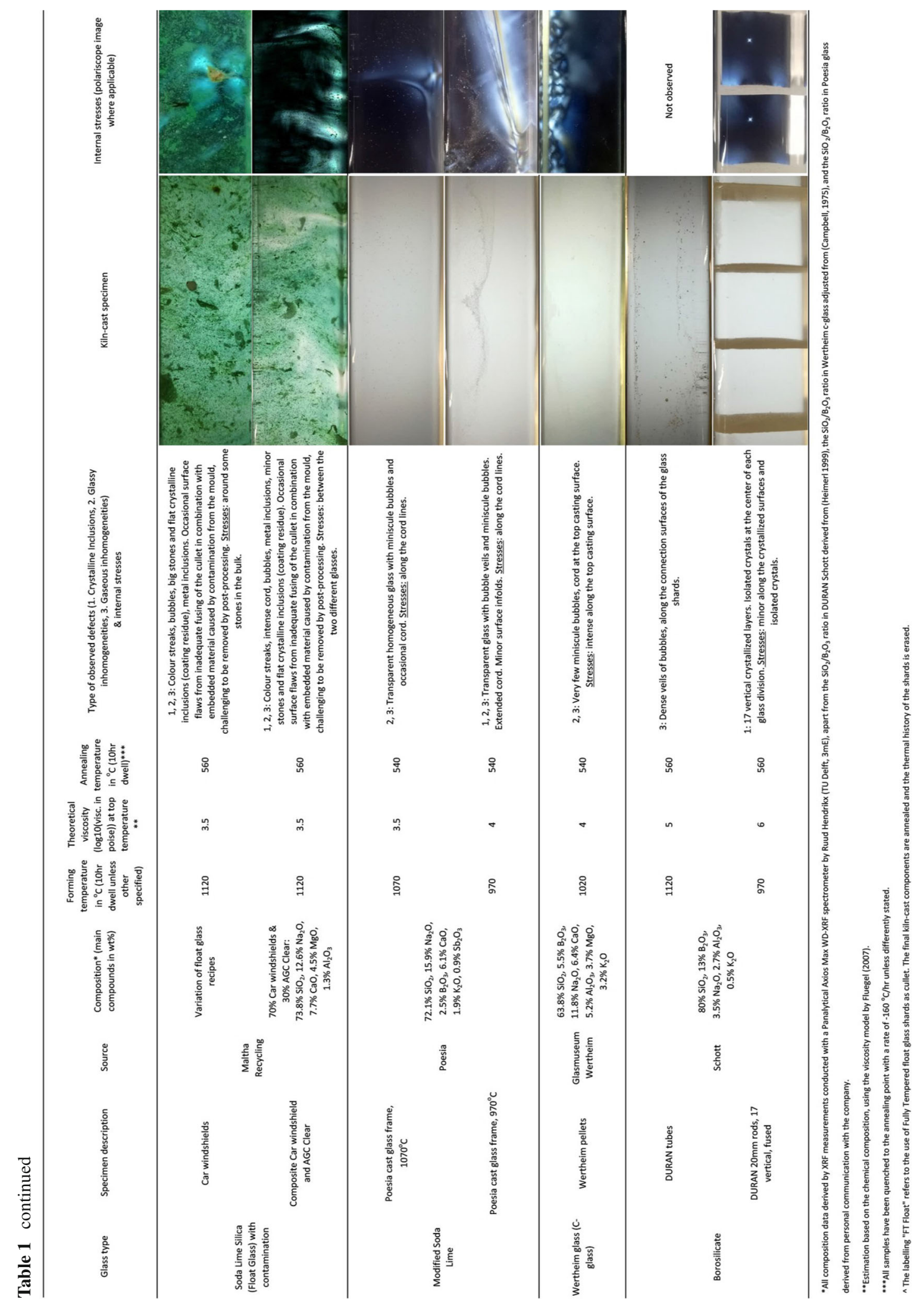


i. Crystalline Inclusions

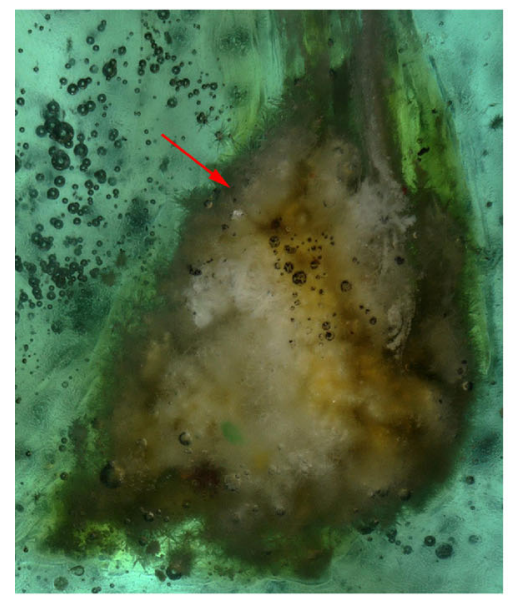

a. Cullet contamination

b. Thermal history

c. Mould contamination ii.

\section{Glassy Inhomogeneities}

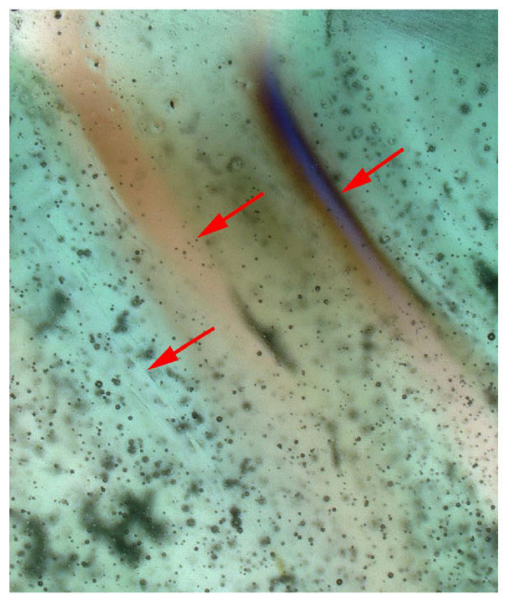

a. Glass cullet variations

b. Impartially molten contaminants

c. Element volatilization

d. Composite glasses iii.

\section{Gaseous Inhomogeneities}

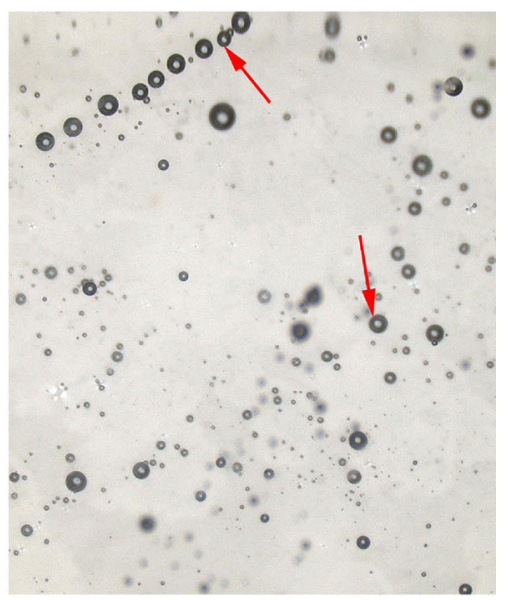

a. Air-entrapment between cullet

b. Chemical reactions

c. Reaction to contaminants

Fig. 8 Overview of the three categories of casting defects (i-iii), and the main causes of their formation

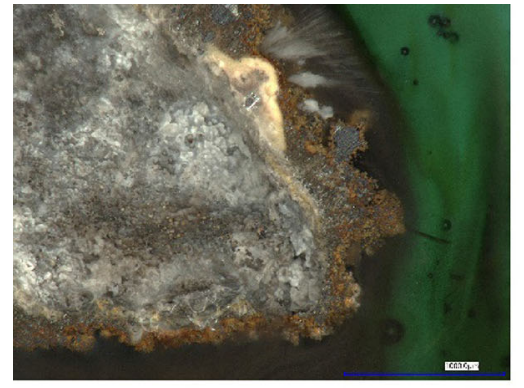

(a) Stones due to contamination

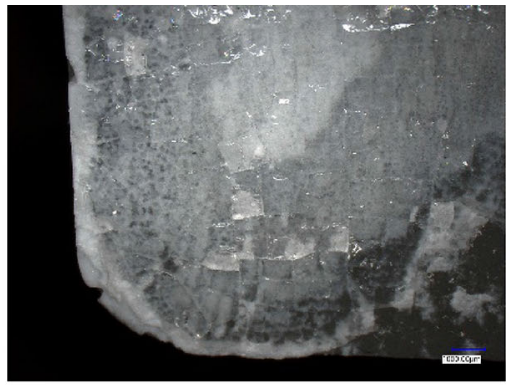

(b) Crystalline fusion interface

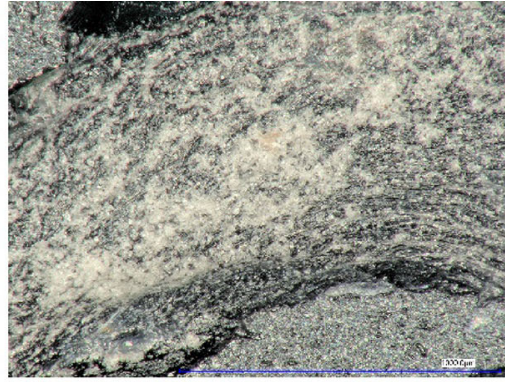

(c) Stones due to mould reaction

Fig. 9 Different causes for the formation of crystalline inclusions in the kiln-cast specimens

(Fig. 8): (i) Crystalline inclusions, (ii) Glassy inhomogeneities and (iii) Gaseous inhomogeneities (characterization according to Bartuška 2008).

The different casting defects and their causes are described below in more detail:

\section{(i) Crystalline Inclusions}

Three main causes for the formation of stones (crystalline inclusions) are observed in the specimens: (a) cullet contamination (coatings, metal/CSP traces), (b) thermal history (top forming temperature falls into the crystallization temperature range) and (c) mould contamination (Fig. 9).
Type (a) will occur both in the glass bulk and at the surface, in relation to the presence of a contaminant, (b) will occur in the fusion interfaces between the cullet pieces and can be either exposed to the surface ("Float $10 \mathrm{~mm} * 35$ vertical layers, $970{ }^{\circ} \mathrm{C}$ " sample) or mainly situated in the bulk ("Float $10 \mathrm{~mm} * 2$ horizontal layers, $970{ }^{\circ} \mathrm{C}$ " sample), and (c) will be formed at the surface and the adjacent interior zone. (Figs. 10,11) provide an overview of the occurred crystalline formations.

(ii) Glassy inhomogeneities

Glassy inclusions in the form of cord, coloured cord ("colour streak") or parallel wavy cord ("cat scratch 


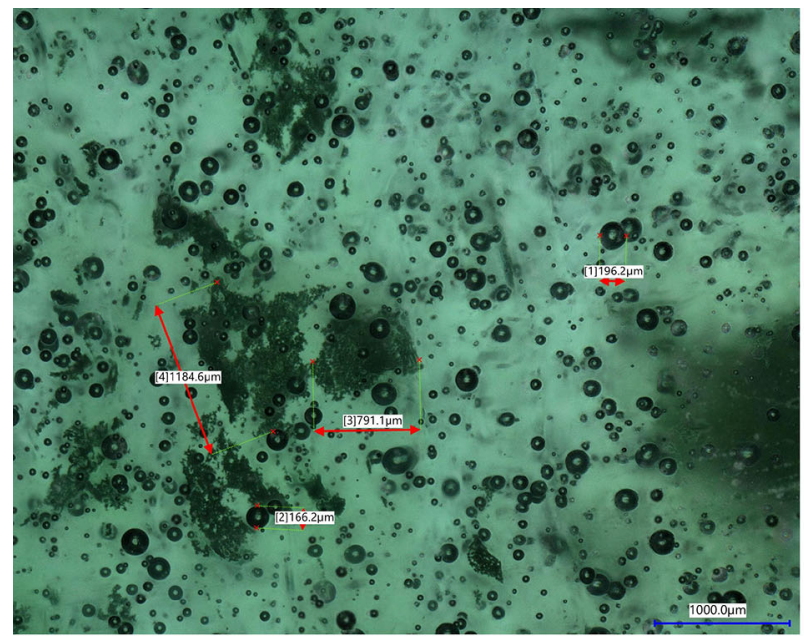

(a)

Fig. 10 Crystalline inclusions in a "Car Glass Maltha $1120^{\circ} \mathrm{C}$ " specimen. a Traces of non-molten coating in the glass bulk. These are flat inclusions of typically $0.5-1 \mathrm{~mm}$ width. b Infolds with

cord") are occasionally observed in the specimens. Cords, although potential miscible to the surrounding glass, differ either in composition, thermal history or structural arrangement (Hulínský 2008). In this study, the main causes for the occurrence of cord involve: (a) glass compositional variations in the cullet (e.g. Car glass Maltha, see Fig. 12a), (b) impartially molten coatings or metal traces (e.g. iron, see Fig. 13) resulting in colour streaks, (c) volatilization of alkali and/or boron starting from the outer surface of each cullet piece (Fig. 14), and (d) intentional mixing of two compatible glass recipes for achieving composite samples (Fig. 12b). Type (a) and (b) are mainly observed in the contaminated car glass cullet, and in the case of minor metal inclusions in the AGC blue cullet (sorted from the float line rejection point ${ }^{15}$ ). Type (c) is observed in the Wertheim and Poesia samples, both of which contain a small amount of $\mathrm{B}_{2} \mathrm{O}_{3}$ (5.5 and 2.5 in wt $\%$ respectively) and a higher content of alkali than typical soda lime silica (SLS) glasses (combined $\mathrm{Na}_{2} \mathrm{O}$ and $\mathrm{K}_{2} \mathrm{O}$ content $=15$ and 17.8 in $\mathrm{wt} \%$ respectively). The evaporation of boron, sodium and potassium from the melt is common in borosilicate furnaces (van Limpt 2007), and can lead to cord and layering in the glass

\footnotetext{
15 In-plant iron contamination is a common phenomenon from hardware and fasteners accidentally entering the cullet stream (Aldinger and Collins 2016).
}

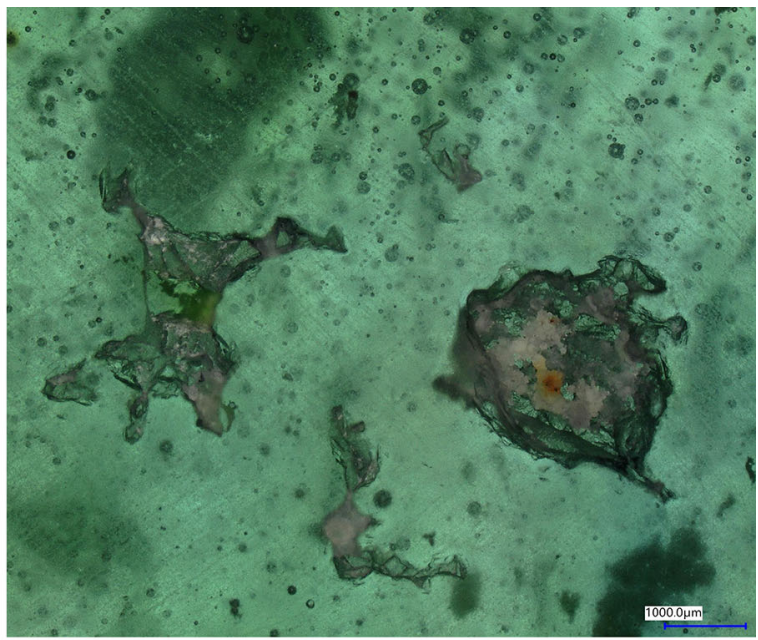

(b)

encapsulated crystalline material, resulting from contamination from the mould. The alien material could be silica, while the yellow singularity could be associated with clay contamination

structure (Hulínský 2008). In the case of the Poesia glass, the cord occurred in half of the samples, in long, often parallel waves, as a result of the chemical reactions and evaporation occurring between the glass shard interfaces during kiln-casting. Therefore this cord may potentially appear in all areas of the bulk, in relation to the initial position of the shards in the mould. On the contrary, a more heavily corded zone appeared in all Wertheim specimens, concentrated along their top casting surface. This cord is associated with the intense volatilization of boron and alkali at the top of the samples. Nonetheless, the Borosilicate DURAN specimens $\left(13 \% \mathrm{~B}_{2} \mathrm{O}_{3}, 4 \%\right.$ alkali oxides in wt $\left.\%\right)$ did not present any cord. This could be related to the lower content of alkali of the later, in combination with the higher casting viscosity used $\left(10^{5} \mathrm{dPa}\right.$ s). Lastly, type (d) cause of cord mainly appears in the form of colour streaks and parallel cord, and will have a direction relevant to the manner the cullet was structured in the mould prior to kiln-casting.

\section{(iii) Gaseous inhomogeneities}

Bubbles are present in all of the produced kiln-cast specimens, due to a number of causes, such as: (a) air-entrapment between the cullet pieces/granules, (b) chemical reactions during the bonding of the cullet pieces and evaporation of volatile components, and (c) 

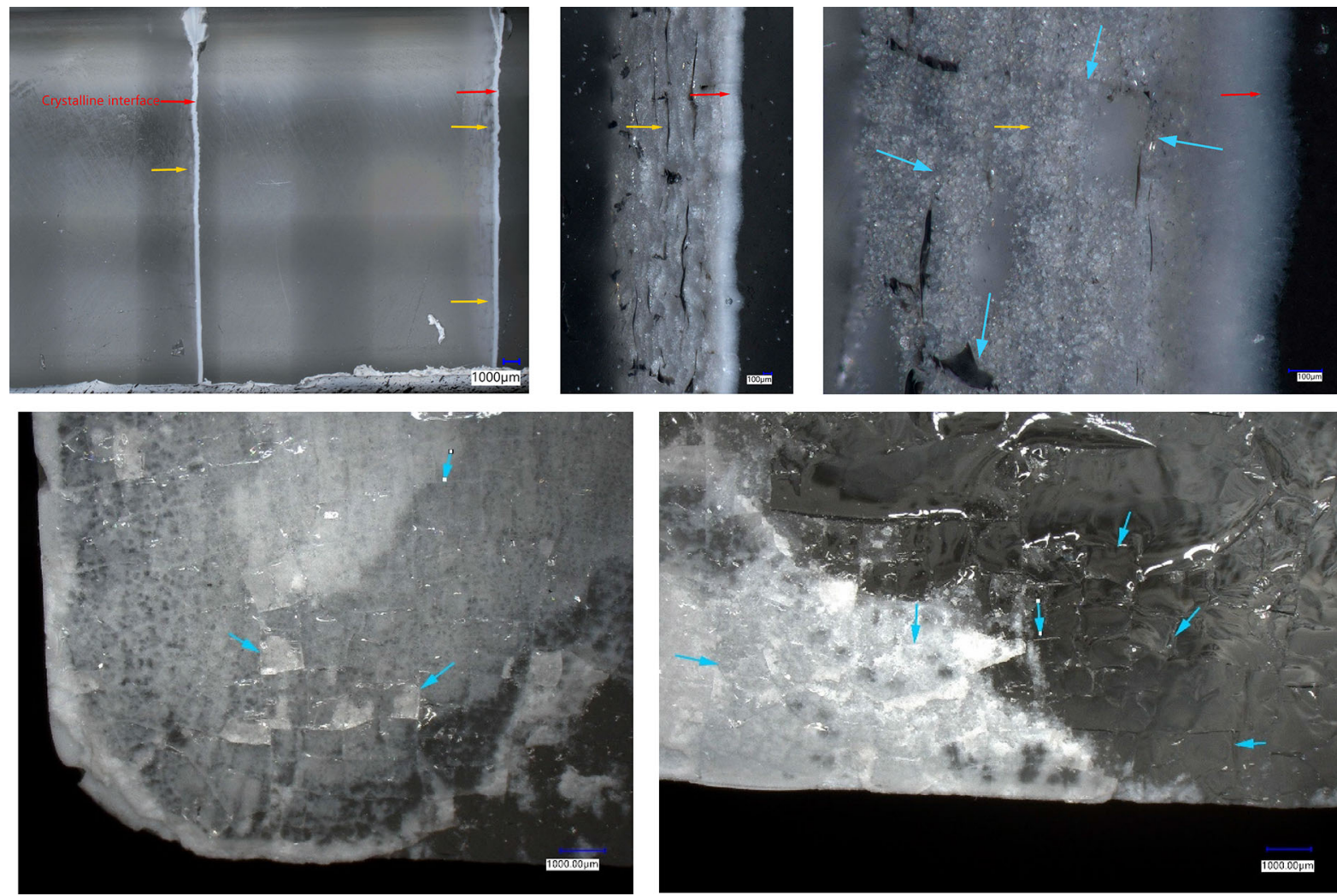

Fig. 11 Crystalline interfaces in the "Borosilicate DURAN rods, $970{ }^{\circ} \mathrm{C}$ specimen. The top row images show the beam's side surface (focusing at different depths). The red arrows point out the interface at the surface (ground and polished) while the orange arrows show part of the interface in the bulk, as seen through the glass. The interior view of the interface reveals parcellation (blue arrows) and miniscule round particles. Previous X-Ray Diffraction analysis (Bristogianni et al. 2020) identified this crystal as $\beta$-cristobalite. $\beta$-cristobalite is a typical crystallization product of low-alkali silicate glasses such as the studied borosilicate glass, and form dendrites that are structured at $90^{\circ}$ angles (Bartuška 2008), leading to the depicted parcellation. This structure (blue arrows) can be seen more clearly in the images at the bottom row, which show a fractured glass-crystalline interface (beam's cross section view). The imprint of this geometry passes also to the glassy part of the fractured interface (bottom right image) reactions and impartial melting of CSP and metal inclusions. Overall, the maximum bubble size measured, was $805 \mu \mathrm{m}$ in a Borosilicate DURAN tubes $1120^{\circ} \mathrm{C}$ specimen. The high forming viscosities used in this study do not facilitate the removal of such bubbles. As a result, glass made from fine-sized cullet (e.g. Car glass Maltha) or random shaped small shards (e.g. FT Float) at a $10^{3.5} \mathrm{dPa}$ s viscosity, will contain numerous, evenly distributed bubbles in the first case, or a network of bubbles that starts along the cullet bonding surfaces and slowly moves upwards with prolonged dwell times in the latter case. The increase of dwell time at top temperature will promote the connection of bubbles into larger air-pockets that can rise more easily out of the melt (see FT Float 2 h vs 10 h, Fig. 15). On the other hand, spec- imens produced from larger orthogonal or cylindrical glass pieces, vertically organized inside the mould (e.g. Borosilicate DURAN rods $970{ }^{\circ} \mathrm{C}$, Float $10 \mathrm{~mm} * 35$ $970{ }^{\circ} \mathrm{C}$ ) would have the least occurrence of bubbles, despite their forming at lower temperatures (corresponding viscosity $10^{4.5 \text { to } 6} \mathrm{dPa}$ s), as the air could easily chimney up. The use of large irregular shaped cullet horizontally structured inside the mould will promote the formation of bubble veils in the bulk but also along the vertical surfaces of the mould (Fig. 16a). In practice, small clusters of bubbles in the bulk are negligible in terms of final component strength, but can deteriorate the strength if exposed at the surface of the cast object. Yet, despite their negative function as defects in the final product, bubbles, according to Němec (2008), can be 


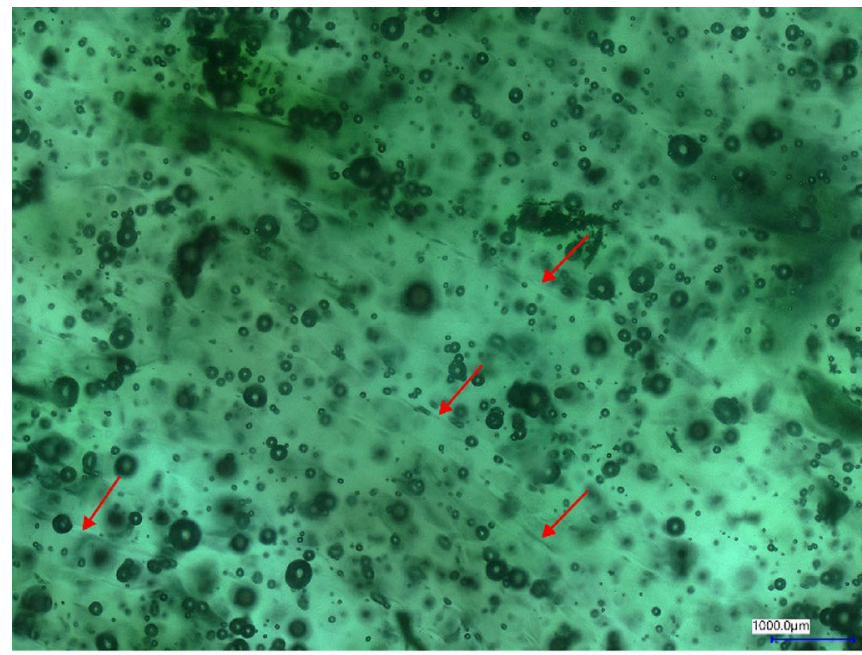

(a)

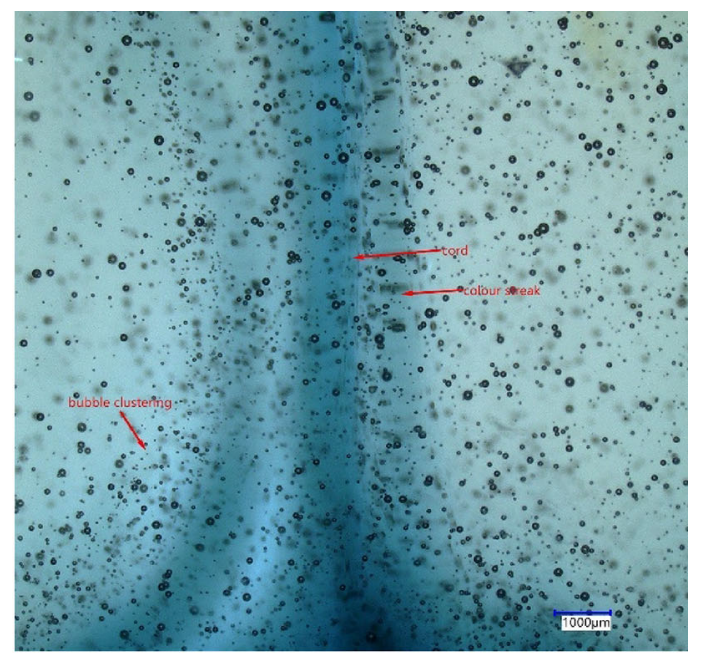

(b)

Fig. 12 a Cord in a Car Glass Maltha specimen due to compositional variations in the cullet, b cord and colour streaks in an composite AGC Blue \& FT Float specimen at the mixing interface of the two glasses

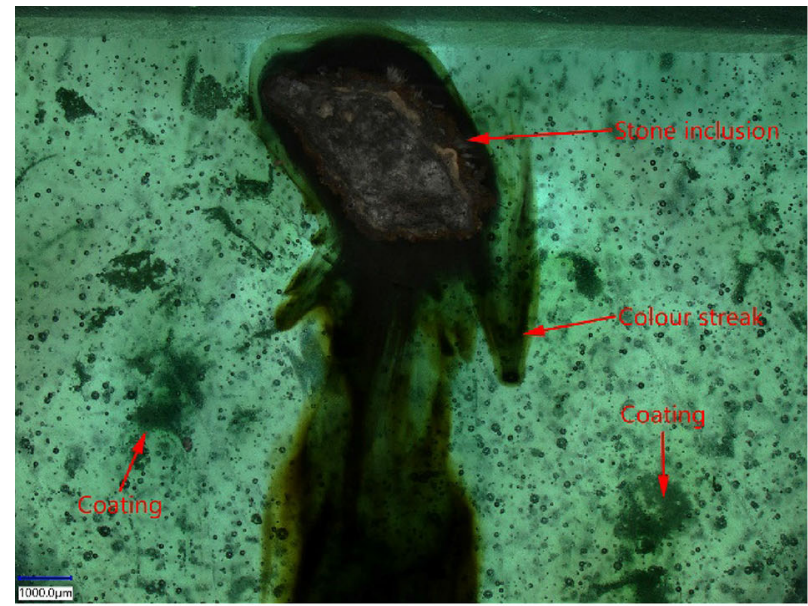

(a)

Fig. 13 Brown-green colour streaks associated with the impartial melting of a stone or metal inclusion in a Car Glass Maltha and $\mathbf{b}$ AGC Blue specimen. The lack of high stress in the cross-

beneficial to the molten glass, as their movement promotes convection and homogenization. This is particularly observed in the "AGC blue \& FT float-blue glass on beam's side" composite samples, where the upward movement of the bubbles assists in the mixing of the AGC blue glass (positioned at the bottom of the mould) with the FT glass (located on top), as seen in Fig. 16b.

A special category of gaseous inhomogeneity is observed in the tack fused "Float $10 \mathrm{~mm} * 2$ horizon-

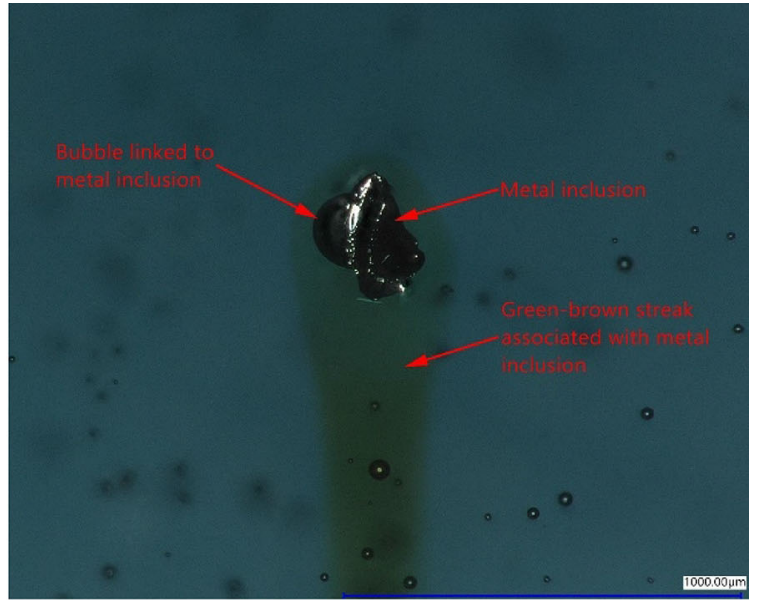

(b)

polarized image on the right, and the colour of the streak suggest iron contamination (Aldinger and Collins 2016)

tal layers, $650^{\circ} \mathrm{C}$ " (Fig. 17), in the interface of the two float plies. Due to the low fusing temperature $\left(650^{\circ} \mathrm{C}\right)$ and the insufficient dwell time $(1 \mathrm{~h})$, extended zones of entrapped air and inadequate fusion appear along the interface. 


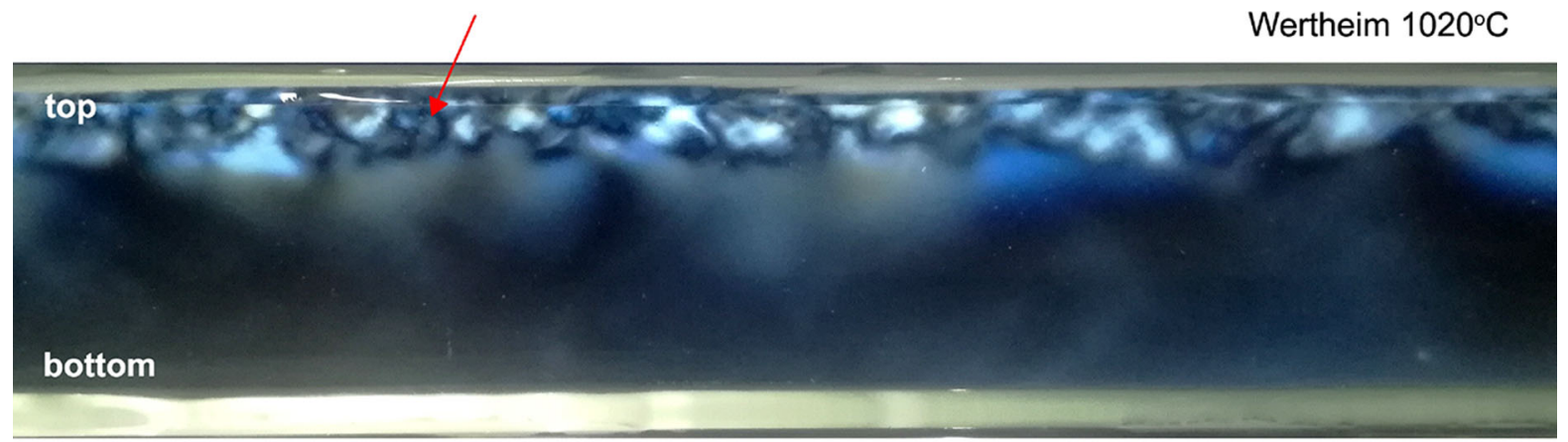

Poesia $1070^{\circ} \mathrm{C}$

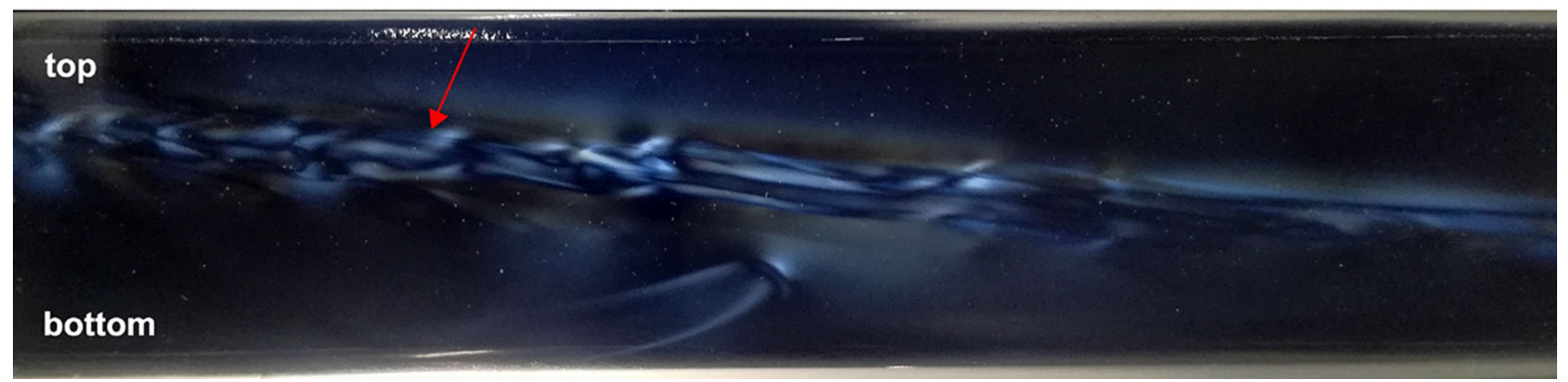

Fig. 14 Cross-polarized images of a Wertheim $1020^{\circ} \mathrm{C}$ and a Poesia $1070{ }^{\circ} \mathrm{C}$ specimen, showing concentrated cord at the top casting surface in the first case, and a diagonal cord across the beam's height in the later. The first example is associated with the volatilization of alkali and boron compounds from the melt, while in the Poesia example, the cord is formed at the meeting point between two large glass shards

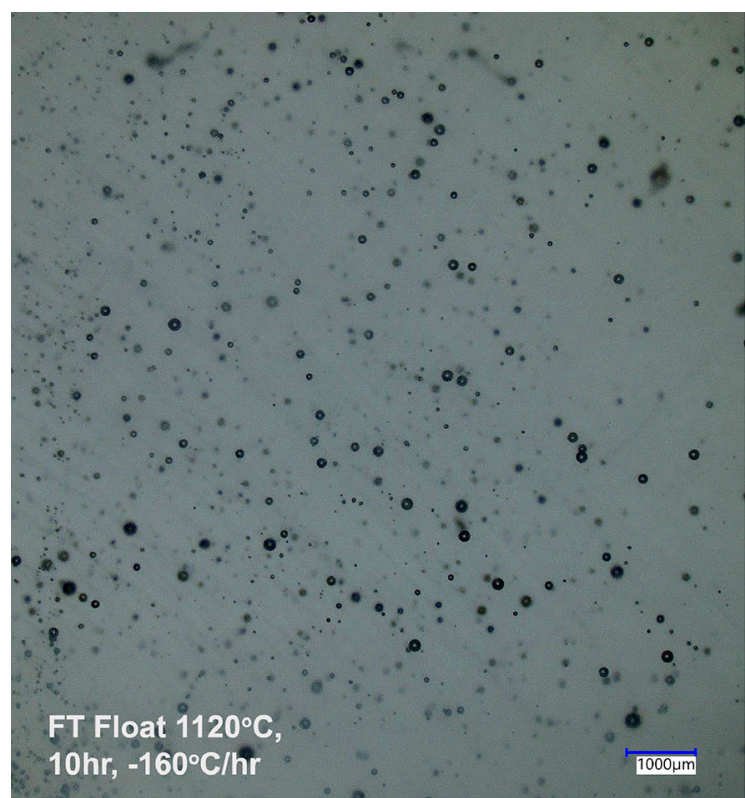

Fig. 15 Differences in the size and population of bubbles due to variations in the imposed thermal history of FT Float specimens. The specimen at the right, due to the shorter dwell at top tem-

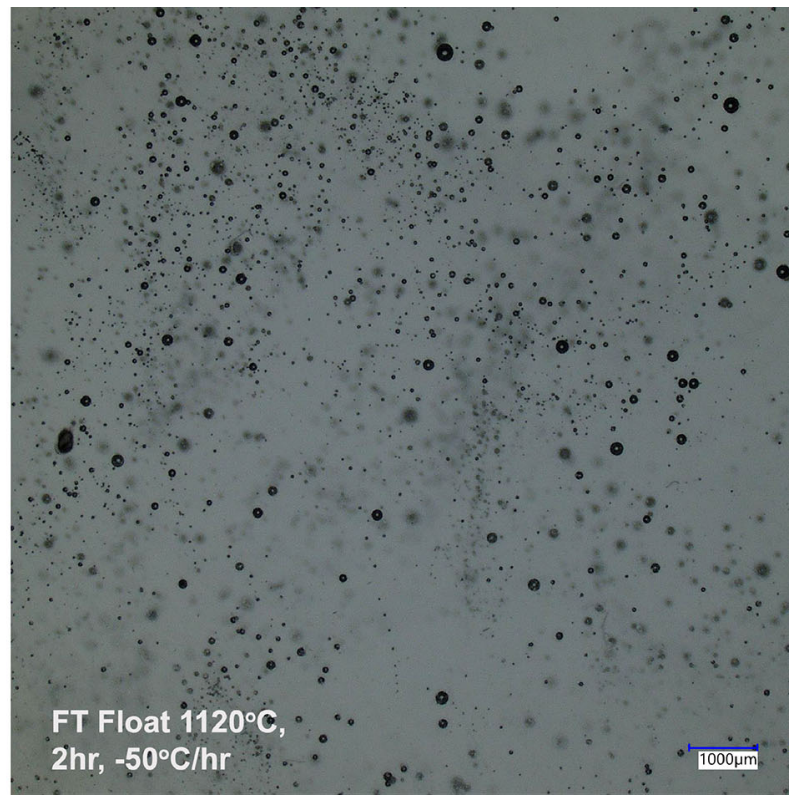

perature $\left(2 \mathrm{~h}\right.$ at $\left.1120^{\circ} \mathrm{C}\right)$ has an increased number of miniscule bubbles, which given more time, would have grouped into larger bubbles, risen to the top surface and escaped 


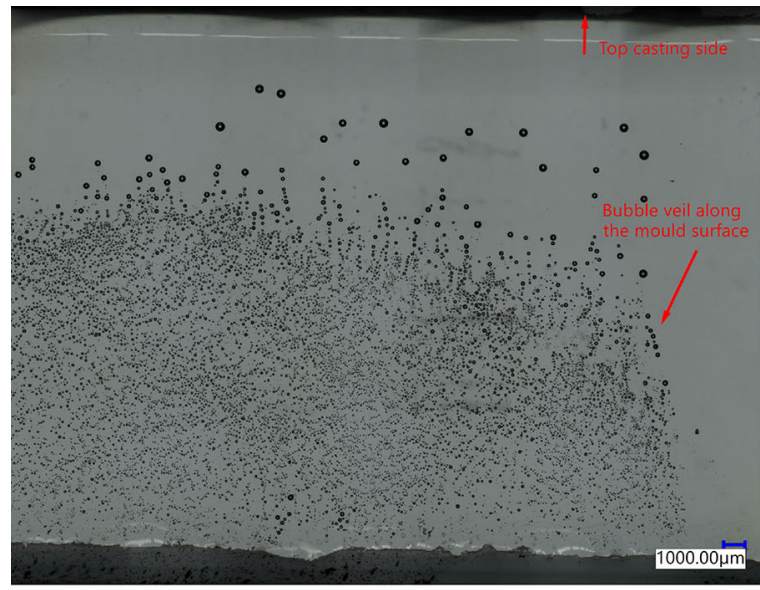

(a)

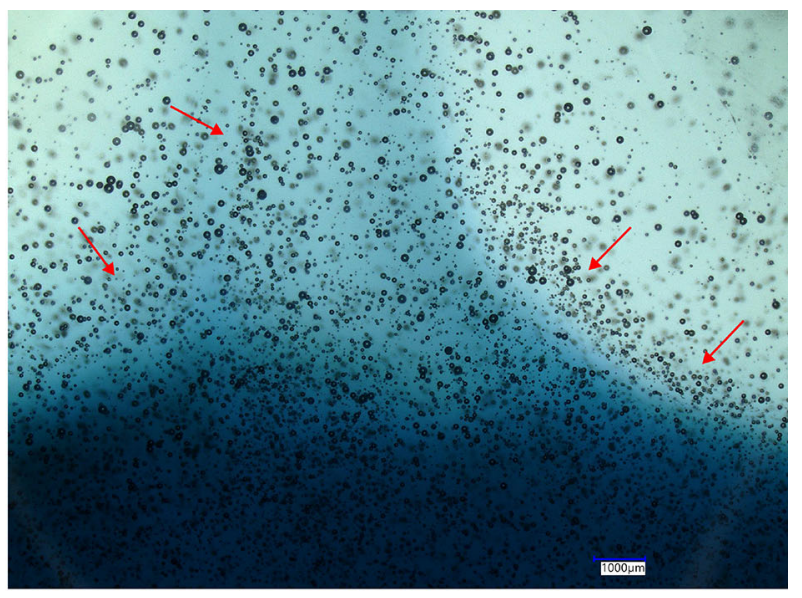

(b)

Fig. 16 Clustering of bubbles a in a bubble veil travelling upwards along the side wall of the mould, in a Poesia $970{ }^{\circ} \mathrm{C}$ specimen, $\mathbf{b}$ along the interface of the two glasses, in a AGC Blue \& FT Float composite specimen

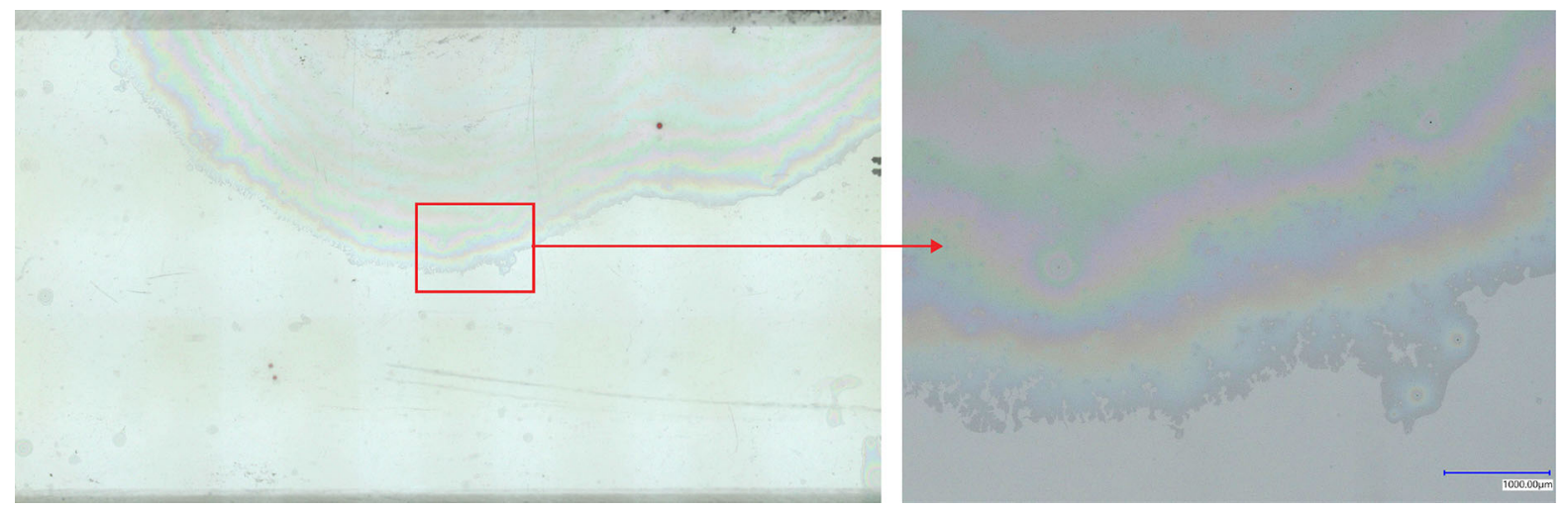

Fig. 17 Interference fringes in tack-fused $\left(650^{\circ} \mathrm{C}\right)$ float glass specimens suggest that the two glass plies are partially separated by a thin film of air
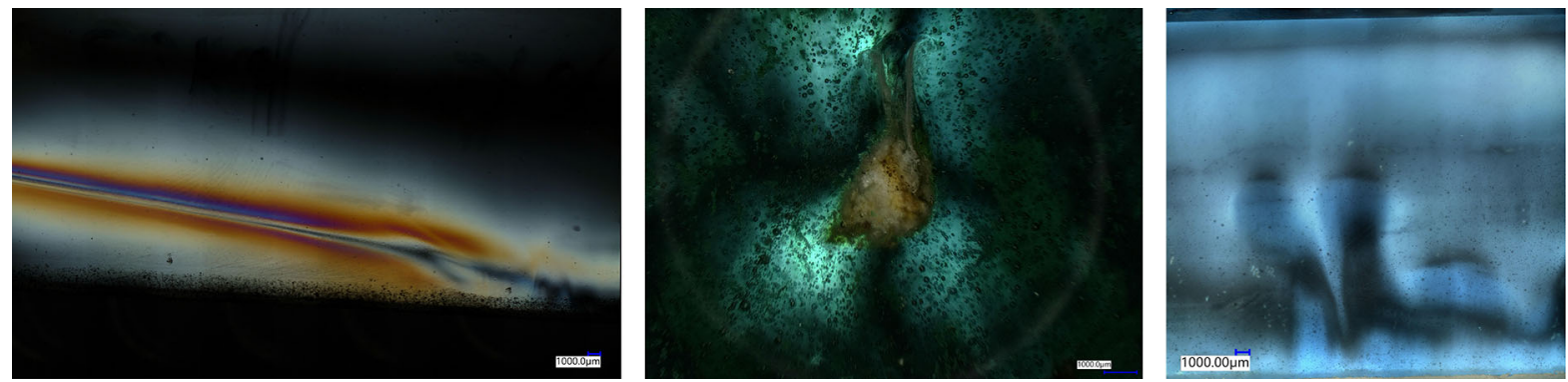

Fig. 18 Overview of stress inducing defects, namely cord (left), crystalline inclusion (middle) and interface between two different glasses in a composite specimen (right) 


\subsubsection{Stress inducing defects}

This category includes only casting related defects (in the bulk and/or surface of the glass beams), as postprocessing and handling defects were not found to be stress increasing in this study. Assessing the above mentioned casting related flaws, four defect types seem to be occasionally inducing stress in the specimens, according to the analysis under cross-polarized light: (a) cord in Boron/Alkali silicate glasses (Poesia, Wertheim), (b) interface and cord between different glasses in the composite specimens, (c) presence of CSP stones in the contaminated glasses, and (d) crystalline interlayer in fused glasses (Figs. 18, 19). In all cases, the induced stress is not sufficient for leading to local/global cracking of the component. Regarding the impact of cord, a range of stress intensities were observed. The intensity of this stress is linked with the mismatch of the thermal expansion coefficient between the cord and the surrounding glass, and although cord on its own may not damage the glass, it can lead to failure when acting together with other stresses (Aldinger and de Haan 2019).

On the contrary, the encountered metal inclusions, coatings and bubbles did not introduce stresses in the samples.

\subsubsection{Strength-reducing defects (surface defects)}

A combination of casting defects acts together with machining (e.g. sawing damage, grinding scratches) and handling damage (e.g. impact, scratch, frictive damage) towards the deterioration of the surface of the specimens (Fig. 20). Bubble veils, stones and crystalline interlayers may be tolerable when situated in the bulk, but will reduce the flexural strength when exposed at the surface of maximum tensile stress (Bristogianni et al. 2020) (Fig. 21a). Another encountered defect that is difficult to remove by polishing, is the formation of infolds/recesses at the surface due to insufficient fusion between the cullet pieces (Fig. 21b). These cavities often promote the creation of a crystalline layer, due to the incorporation of loose mould material. The quality of glasses that are prone to such defects (e.g. FT float) can be improved by locally reinforcing the surface with a less prone, smoother compatible glass (e.g. AGC blue). However, to achieve such a distinct layering, careful selection of the forming temperature and dwell time is required to avoid the transferring of faulty material to the good glass region - a problem identified in the composite beams of this study.

Although all specimens were ground and polished down to a 600 grit level, following the same procedure, the final surface quality of the different glass beams is not equal. Some glasses were easier/softer to postprocess (Borosilicate, Poesia) than others (FT Float, AGC Blue, Car Glass). In addition, some glasses were more prone to scratches (softer glasses) or chipping (Figs. 20b, 21b). As seen in Fig. 22, the Borosilicate and Poesia surfaces look smoother than the rougher AGC Blue or Car Glass surfaces. However, by studying the 3-dimensional (3D) profile of a transverse section at the bottom surface of the beams (Fig. 23), it can be seen that less variations occur in the AGC Blue or Car glass profile than in the FT Float or Borosilicate sample. These deviations are associated with the occurrence of deeper scratches in the later samples. Lastly, Fig. 24 shows the differences at the bottom surface between the cutto-size Poesia frame glass and its kiln-cast version at $1070{ }^{\circ} \mathrm{C}$, which appears to be smoother. The observed differences in the final surface quality are expected to affect the flexural strength of the different glasses. 

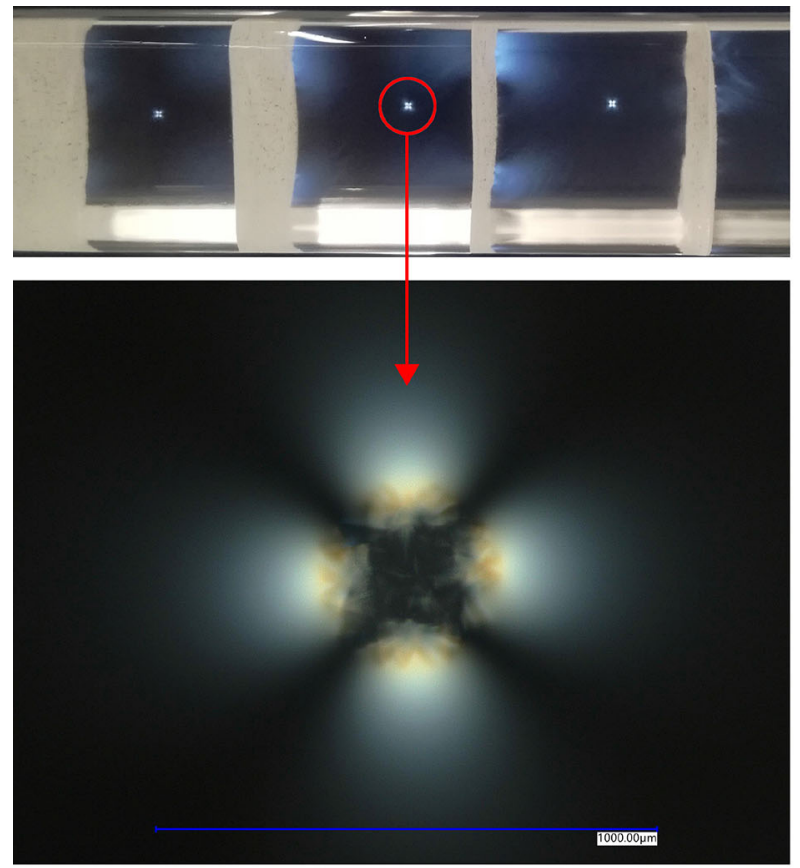

(a)

Fig. 19 Cross-polarized images of a "Borosilicate DURAN rods $970{ }^{\circ} \mathrm{C}$ " specimen (left) and a "Float $10 \mathrm{~mm} * 2$ layers $970{ }^{\circ} \mathrm{C}$ " specimen (right). Minor stress (in the form of while light) is observed at the crystalline interfaces as well as around isolated
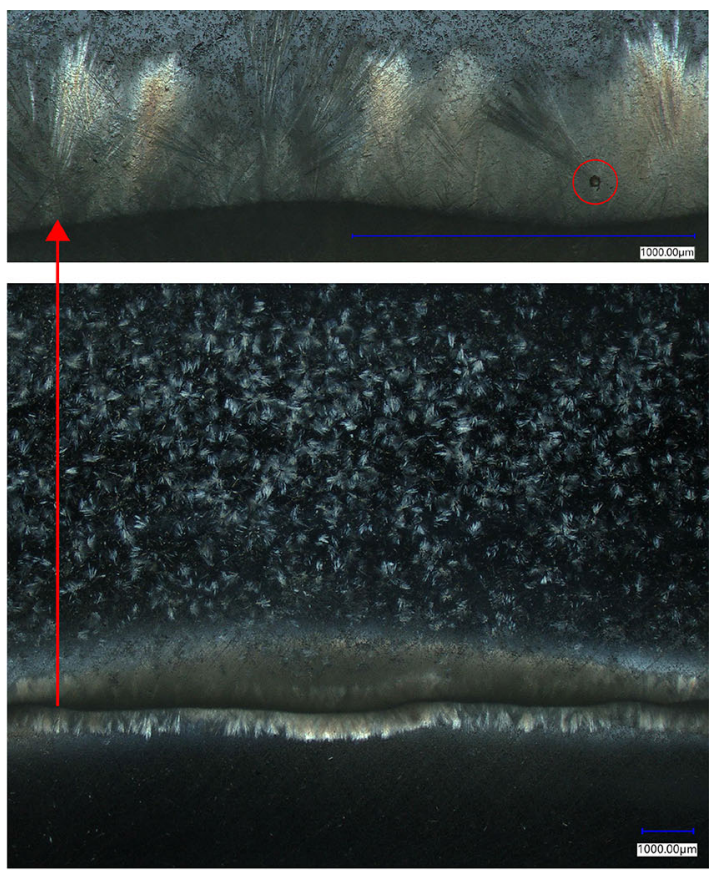

(b)

crystal formations in the middle of the glass region a or at the surface b. According to prior X-Ray Diffraction analyses (Bristogianni et al. 2020), the crystal in $\mathbf{a}$ is $\beta$-cristobalite while in $\mathbf{b}$ is devitrite

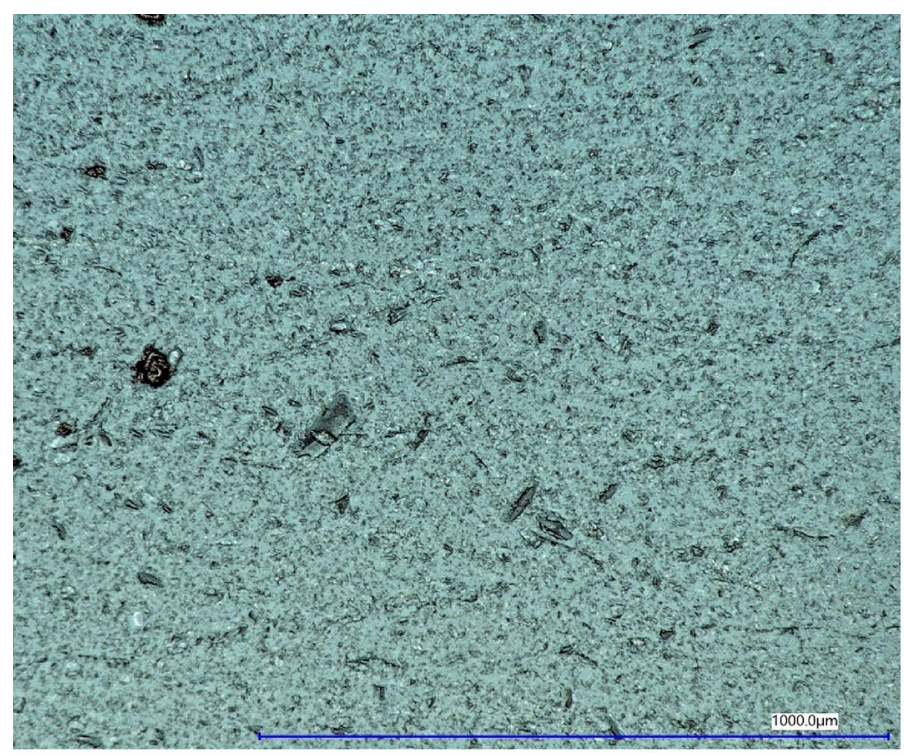

(a)

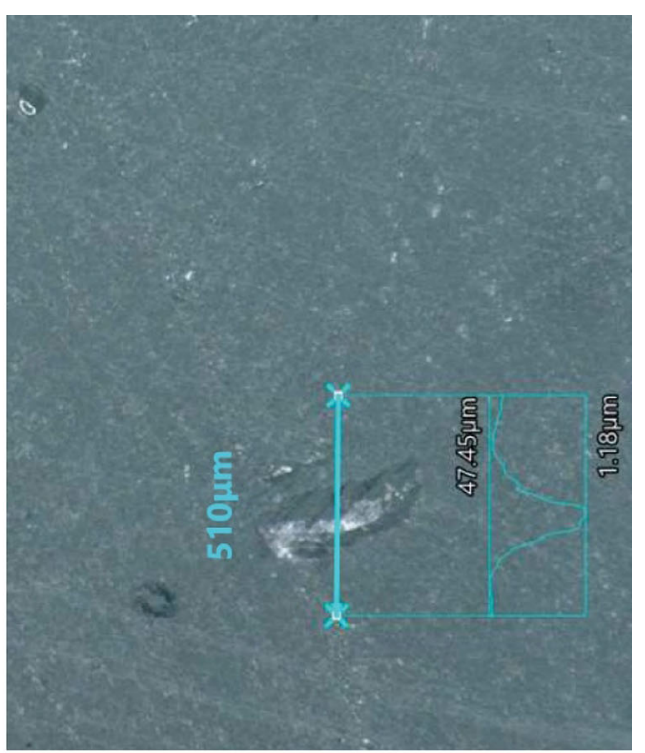

(b)

Fig. 20 a Micro-damage at an AGC blue surface due to machining, b shows a $46 \mu \mathrm{m}$ deep surface chipping damage evoked during grinding around a crystalline inclusion 


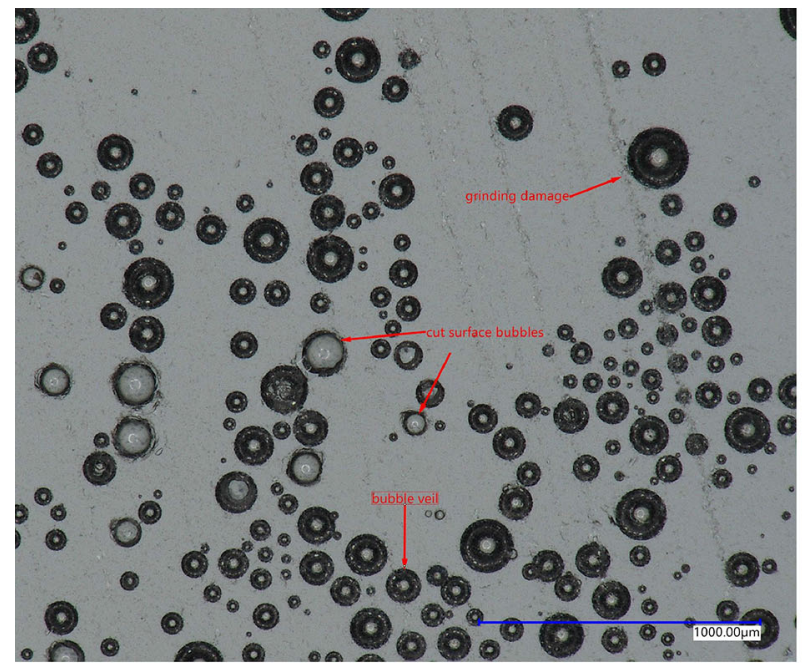

(a)

Fig. 21 a Bubble veil at the bottom surface of a Poesia $970{ }^{\circ} \mathrm{C}$ specimen. During grinding, several bubbles are exposed, becoming craters of stress concentration during loading. Deep grinding striations from a "renegade-grit" also act upon the exposed bub-

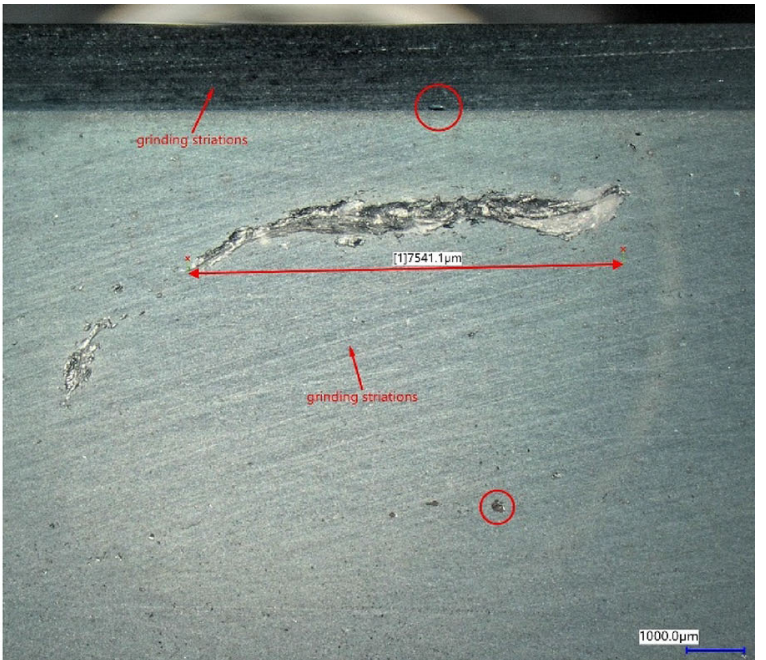

(b)

ble veil to deteriorate the surface quality (Quinn et al. 2005). b Surface damage at an AGC blue specimen. Extended infolds are present $(7.5 \mathrm{~mm}$ length) together with grinding striations and small machining cracks (in circle)
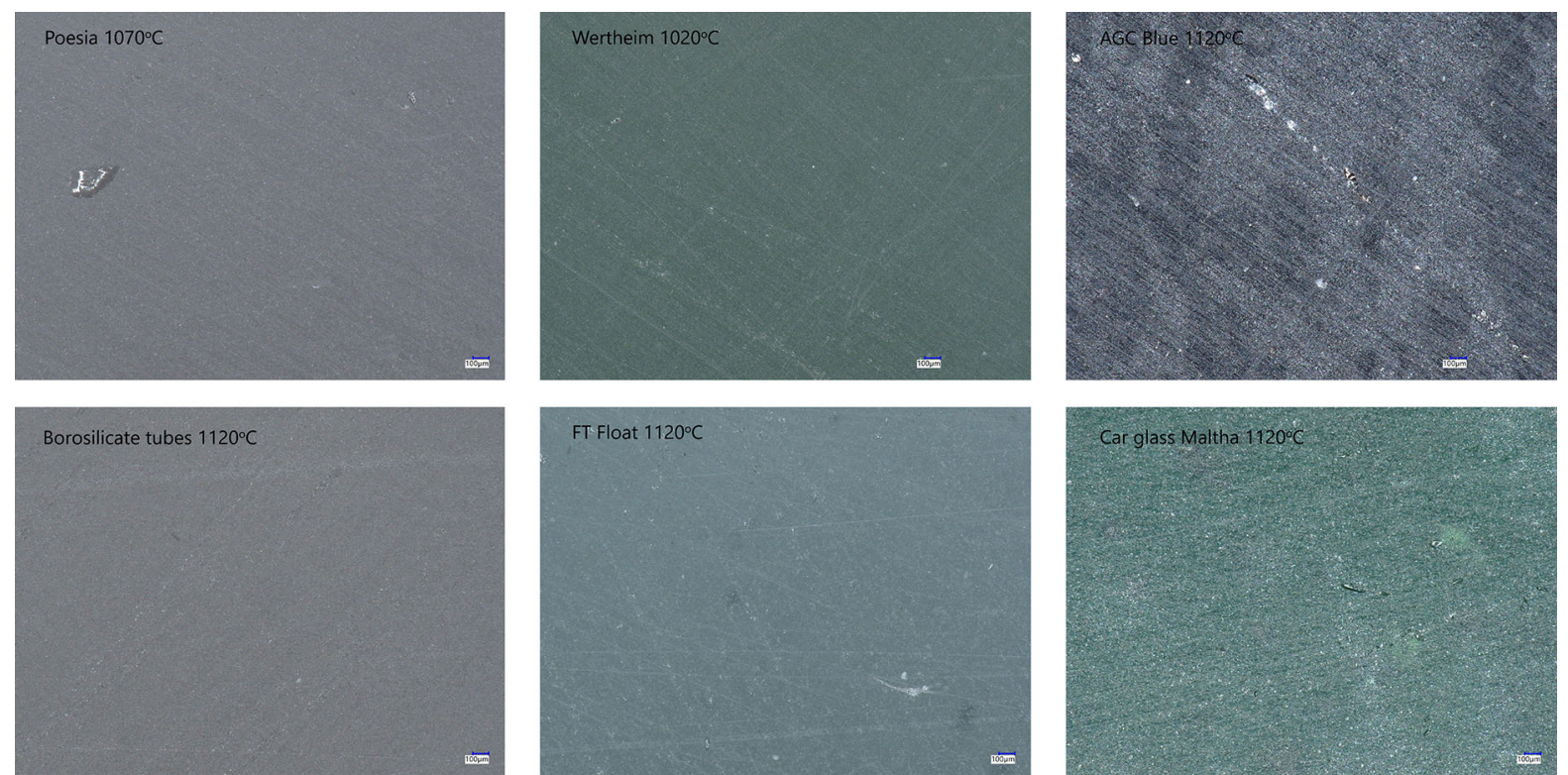

Fig. 22 Microscope images of the bottom surfaces of different glass samples. The left-right orientation of the images is aligned with the field of tensile stress 


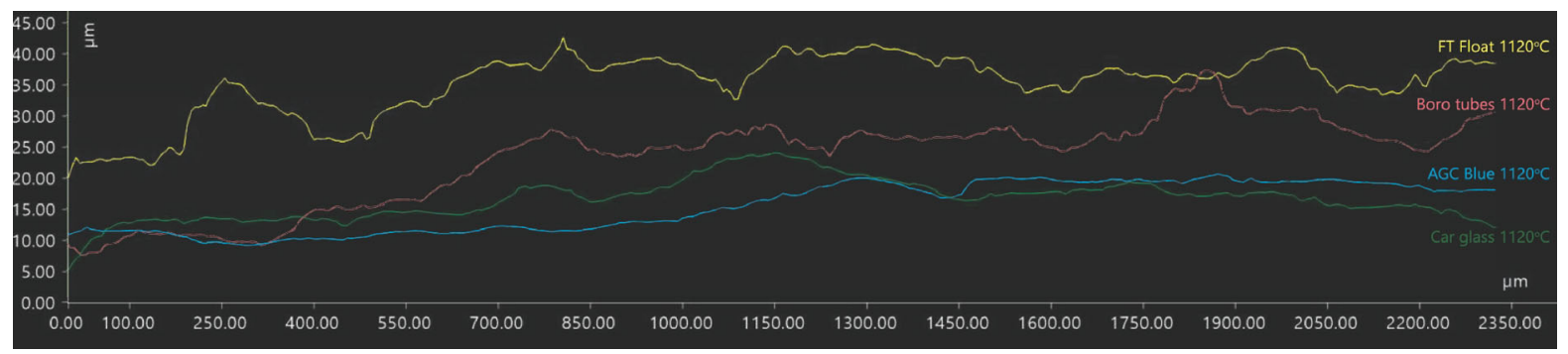

Fig. 23 3D profile of a transverse section (perpendicular to the tensile stress) at the bottom surface of different glass specimens
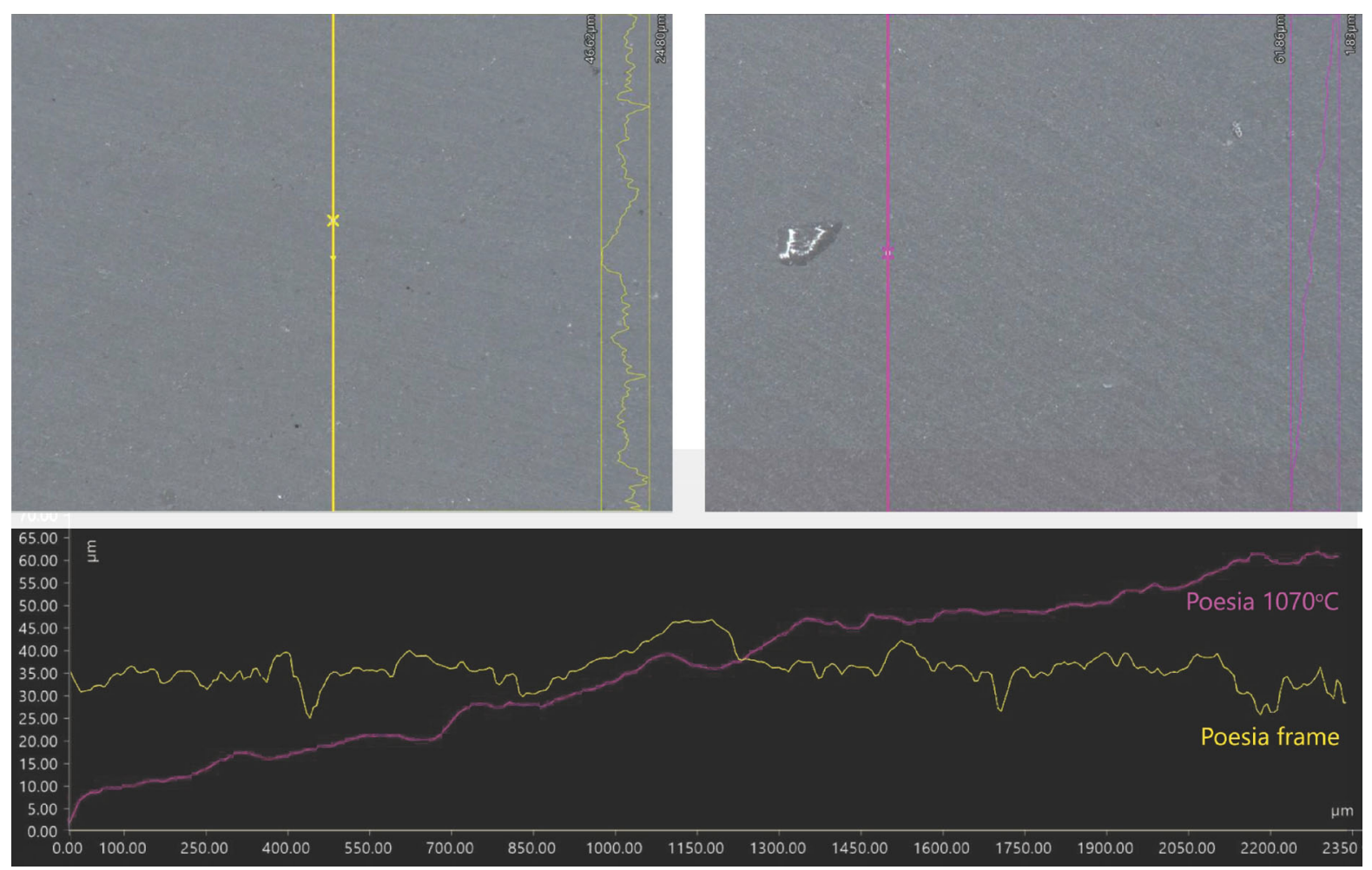

Fig. 24 3D profile of a transverse section at the bottom surface of a standard Poesia (yellow) and a kiln-cast Poesia $1070{ }^{\circ} \mathrm{C}$ specimen

\subsection{Impulse excitation test}

From the obtained flexural vibration frequencies during the impulse excitation experiment, the Young's modulus of the tested specimen is calculated (Table 2). The resulting $\mathrm{E}$ values are in accordance with the literature and prior testing (Bristogianni et al. 2020): $62 \mathrm{GPa}$ for DURAN borosilicate glass, 70-76 GPa for float sodalime and $79 \mathrm{GPa}$ for Wertheim C-glass, and only the stiffness of the Poesia glass is found lower than previously reported. In addition, the IET shows changes in the E modulus of the same glass composition by 1$3 \mathrm{GPa}$, when a different thermal history is applied (e.g. FT Float, Poesia). More specifically, in the case of the FT Float, the shorter homogenization time at $1120{ }^{\circ} \mathrm{C}$ ( $2 \mathrm{~h}$ ) seems to have a negative effect to the stiffness. Regarding the Poesia glass, the increase in E modulus (standard ${ }^{16}<$ kiln-cast at $1070{ }^{\circ} \mathrm{C}<$ kiln-cast at

\footnotetext{
${ }^{16}$ Regarding the melt-quenching production of standard Poesia bricks and frames, molten glass at around $1200^{\circ} \mathrm{C}$ temperature is poured in a preheated mould and rapidly cooled down to approx.
} 
$970{ }^{\circ} \mathrm{C}$ ) is aligned with the increase in density, and the maximum stiffness is achieved at the lowest casting temperature $\left(970{ }^{\circ} \mathrm{C}\right)$.

The results of the internal friction ${ }^{17} \mathrm{Q}^{-1}$ measurement at room temperature by IET can be found in Table 2, Fig. 25. The internal friction in a material is the dissipation of energy after an applied elastic strain or stress. Mechanical losses in alkali containing glasses are related to the relaxation of the alkali ions in the network as a result of the applied deformation (Stevels 1962). In addition, large structural defects such as cracks can lead to energy losses though friction (Roebben et al. 1997), and $\mathrm{Q}^{-1}$ is closely related to the micro-mobility of defects in the microstructure (Duan et al. 2001; Roebben et al. 1998). The internal friction measurement can provide therefore information about the connectivity of the glass network.

Minor thermal history variations per glass category (e.g. Poesia $970{ }^{\circ} \mathrm{C}$ to Poesia $1070{ }^{\circ} \mathrm{C}$ ) and contamination variations (e.g. pure "FT Float" to contaminated "Car glass") do not seem to have a major impact to the internal friction of the cast glass samples ${ }^{18}$ (Float reference glass is excluded). The chemical composition is dominant as portrayed by the "clustering" of the glasses per category in Fig. 25. Analyzing the internal damping results, a reduction in the damping is observed with an increase in the $\mathrm{B}_{2} \mathrm{O}_{3}$ content, with the "Borosilicate Tubes" glass (4\% Alkali oxides, $13 \% \mathrm{~B}_{2} \mathrm{O}_{3}, 81 \%$ $\mathrm{SiO}_{2}$ ) presenting the lowest internal friction. A lower internal friction of such borosilicate composition in comparison to SLS is also reported in bibliography (Duan et al. 2003). In the case of the "Borosilicate Tubes" glass, the low alkali to boron ratio, favours the association of the alkali to the boron, converting the oxygen coordination of boron from 3 (triangle) to 4

Footnote 16 continued

$700{ }^{\circ} \mathrm{C}$ at atmospheric conditions, before the glass components are inserted in the annealing lehr (Oikonomopoulou et al. 2018a).

17 The internal friction $Q^{-1}$ is calculated from the amplitude decay of the free vibration:

$Q^{-1}=\frac{k}{\pi \cdot f_{r}}$

Where $\mathrm{k}$ is the exponential decay parameter of the vibration and $\mathrm{f}_{\mathrm{r}}$ the resonant frequency of the tested material (Roebben et al. 1997).

18 All cast samples tested via the IET have a similar annealing history but may differ in the selection of top forming temperature, dwell at top temperature or cooling rate down to the annealing point, as explained in Sect. 2.1. (tetrahedra), and thus increasing the degree of connectivity of the network, without creating Non-Bridging Oxygen (NBO) ions (Biscoe and Warren 1938; Bray and O.K 1963; Milberg et al. 1972). However, an increase of the alkali content above a threshold ${ }^{19}$ will lead to the creation of NBOs and therefore a looser structure, which is the case in the Wertheim and Poesia glass. The float glass samples, as typical soda-limesilica compositions, are expected to have $\approx 0.75 \mathrm{NBO}$ per tetrahedron $(\mathrm{T})^{20}$ (Glass for Europe 2015). The difference though between the SLS glasses and Poesia and Wertheim glasses, is that the latter two are falling under the "mixed-alkali" category. A densification is reported in silica glasses containing more than one alkali type, due to the packing efficiency in the interstices of the glass network resulting from the different ion sizes (Sheybany 1948). Shelby and Day (1969) report changes in the internal friction of soda-silicates when there is a partial substitution of the $\mathrm{Na}_{2} \mathrm{O}$ with a second alkali oxide, and in particular a shift in the internal friction peak to a higher temperature.

Given that a more open network will absorb more energy during mechanical excitation thus reporting a higher damping, information on the internal friction can suggest the level of connectivity of the glass network. However to reach meaningful comparisons between the different glasses, an internal friction measurement over a temperature range of $\approx 0-400{ }^{\circ} \mathrm{C}$ is required. In this manner, misinterpretations resulting from isolated data with no indication of the corresponding temperature peak can be avoided. Such a measurement would also shed light to structural variations occurring in the cast glass due to differences in the thermal history.

Attention should be also given to the network structural changes that can occur from the thermal history of the glass at and below the glass transition region, and during the cooling process down to room temperature. This is of relevance given that the glasses in this study are characterized by longer annealing times and slower cooling rates than the ones followed in the industry.

Varshneya (2013) indicates that glass properties are linked with the imposed thermal history. In specific, the

\footnotetext{
${ }^{19} \mathrm{In}$ an alkali borosilicate $\mathrm{RM}_{2} \mathrm{O} \cdot \mathrm{KSiO}_{2} \cdot \mathrm{B}_{2} \mathrm{O} 3$ glass, an alkali content of $\mathrm{R}>0.5$ will create $\mathrm{NBOs}$ according to the $\mathrm{K}$ value (Milberg et al. 1972).

20 The float glass network is considered fairly polymerized. As a reference, the $\mathrm{NBO} / \mathrm{T}$ ratio for amorphous silica is 0 (all oxygen ions are bridging) and of pure $\mathrm{Na}_{2} \mathrm{O} \cdot \mathrm{SiO}_{2}$ is 2 ( $2 \mathrm{BO}$ and $2 \mathrm{NBO}$ per tetrahedra) (Glass for Europe 2015).
} 


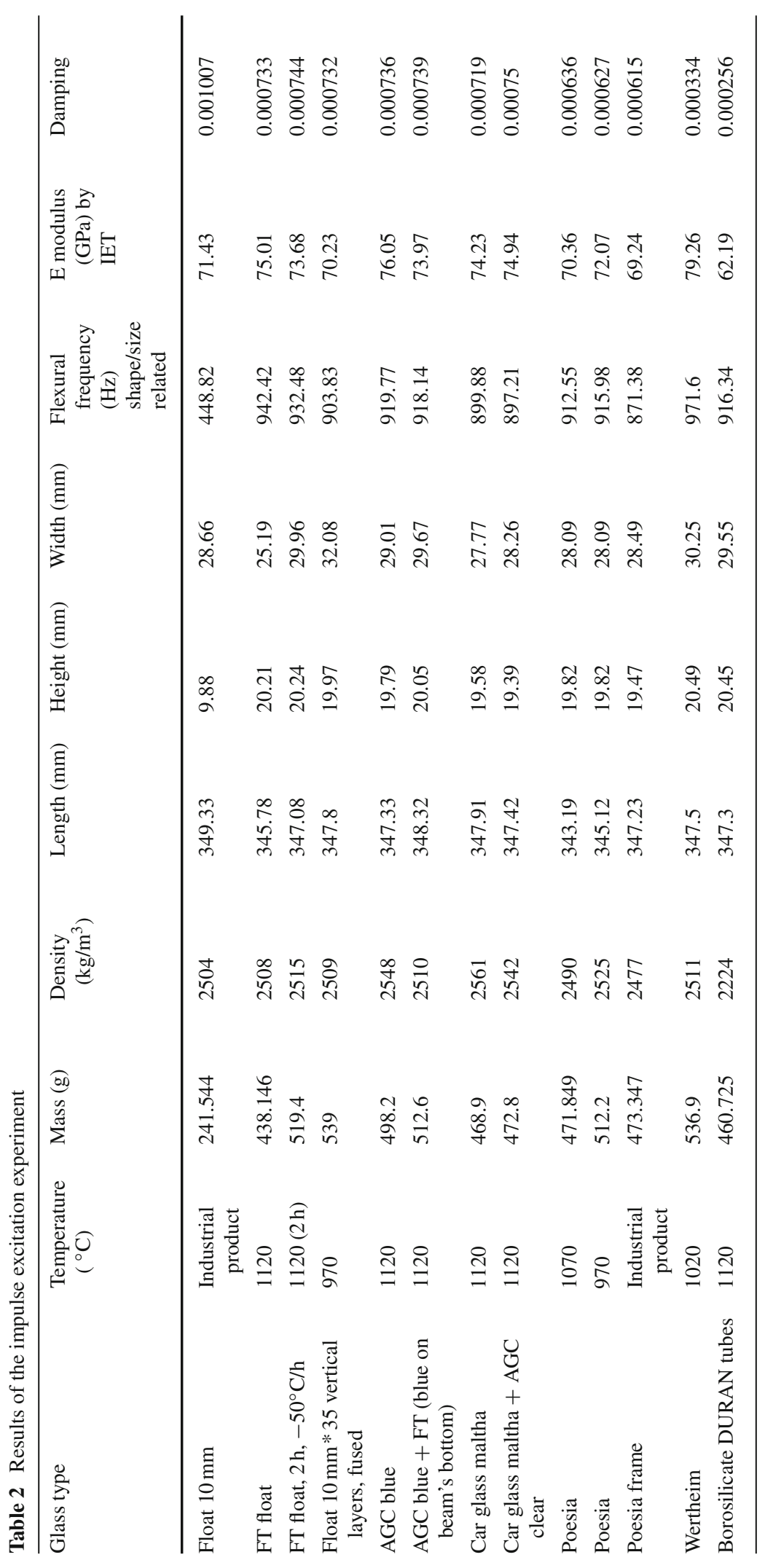




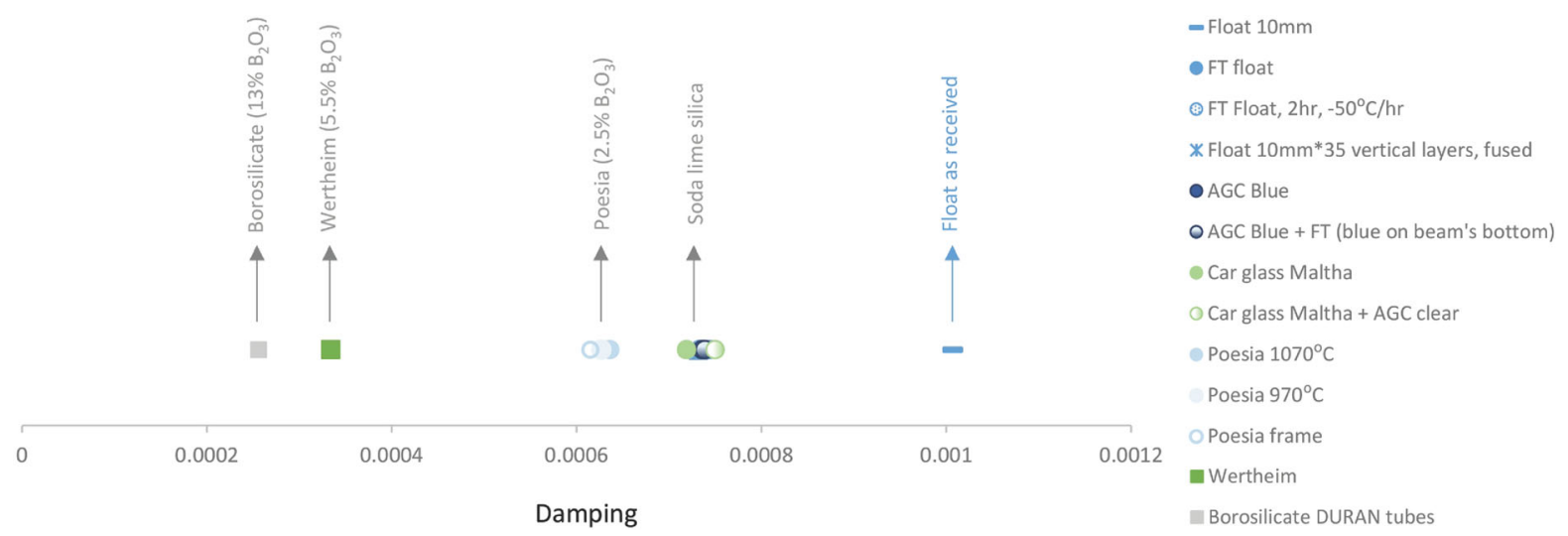

Fig. 25 Internal friction measurement by IET. For glass compositions containing boron trioxide, this content is noted in the parenthesis

temperature scheme followed around the glass transition range $T_{g}$ is the most crucial for structural rearrangements and for a consequent change in properties to occur. A slower cooling rate will lead to a smaller final volume (higher density) and a lower fictive temperature $\mathrm{T}_{\mathrm{f}}{ }^{21}$ Standard SLS glasses (Gross and Tomozawa 2008) and E-fiber glasses (Smedskjaer et al. 2010) will exhibit an increasing hardness with decreasing $\mathrm{T}_{\mathrm{f}}$, imposed by a longer heat-treatment. A prolonged annealing will increase the structural density (APF) without affecting the macroscopic glass density (Smedskaer et al. 2010). Ito and Taniguchi (2004) prove using molecular dynamics (MD) simulations that a fast cooling rate will reduce the polymerization of a typical SLS glass network leading to a smaller E modulus and lower brittleness. Varughese et al. (1998) heattreated SLS glasses at and below $\mathrm{T}_{\mathrm{g}}$, reporting higher strength with higher $\mathrm{T}_{\mathrm{f}}$, while and $\mathrm{Li}$ et al. (1995) show an increase in fatigue resistance. Striepe et al. (2013) report similar behavior in alkaline earth aluminosilicate glass after prolonged annealing; the Young's modulus, hardness $^{22}$ and brittleness increases with decreasing fictive temperature. Overall, the more open, unstable structure of a quenched glass will change more easily

${ }^{21}$ Considering the typical free volume-temperature graph for a glass-forming liquid, the Fictive Temperature $T_{f}$ is found in the intersection of the extrapolated lines of the glass and supercooled liquid.

22 For a glass of $25 * 25 * 0.7 \mathrm{~mm}$ size, $18,300 \mathrm{~min}(\approx 12.7$ days $)$ of annealing versus $15 \mathrm{~min}$ would lead to a raise of $\mathrm{E}$ modulus by $2 \mathrm{GP}$, while the crack resistance would drop from $6 \mathrm{~N}$ to $2.8 \mathrm{~N}$. upon mechanical stress, thus the higher strength and lower brittleness reported in the literature.

In addition, Duan et al. (2001) shows that the heating of $15 \mathrm{Na}_{2} \mathrm{O}-20 \mathrm{CaO}-65 \mathrm{SiO}_{2}$ glass up to $500{ }^{\circ} \mathrm{C}$ (so below their glass transition temperature) leads to the rearrangement of the $\mathrm{SiO}_{4}$ structure, inducing irreversible changes to the stiffness of glass once cooled down, while even at lower temperatures (in this case $230^{\circ} \mathrm{C}$ ), the $\mathrm{Na}^{+}$and $\mathrm{Ca}^{2+}$ ions will diffuse into the silica network holes. In specific, a reduced internal friction and a higher frequency (so higher E modulus) is reported after the heat treatment of the glass below the glass transition point.

It is therefore speculated that the cast glass specimens created in this study, which are characterized by a longer dwell time at the forming temperature, a slower cooling rate and a more conservative annealing and cooling schedule, will have a more compact network, as the prolonged processing time favors the rearrangement of the alkali ions and the polymerization of the network. The above is supported by the much higher damping, lower E modulus and lower density reported for the industrially produced float glass specimen ("Float $10 \mathrm{~mm}$ ", see Table 2, Fig. 25) in comparison to the rest of the specimens.

\subsection{Differential Scanning Calorimetry experiment}

The DSC technique has been used to study the glass transition and fictive temperature of a selection of glasses, and specifically to identify changes in glasses 
Fig. 26 Heat Flow versus Temperature graph for a selection of glasses, prior and after kiln-casting. The DSC curves show the required heat to change the temperature of the samples. The first endotherm peak around $500-600^{\circ} \mathrm{C}$ corresponds to the glass transition range

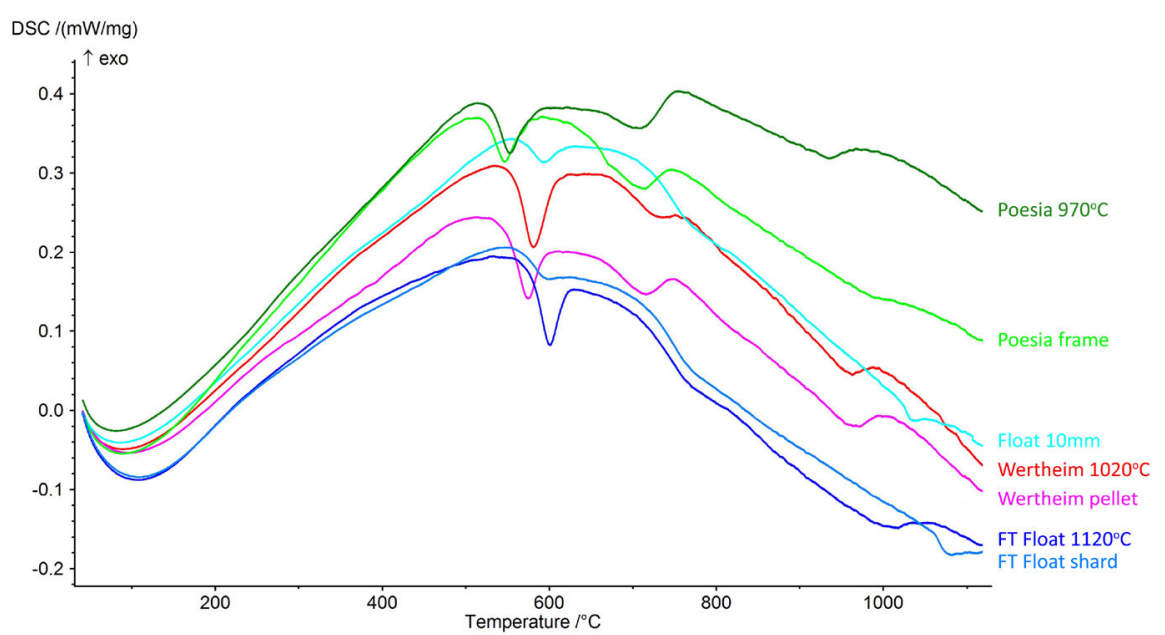

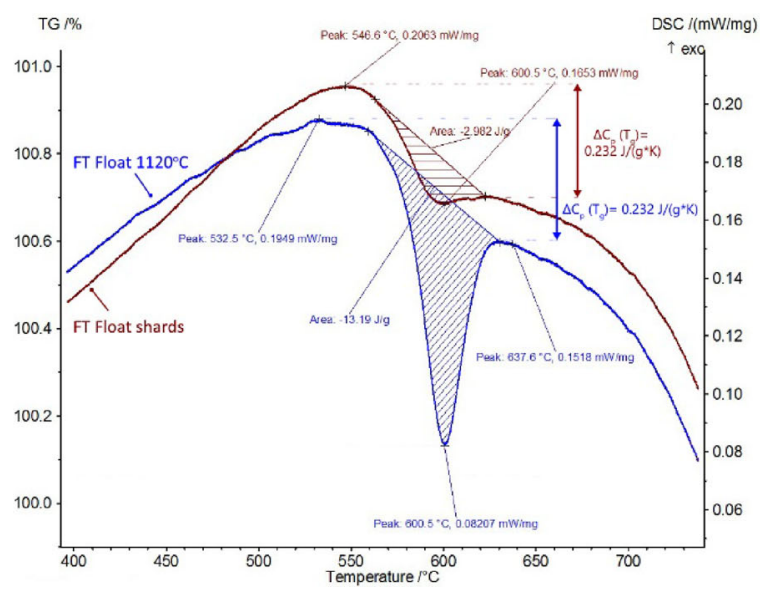

Fig. 27 DSC curve showing the enthalpy overshoot after the Tg of a selection of glasses, before and after kiln-casting. In the case of FT Float (left), the enthalpy change between the original and the kiln-cast glass is larger than in the case of the Wertheim glass

of same composition due to different thermal history. The results of the DSC measurements can be found in Figs. 26, 27 and Table 3.

The comparison between the DSC curves of the "as received" and upon kiln-casting glasses shows an increase in the $\mathrm{T}_{\mathrm{g}}$ and decrease in the $\mathrm{T}_{\mathrm{f}}$ of the longer annealed and slower cooled kiln-cast glasses. Characteristic of the kiln-cast glasses is the deeper endothermic drop or " $\mathrm{C}_{\mathrm{p}}{ }^{23}$ overshoot" after $\mathrm{T}_{\mathrm{g}}$. Shelby (2005) explains, based on the method for the determination of the fictive temperature suggested by Moynihan et al.

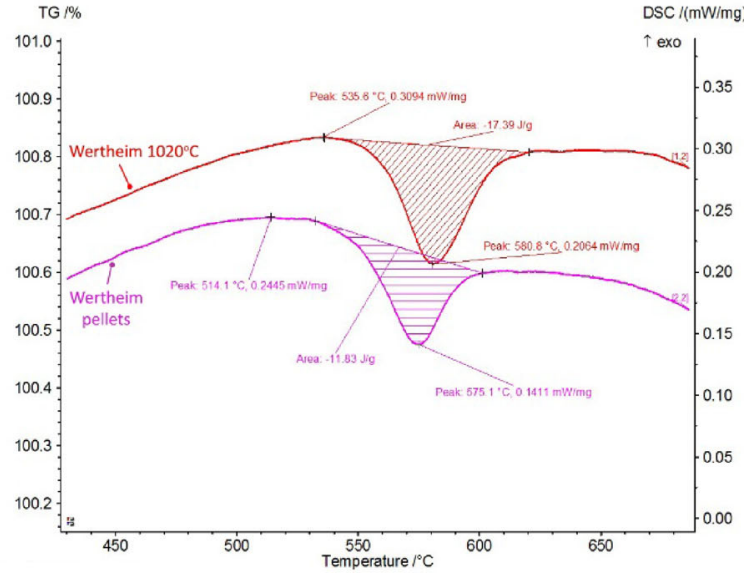

(right). The graph on the left also shows the $\Delta \mathrm{Cp}$ at $\mathrm{Tg}$ (equal to the configurational heat capacity $\mathrm{Cp}$, conf at $\mathrm{Tg}$ ), which characterizes the glass-liquid transition. The $\mathrm{Cp}$,conf at $\mathrm{Tg}$ value is the same for the two FT glasses

(1976), that such a deep endotherm between the glass and liquid DSC curve shows a lower fictive temperature than a shallow endotherm for the same glass composition. The magnitude of the overshoot reflects the enthalpy loss occurring during the annealing (Hodge 1994; Zheng et al. 2019), and more specifically, the slower the cooling rate and the longer the annealing around $\mathrm{T}_{\mathrm{g}}$, the higher the extent of the overshoot (Boehm et al. 1981). Boehm also reports the increase of $\mathrm{T}_{\mathrm{g}}$ with decreasing $\mathrm{T}_{\mathrm{f}}$, arguing that a better annealing lowers the intrinsic mobility of the system's particles,

${ }^{23} \mathrm{C}_{\mathrm{p}}$ refers to the isobaric hear capacity. 
Table 3 Results of the DSC experiments

\begin{tabular}{|c|c|c|c|c|}
\hline Glass type & $\begin{array}{l}\text { Process/temperature } \\
\left({ }^{\circ} \mathrm{C}\right)\end{array}$ & $\begin{array}{l}\text { Glass } \\
\text { transition } \\
\mathrm{T}_{\mathrm{g}}\left({ }^{\circ} \mathrm{C}\right)\end{array}$ & $\begin{array}{l}\text { Configurational heat } \\
\text { capacity at } \mathrm{T}_{\mathrm{g}}: \\
\mathrm{C}_{\mathrm{p}, \text { conf } \approx} \approx \\
\Delta \mathrm{C}_{\mathrm{p} \text {, glass to liquid }}(\mathrm{J} /(\mathrm{g} \cdot \mathrm{K}))\end{array}$ & $\begin{array}{l}\text { Enthalpy of } \\
\mathrm{T}_{\mathrm{g}} \\
\text { Overshoot } \\
(\mathrm{J} / \mathrm{g})\end{array}$ \\
\hline Float $10 \mathrm{~mm}$ & Float line & 557 & 0.059 & -4.382 \\
\hline FT float shard & $\begin{array}{l}\text { Float line and } \\
\text { tempering }\end{array}$ & 554 & 0.232 & -2.982 \\
\hline $\begin{array}{l}\text { FT float } \\
1120{ }^{\circ} \mathrm{C}\end{array}$ & $\begin{array}{c}\text { Kiln-cast at } \\
1120{ }^{\circ} \mathrm{C}\end{array}$ & 568 & 0.232 & -13.19 \\
\hline Poesia frame & $\begin{array}{c}\text { Hot-pour } \\
\text { casting }\end{array}$ & 516 & 0.007 & -8.926 \\
\hline Poesia $970{ }^{\circ} \mathrm{C}$ & $\begin{array}{c}\text { Kiln-cast at } \\
970{ }^{\circ} \mathrm{C}\end{array}$ & 523 & 0.036 & -10.78 \\
\hline $\begin{array}{l}\text { Wertheim } \\
\text { pellet }\end{array}$ & $\begin{array}{l}\text { Drawn glass, } \\
\text { hot-cut }\end{array}$ & 533 & 0.256 & -13.18 \\
\hline $\begin{array}{l}\text { Wertheim } \\
1020^{\circ} \mathrm{C}\end{array}$ & $\begin{array}{c}\text { Kiln-cast at } \\
1020^{\circ} \mathrm{C}\end{array}$ & 550 & 0.056 & -17.39 \\
\hline
\end{tabular}

Table 4 Determination of the chemical composition of FT Float glass (as received and after kiln-casting) by X-Ray Fluorescence

\begin{tabular}{|c|c|c|c|c|c|c|c|c|c|c|c|c|}
\hline \multirow[t]{2}{*}{ Name } & \multirow[t]{2}{*}{ State } & \multirow[t]{2}{*}{ Sample } & \multirow[t]{2}{*}{ Side } & \multicolumn{9}{|c|}{ Composition* (wt\%) } \\
\hline & & & & $\mathrm{SiO}_{2}$ & $\mathrm{Na}_{2} \mathrm{O}$ & $\mathrm{CaO}$ & $\mathrm{MgO}$ & $\mathrm{Al}_{2} \mathrm{O}_{3}$ & $\mathrm{SnO}_{2}$ & $\mathrm{~K}_{2} \mathrm{O}$ & $\mathrm{Fe}_{2} \mathrm{O}_{3}$ & $\mathrm{~S}$ \\
\hline \multirow[t]{5}{*}{ FT float } & As received & a & Non-Sn & 75.4 & 12.4 & 7.6 & 4 & 0.38 & - & 0.1 & 0.09 & 0.07 \\
\hline & & & $\mathrm{Sn}$ & 74.2 & 12.5 & 7.6 & 4 & 0.36 & 1 & 0.1 & 0.09 & 0.06 \\
\hline & & $\mathrm{b}$ & Non-Sn & 75.9 & 11.8 & 7.6 & 4 & 0.36 & - & 0.1 & 0.08 & 0.1 \\
\hline & & & $\mathrm{Sn}$ & 74.8 & 12.5 & 7.9 & 4.1 & 0.34 & 0.03 & 0.1 & 0.14 & 0.05 \\
\hline & Kiln-cast at $1120^{\circ} \mathrm{C}$ & $\mathrm{c}$ & - & 75.3 & 11.5 & 8.1 & 3.9 & 0.43 & - & 0.1 & 0.09 & 0.36 \\
\hline
\end{tabular}

*All composition data derived by XRF measurements conducted with a Panalytical Axios Max WD-XRF spectrometer by Ruud Hendrikx (TU Delft, $3 \mathrm{mE}$ )

increasing thus the required energy to initiate their rearrangement.

The largest difference in the endothermic peak is observed between the "FT float" shards (and of the standard Float) and the "FT float" $1120^{\circ} \mathrm{C}$, and the smallest between the hot-poured and kiln-cast "Poesia" samples. This is attributed to the distinct differences between the float and kiln-casting production methods, especially regarding the annealing process. In a standard float line, the entering of the glass strip in the annealing lehr at around $600^{\circ} \mathrm{C}$ and the exiting at $60^{\circ} \mathrm{C}$ is a matter of less than an hour ${ }^{24}$, which forms a great contrast to the prolonged scheme used in this study for

$\overline{24}$ Cooling rates used by the float industry are based on the work of Narayanaswamy (1981) and Gardon (1982). As an indication, Narayanaswamy suggests a $5 \mathrm{~min}$ long cooling schedule from $600{ }^{\circ} \mathrm{C}$ down to $380{ }^{\circ} \mathrm{C}$ for a float glass of $6.9 \mathrm{~mm}$ thickness. the cooling of the $20 \mathrm{~mm}$ thick beams. It should be mentioned that despite the different thermal history between the two samples-as reflected in the deep overshoot and higher $\mathrm{T}_{\mathrm{g}}$ for the kiln-cast glass - no significant changes in the chemical composition are observed in the XRF analyses (Table 4), apart from a minor alkali $\left(\mathrm{Na}_{2} \mathrm{O}\right)$ volatilization. This is also confirmed by the fact that the configurational heat capacity $\mathrm{C}_{\mathrm{p}, \text { conf }}$ at $\mathrm{T}_{\mathrm{g}}$ is the same for the two samples (Fig. 27, Table 3).

Footnote 24 continued

Rough calculations considering the daily production of $800 \mathrm{tn}$ in a typical float glass factory such as the Euroglas plant in Osterweddingen (DE), which is equipped with a $140 \mathrm{~m}$ long annealing lehr (EUROGLAS 2016), shows that a $10 \mathrm{~mm}$ thick and $3210 \mathrm{~mm}$ wide glass would need approximately $20 \mathrm{~min}$ to travel through the annealing lehr and cool down from 600 to $60^{\circ} \mathrm{C}$. This implies that for the same production volume, the much more common $4 \mathrm{~mm}$ glass pane is cooled 2.5 times faster. 


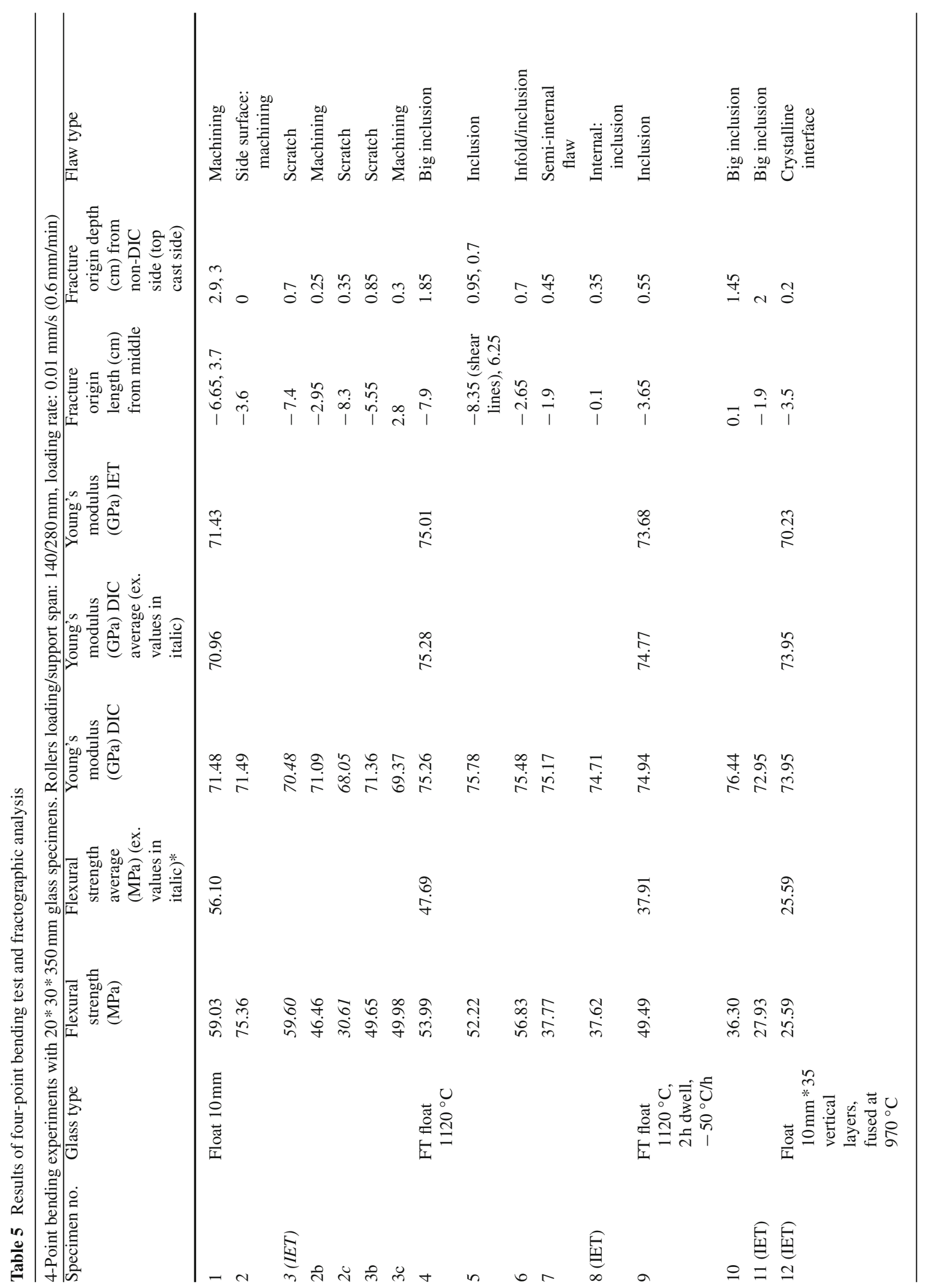




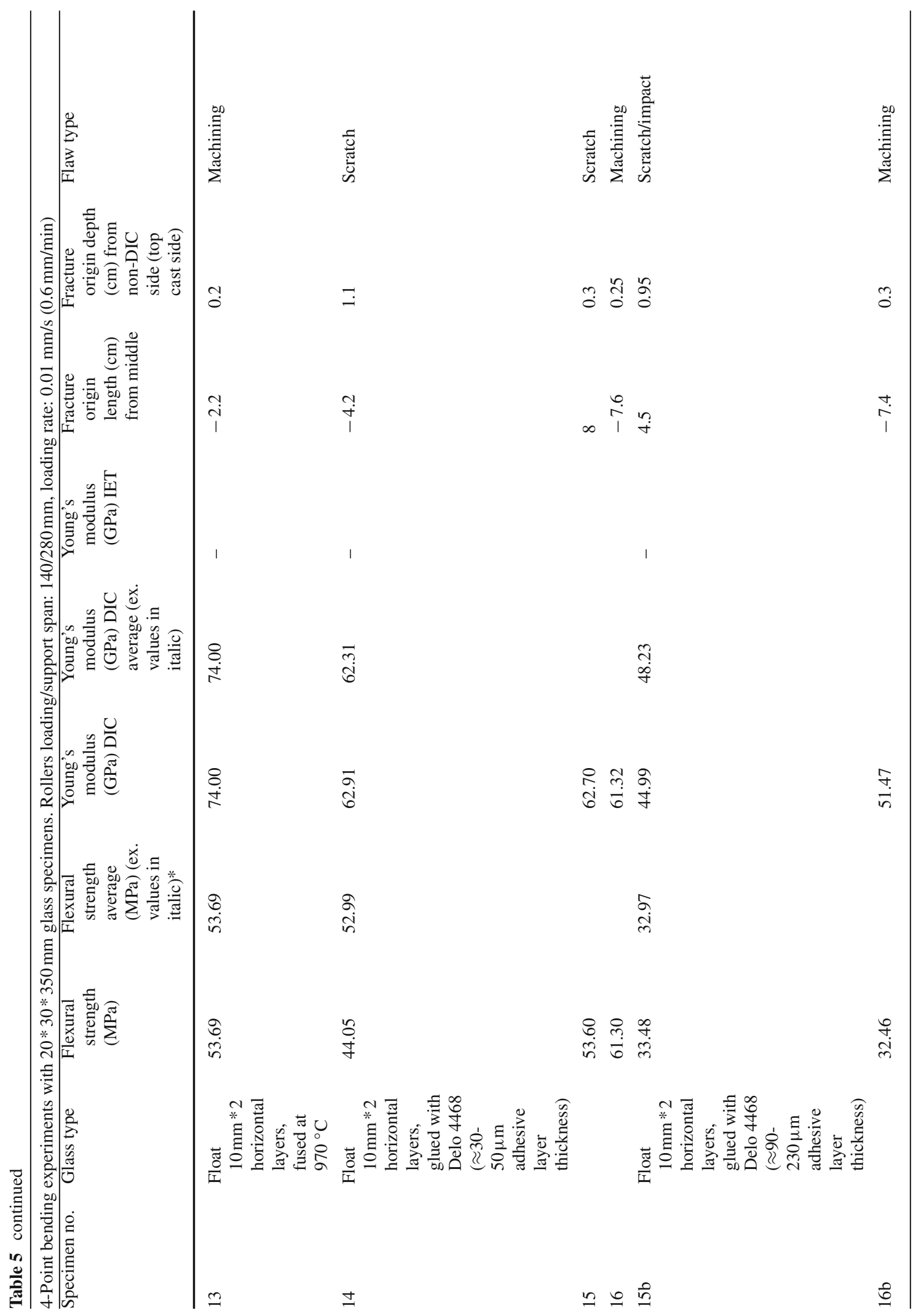




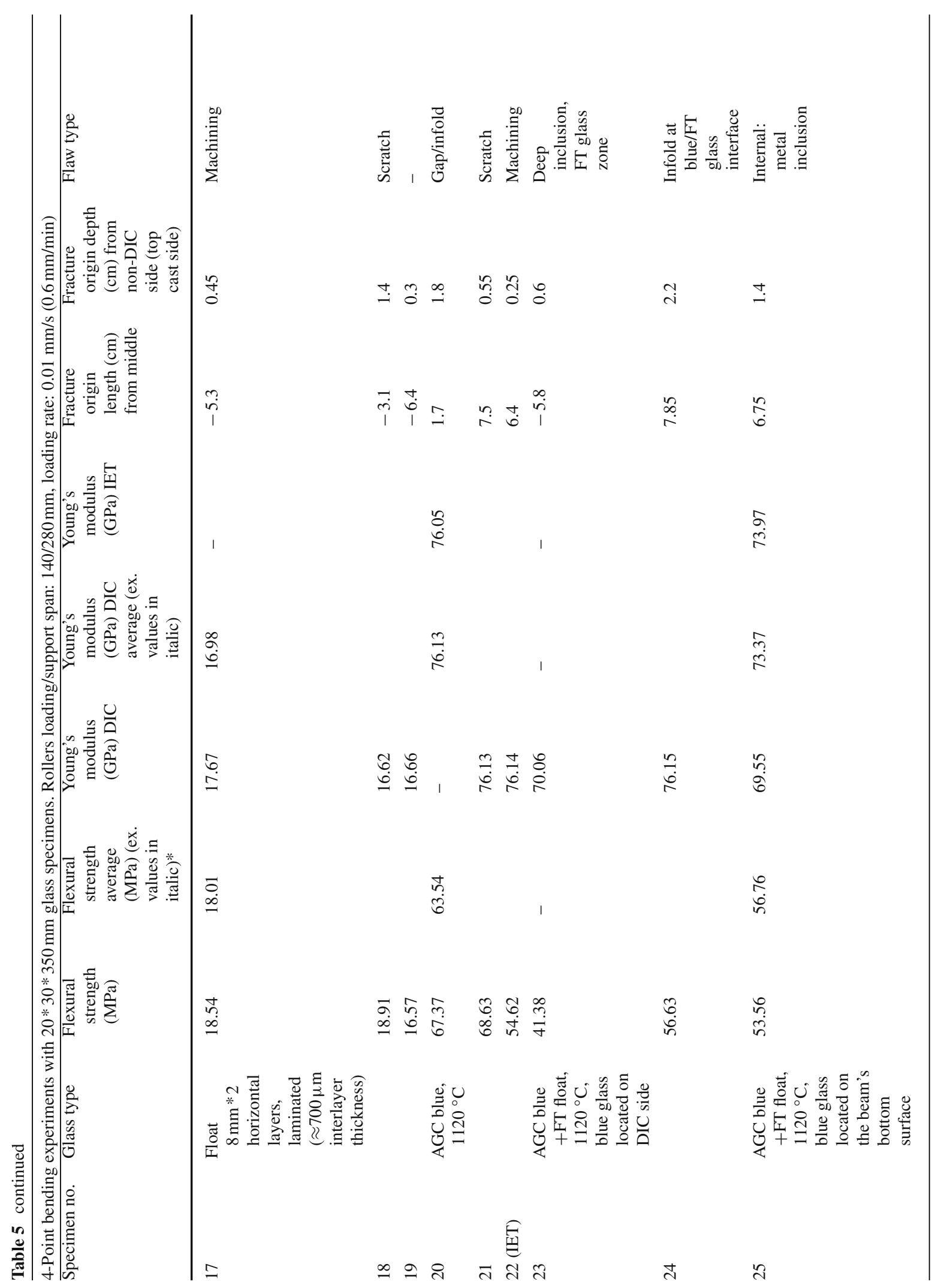




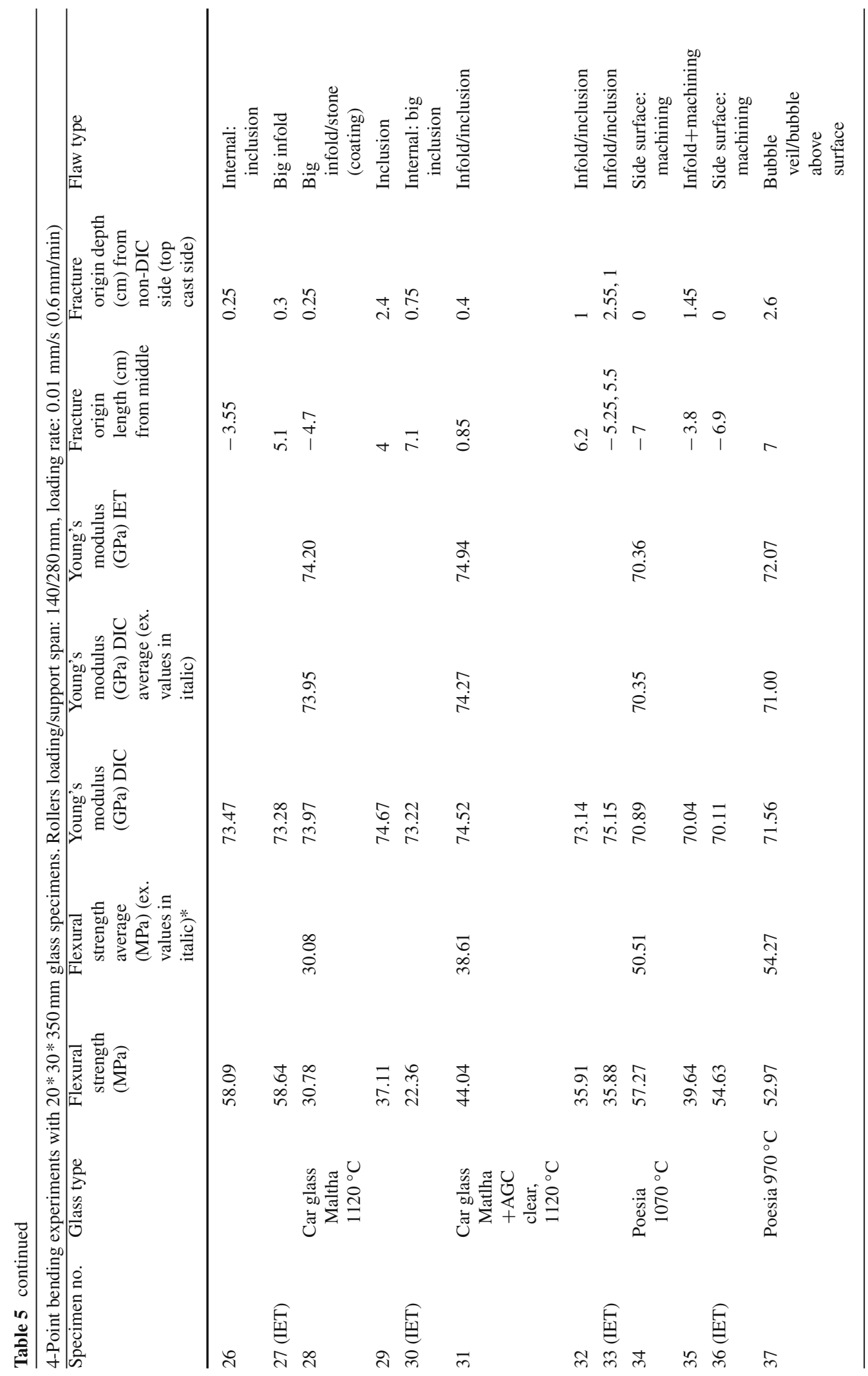




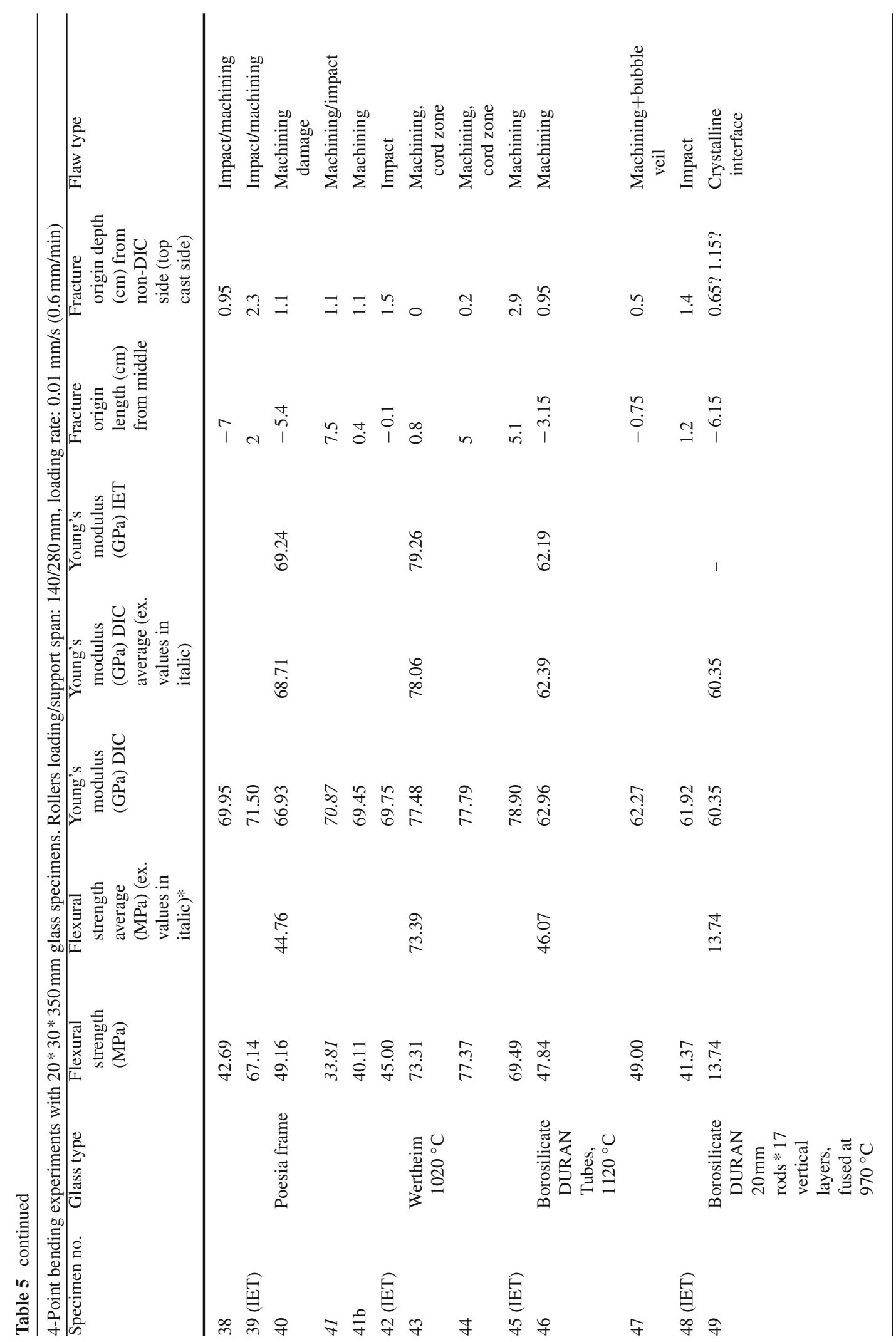




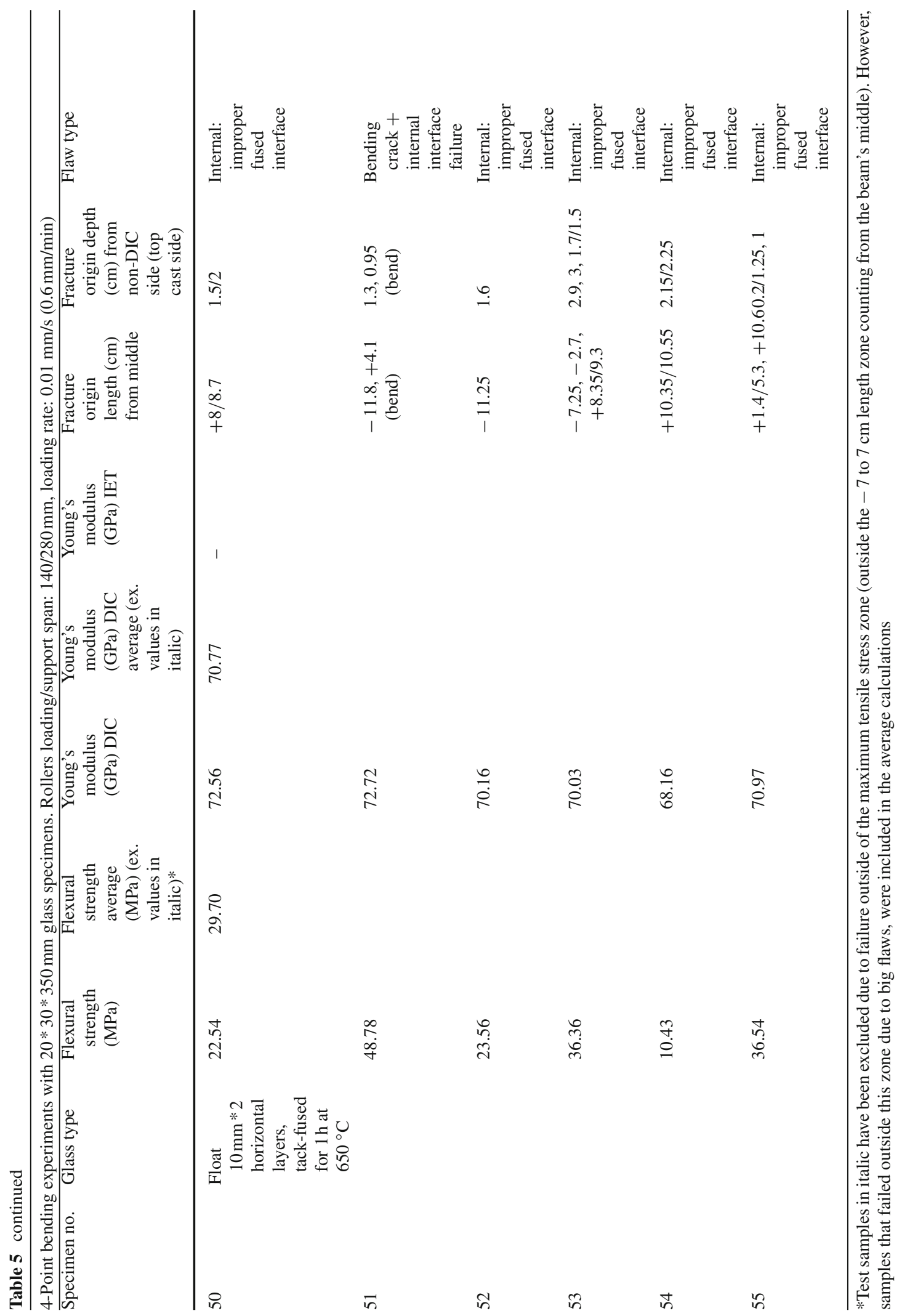




\subsection{Four-point bending experiment}

The results of the four-point bending experiments can be found in Table 5 and (Figs. 28, 29). The reader should take into account that only a low number (1-5) of specimens could be tested per category, and thus the results are indicative, and not statistically conclusive.
Regarding the performance of the soda lime silica kiln-cast glasses (Specimens 4-13 and 20-33, produced from float glass), AGC Blue has the highest stiffness and flexural strength (64 MPa) while the FT Float $1120^{\circ} \mathrm{C}$ has a lower strength $(\approx 48 \mathrm{MPa})$ and stiffness. The "FT Float $1120^{\circ} \mathrm{C}, 2 \mathrm{~h},-50 \mathrm{C} / \mathrm{h}$ " has even lower strength $(38 \mathrm{MPa})$ due to the increased population of

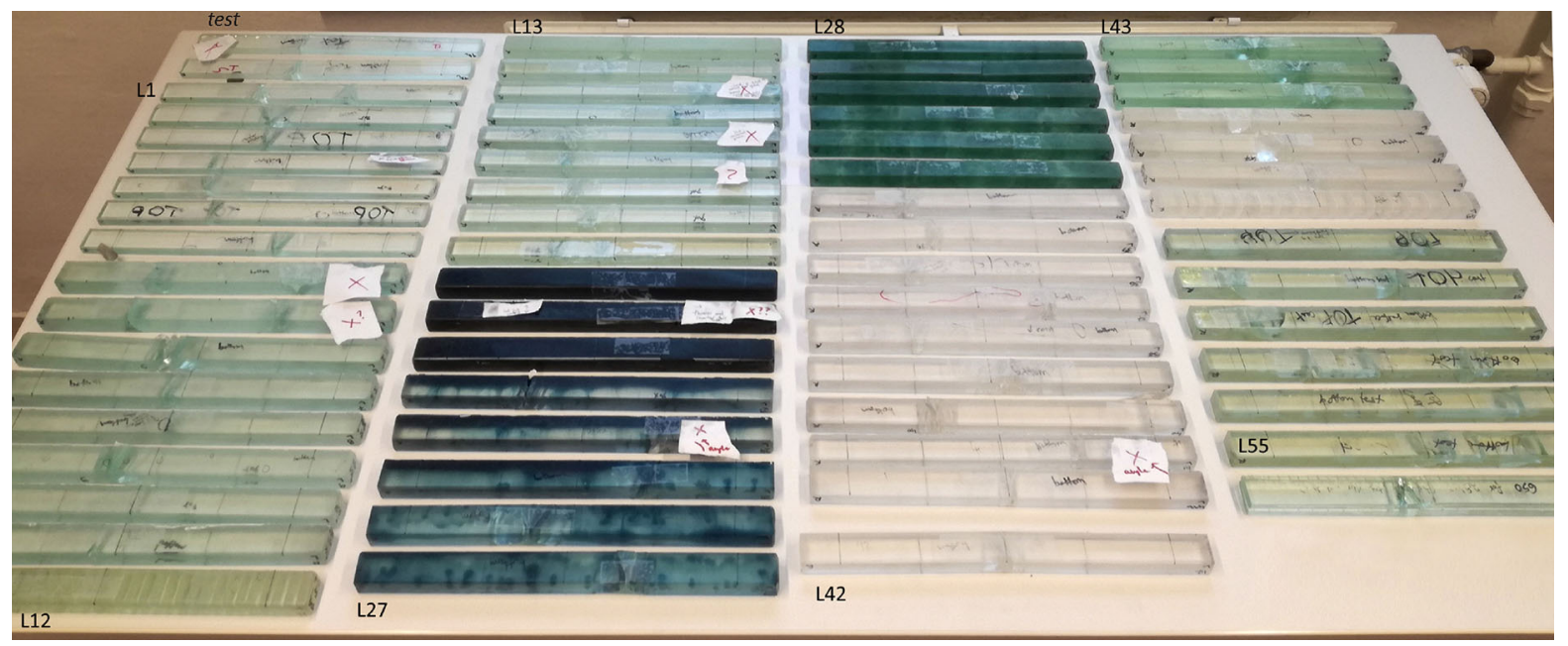

Fig. 28 Overview of tested glass specimens. The specimens in this figure are organized according to the L1-55 order seen in Table 5. More specifically, the row to the left contains specimens
L1-L12, the row to the middle-left L13-L27, the row to the middle-right L28-L42 and finally the row to the right specimens L43-L55
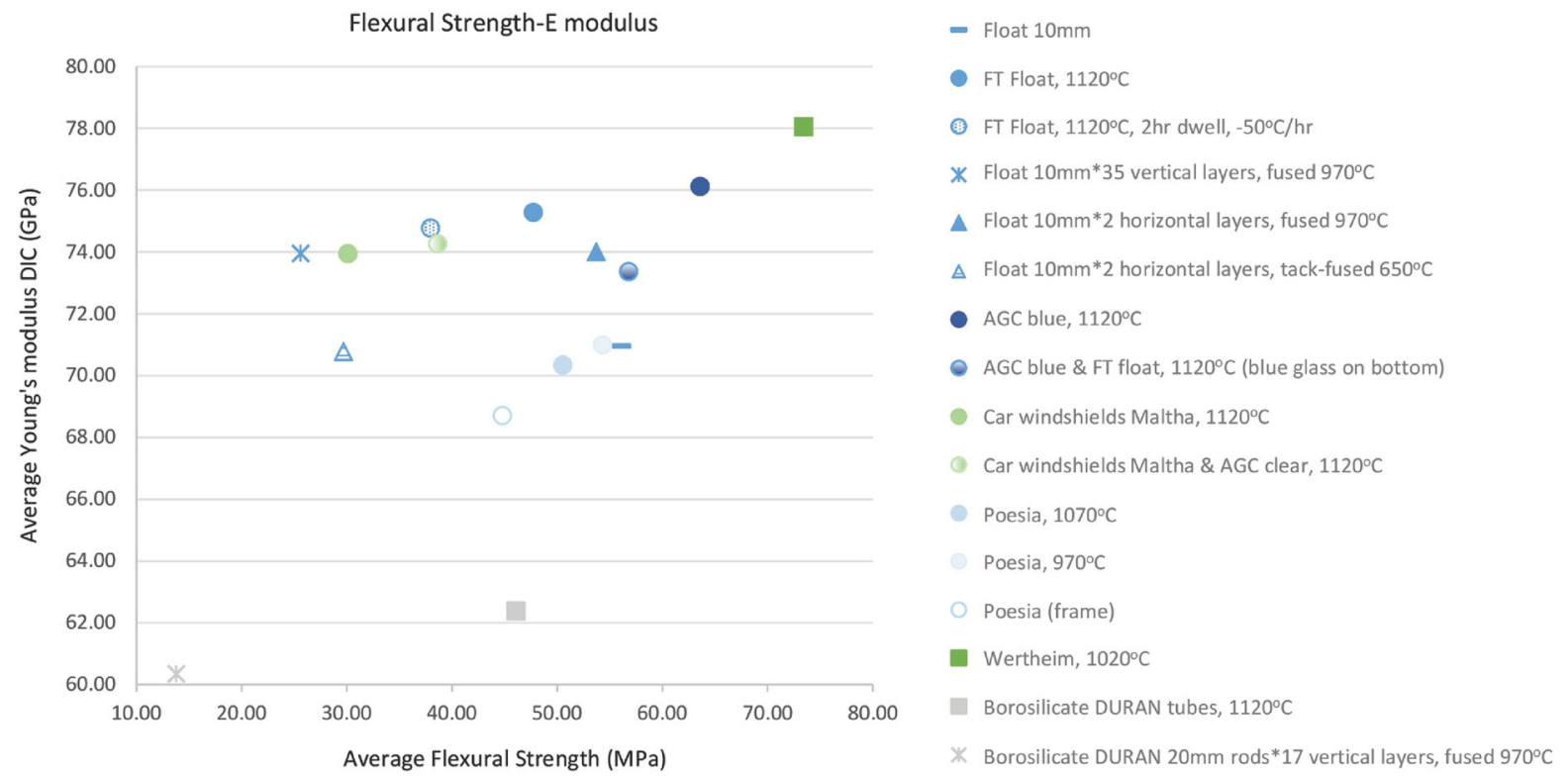

Fig. 29 Average E modulus versus flexural strength 
defects resulting from the poor homogenization of the glass at the top temperature. The fused float sample with exposed crystalline layers at the bottom surface (“35 layers fused at $970^{\circ} \mathrm{C}$ ) has a significantly reduced strength as well (26 MPa), whereas the fused sample with one crystalline interface in the bulk, has double the strength ( $54 \mathrm{MPa})$. The crystalline interface will be a certain cause of early failure when exposed to the zone of maximum stress, but will have a negligible effect when located at the middle horizontal zone of the beam. Lastly, the heavily contaminated Car glass Maltha series has a rather low average strength (30 MPa).

The concept of improving a lower strength glass (FT Float, Car glass Maltha) with a purer compatible glass (AGC Blue, AGC clear respectively) seems to be effective. Both composite versions showed an improvement in strength in relation to the poorer glass quality (FT float improved by 19\%, Car glass improved by 29\%) regardless the occurrence of stress zones in the interface between the two glasses.

Regarding the boron containing glasses, "Borosilicate DURAN tubes $1120^{\circ} \mathrm{C}$ " samples have a similar flexural strength (46 MPa) to "FT Float $1120^{\circ} \mathrm{C}$ " samples, but a lower E modulus (62 GPa), which matches the stiffness of the original cullet $(63 \mathrm{GPa}$, Schott 2017). The fused Borosilicate sample $\left(970{ }^{\circ} \mathrm{C}\right)$ has a $70 \%$ reduced strength due to the crystalline interfaces exposed to the bottom beam surface. Poesia glass showed a better performance, with the samples kilncast at $970{ }^{\circ} \mathrm{C}$ having a slightly higher strength and $\mathrm{E}$ modulus than the samples prepared at a $100{ }^{\circ} \mathrm{C}$ higher temperature. The highest flexural strength and $\mathrm{E}$ modulus were measured for the Wertheim $1020{ }^{\circ} \mathrm{C}$ specimens. The high $\mathrm{E}$ modulus of this glass was previously associated (Bristogianni et al. 2020) with the small $(\approx 5 \%)$ addition of $\mathrm{B}_{2} \mathrm{O}_{3}$ and $\mathrm{Al}_{2} \mathrm{O}_{3}$ to the standard SLS composition.

Comparing the performance of the kiln-cast specimens to the reference samples, the "FT Float $1120^{\circ} \mathrm{C}$ " samples have a lower average flexural strength $\left(\sigma_{\mathrm{f}}=\right.$ $48 \mathrm{MPa}$ ) than the single $10 \mathrm{~mm}$ float panes (56 MPa) or the adhesively bonded DELO 4468 samples, ${ }^{25}$ in

\footnotetext{
25 DELO Photobond 4468 adhesive has been chosen due to the strong bonding to glass, which leads to monolithic behaviour of the bonded glass, as proven by Oikonomopoulou et al. (2018a). When the applied adhesive layer is thin enough, during the bending of the horizontally bonded glass sample, any shear gradient in the adhesive layer is eliminated, and thus the stress/strain is
}

the case where the adhesive thickness was between $30-50 \mu \mathrm{m}(53 \mathrm{MPa})$. Nonetheless, the DELO bonded specimens show a reduced strength with the increase of the adhesive layer up to $230 \mu \mathrm{m}$ (33 MPa). The FT Float kiln-cast samples have a higher E modulus $(75 \mathrm{GPa})$ than the single float $(71 \mathrm{GPa})$ or DELO bonded samples $(62 \mathrm{GPa}$ for the $30-50 \mu \mathrm{m}$ series, $48 \mathrm{GPa}$ for larger adhesive thicknesses). The best performing kiln-cast samples on the other hand (e.g. AGC Blue, Wertheim) present both a higher strength (64 MPa and $73 \mathrm{MPa}$ respectively) and $\mathrm{E}$ modulus (76 GPa and $78 \mathrm{GPa}$ respectively) in comparison to the industrially produced reference beams. The case of the laminated float glass samples is somewhat different, as in this case, due to the very low shear modulus ${ }^{26}$ and increased thickness of the interlayer $(700 \mu \mathrm{m})$, the float glass plies act separately (the bottom ply will fail at a similar load to a single ply). As a result, both the strength and $\mathrm{E}$ modulus are low in comparison to the cast samples $\left(\sigma_{\mathrm{f}}=18 \mathrm{MPa}, \mathrm{E}=17 \mathrm{GPa}\right)$.

The tack-fused $\left(650^{\circ} \mathrm{C}\right)$ float samples, due to the insufficient bonding at the interface, fail at low average strength values ( $30 \mathrm{MPa})$, from a flaw originating at the interface and not the bottom surface, and more specifically at the shear zone (area between the loading and the support rollers). After failure, the separated glass panes have often clear delaminated surfaces, which is a proof of non-fusion. Nonetheless, despite the prolonged zones of non-bonding in the interface, the modulus of the tack-fused components is the same ( $71 \mathrm{GPa}$ ) as of the original float glass used for its making.

The industrially produced Poesia glass beams were $15 \%$ less strong than the kiln-cast beams at $970{ }^{\circ} \mathrm{C}$, accompanied by a decrease in $\mathrm{E}$ modulus of $2 \mathrm{GPa}$.

The E Moduli measured by the Impulse Excitation technique were to a great extent coinciding with the values calculated from the four-point bending experiment and DIC measurement. Radovic et al. (2004) have already reported the great precision of dynamic measurements, such as impulse excitation, for determining the elastic properties of solids, in comparison to the higher percentage of uncertainty of the four-point

\section{Footnote 25 continued}

directly transferred from the bottom glass layer to the top, contributing to the successful cooperation of the two layers.

26 As an indication, the shear modulus of a standard PVB interlayer ranges between 10 and $20 \mathrm{MPa}$ in comparison to the shear modulus of SLS glass that is $\approx 29 \mathrm{GPa}$ (van Dam 2017). 


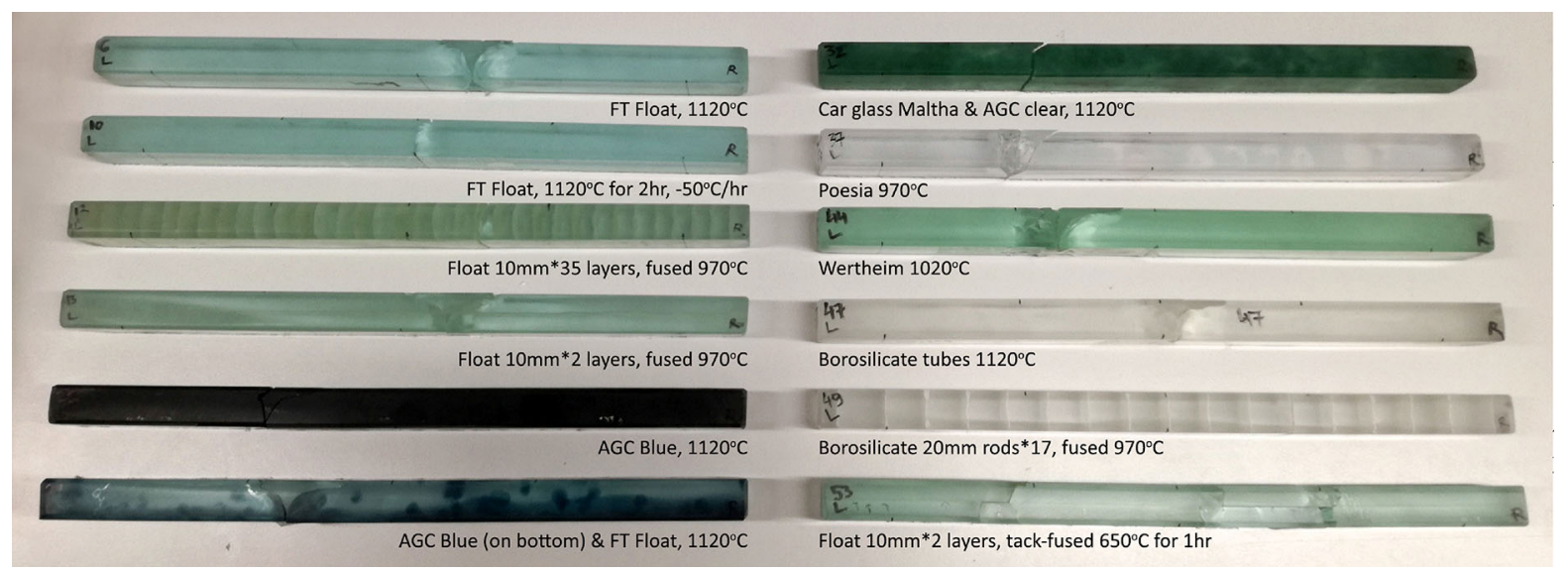

Fig. 30 Side view of a selection of tested specimens. All beams apart from the tack-fused specimen (L53: bottom right) failed from a defect situated at the bottom surface, within the maximum tensile stress zone. Low energy failures are manifested with

bending test due to strain gauge associated errors. ${ }^{27}$ The proximity of the results of this study between the two tests is associated to the high accuracy of the DIC measuring method. ${ }^{28}$

\subsection{Fractographic analysis}

The majority of the kiln-cast specimens (excluding the tack-fused samples), failed from a defect or combination of defects situated at the bottom surface, predominantly at the maximum tensile stress zone (area under the upper loading rollers), or in close proximity in the case of a wide flaw (0.5-1 mm size) (Fig. 30). Only four

\footnotetext{
27 The comparative study by Radovic and co-workers included specimens of Pyrex glass, 4140 steel, pure alumina and 7075 aluminum, of various shapes and sizes. The Young's and Shear moduli of the materials were measured using static (Four-point bending, Nanoindentation) and dynamic (impulse excitation, resonant ultrasound spectroscopy) techniques. The dynamic techniques presented the lowest variability of results, below $0.5 \%$. For the pyrex glass samples, the four-point bending technique showed the highest coefficient of variation $(1.4 \%)$ and typically higher $\mathrm{E}$ modulus values than the other techniques. The lower confidence level of the four-point bending test $(95 \%)$ is attributed to inaccuracies from the strain gauge readings. Such inaccuracies have also been observed by the authors in several studies.

28 A Linear Variable Differential Transformer (LVDT) displacement sensor was also employed during the four-point bending tests but the reported displacement was higher than the actual movement, due to micro-movements of the sensor during bending. The values obtained were therefore not used.
}

a single fracture surface (e.g. L10: FT Float 2h, L49: Borosilicate $970{ }^{\circ} \mathrm{C}$ ) while branching will occur when higher failure loads are achieved (e.g. L44: Wertheim). Note the characteristic for flexural fractures compression curl at the top of the beams

specimens failed from an entirely interior flaw, situated just above the bottom surface $(75-100 \mu \mathrm{m}$ above the surface for flaw width around $160-380 \mu \mathrm{m}$ ) or $1 \mathrm{~mm}$ above for bigger flaw size (width $\approx 3.6 \mathrm{~mm}$ ) (Fig. 31 ). Defects situated in the mesostructure, typically from miniscule in size up to $4 \mathrm{~mm}$ wide (different defect types and sizes as described in Sect. 2.1), were not activated.

Figures 32, 33 and 34 show the cause of failure in relation to the flexural strength and mirror size. The type of flaw (machining/handling, infold, stone or bubble), and its location act upon the glass composition and correlated mechanical properties. In general, the purer specimens fail from machining/handling flaws at a higher strength (Fig. 35), while the stone containing specimens will have a reduced strength according to the width and location (at or above the bottom surface) of the stone. For pure specimens with machining flaws of similar size as the fracture cause (e.g. Wertheim, AGC Blue, FT Float), a higher E modulus will correspond with a higher flexural strength. Only in two cases is the fracture origin associated with a surface bubble or bubble veil (Fig. 36a). None of the specimens failed due to the presence of cord. The presence of cord does not seem to be decisive for a specimen's fracture, as failure from flaws outside the cord zone was equally possible. The fused $\left(970{ }^{\circ} \mathrm{C}\right)$ specimens failed from the crystalline-glass interface at low strength values, 

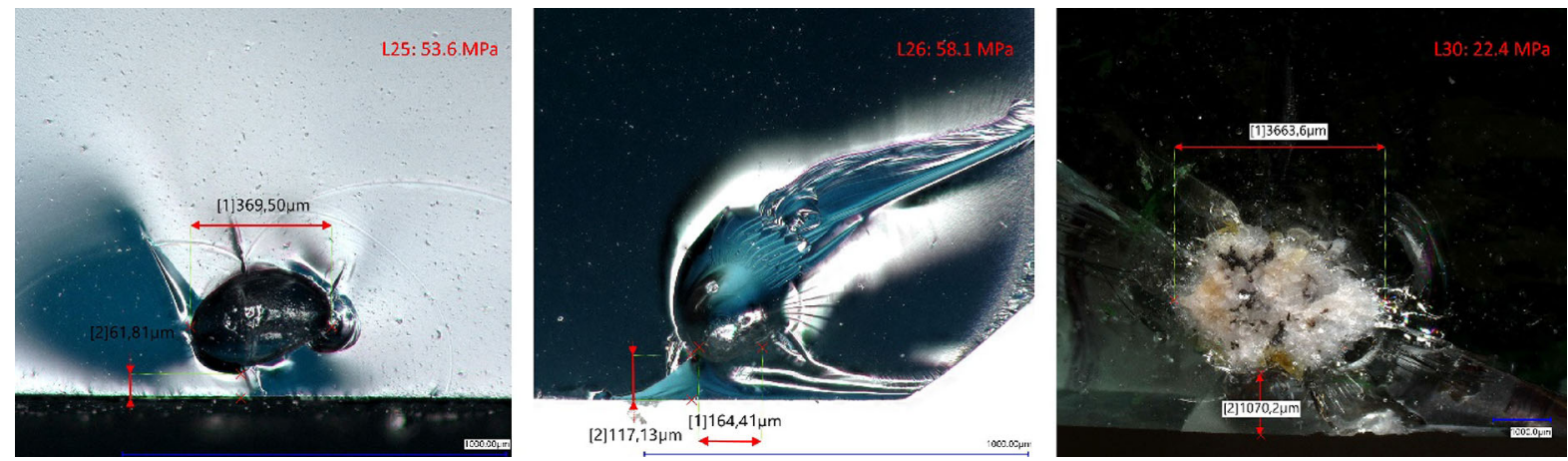

Fig. 31 Fracture mirror surfaces of AGC Blue \& FT Float composite specimens (left, middle) and a Car glass maltha specimen (right). In all of the above cases, the fracture initiated from a crystalline inclusion above the bottom surface

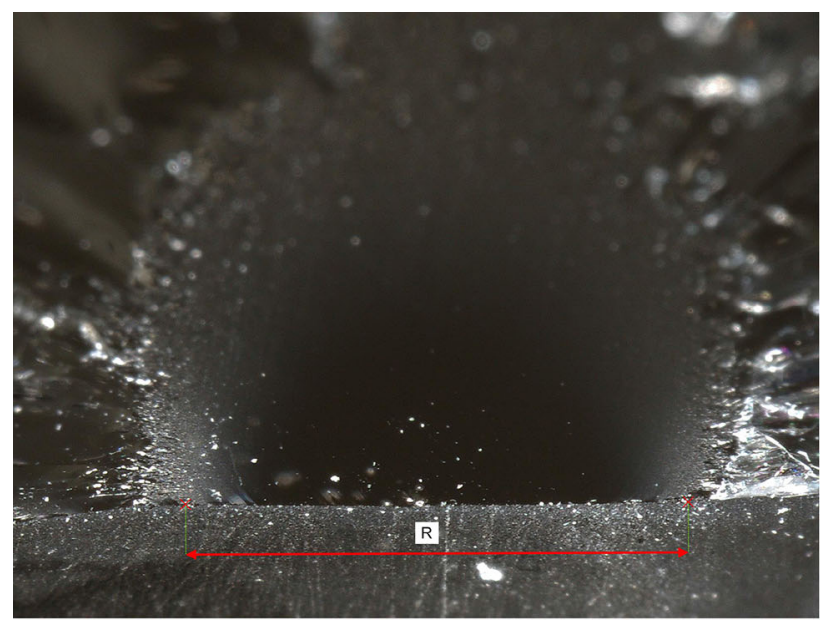

Fig. 32 Example of how the mirror radius (left) and flaw width (right) are measured in this study. Regarding the mirror radius, the diameter between the mist/hackle bouaries at the level of the bottom surface is measured, and divided by two. Often in elon-

when this interface was exposed at the bottom surface of maximum stress (Fig. 36b).

The reference float glass specimens (single, laminated, adhesively bonded) and the standard Poesia specimens all failed from a machining or handling flaw. For the float specimens with "as received" polished bottom surface, the critical flaw would be either situated at the fillet edge line (cut, ground and polished at the laboratory down to 600 grit) or would start from a deep scratch at the surface.

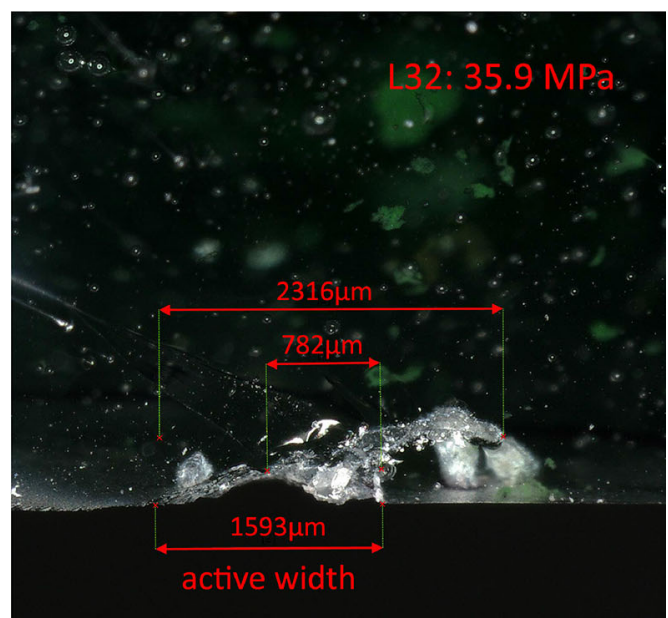

gated defects that extend towards the interior of the glass (right image), only the width exposed at the bottom surface is measured as active

The tack fused specimens are the only cases where failure originated from the bulk, and more precisely at the horizontal interface at the middle of the beam (Fig. 37a). The extended zones of improper fusion along this interface lead to local stress concentrations at the connection zones that exceed the tensile strength of the material during loading. All specimens had a low flexural strength, between 10 and $37 \mathrm{MPa}$, apart from a single specimen that failed from a flaw at the maximum tensile stress zone at the bottom surface (Fig. 37b). This sample had a comparable strength ( $49 \mathrm{MPa})$ to the kilncast float components (FT Float $1120^{\circ} \mathrm{C} \approx 48 \mathrm{MPa}$ ). 

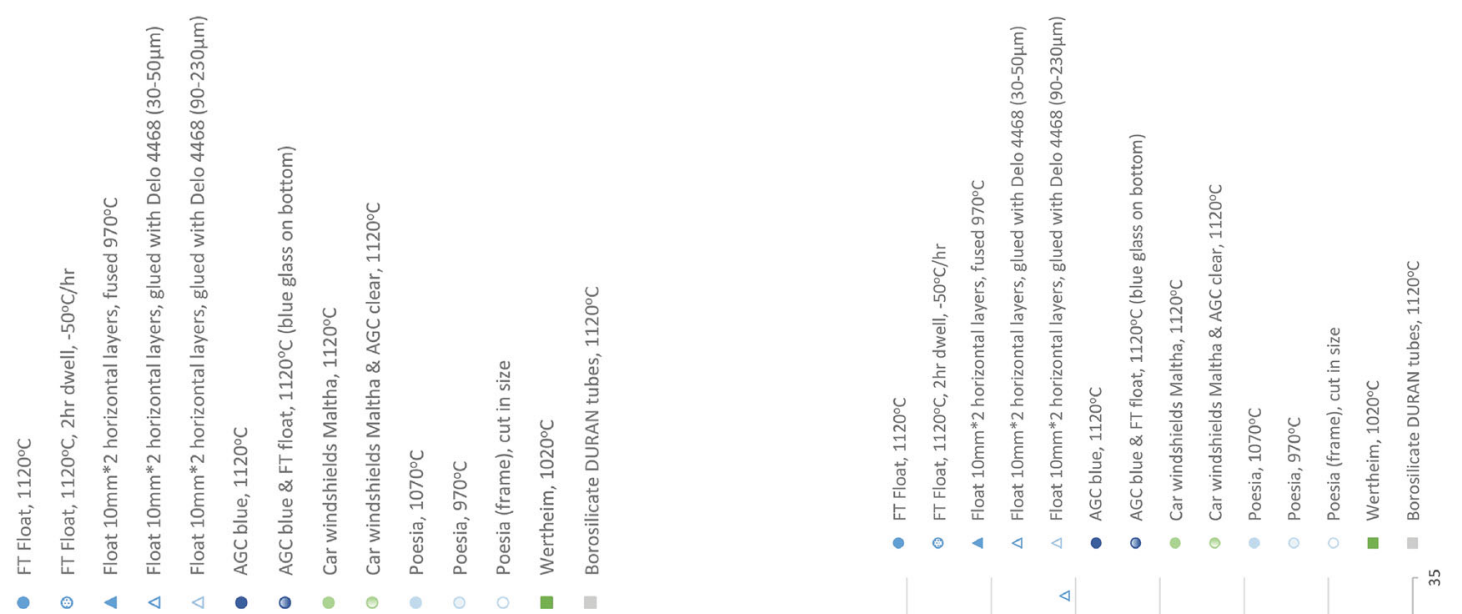

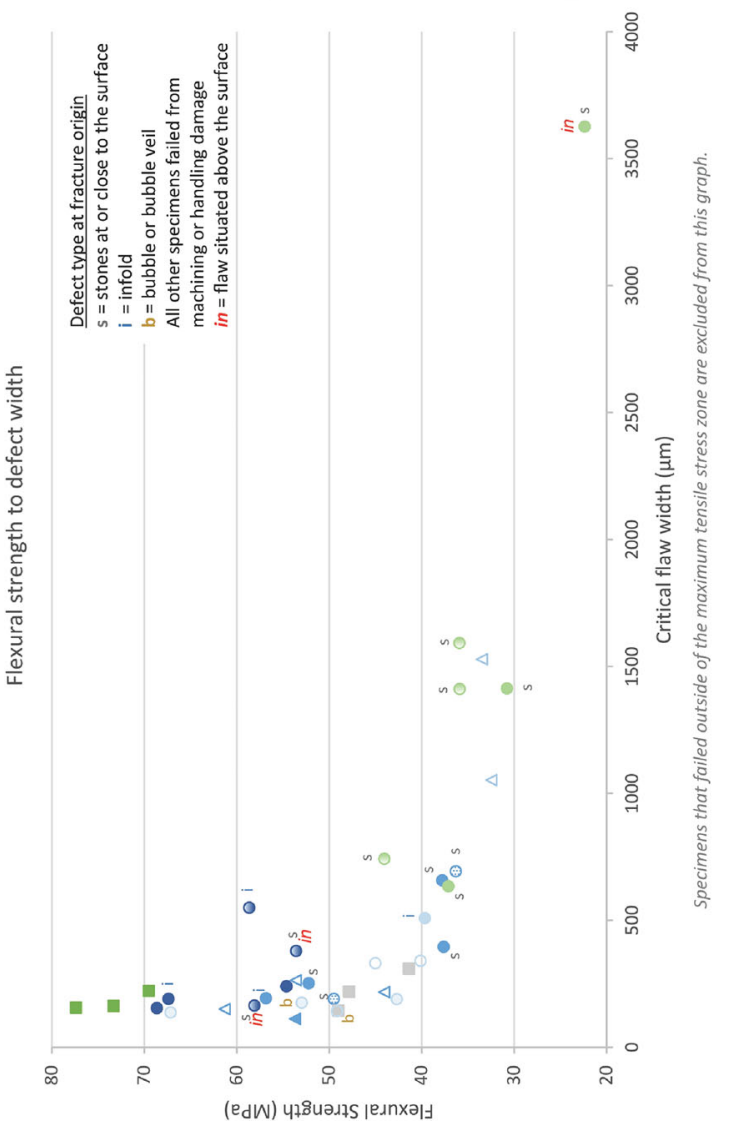

Fig. 33 Flexural strength as a function of critical flaw width. The cause of failure is noted for each specimen

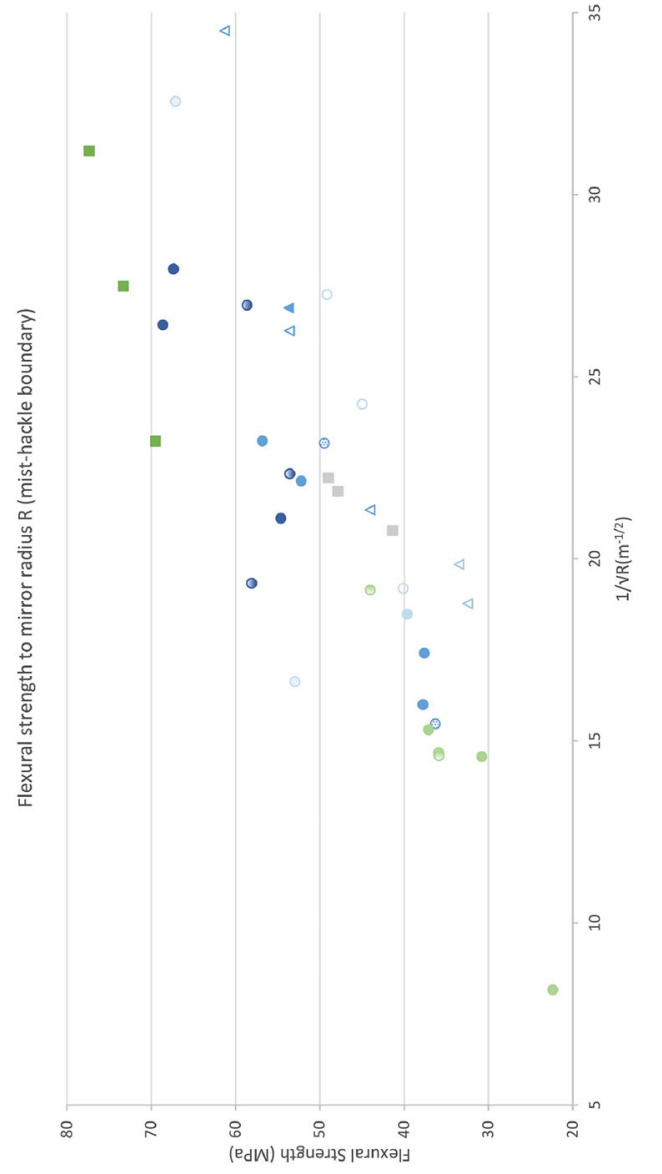

Fig. 34 Flexural strength to $1 / \sqrt{ } \mathrm{R}$ graph. As a general trend, the higher the strength, the smaller the mirror size 

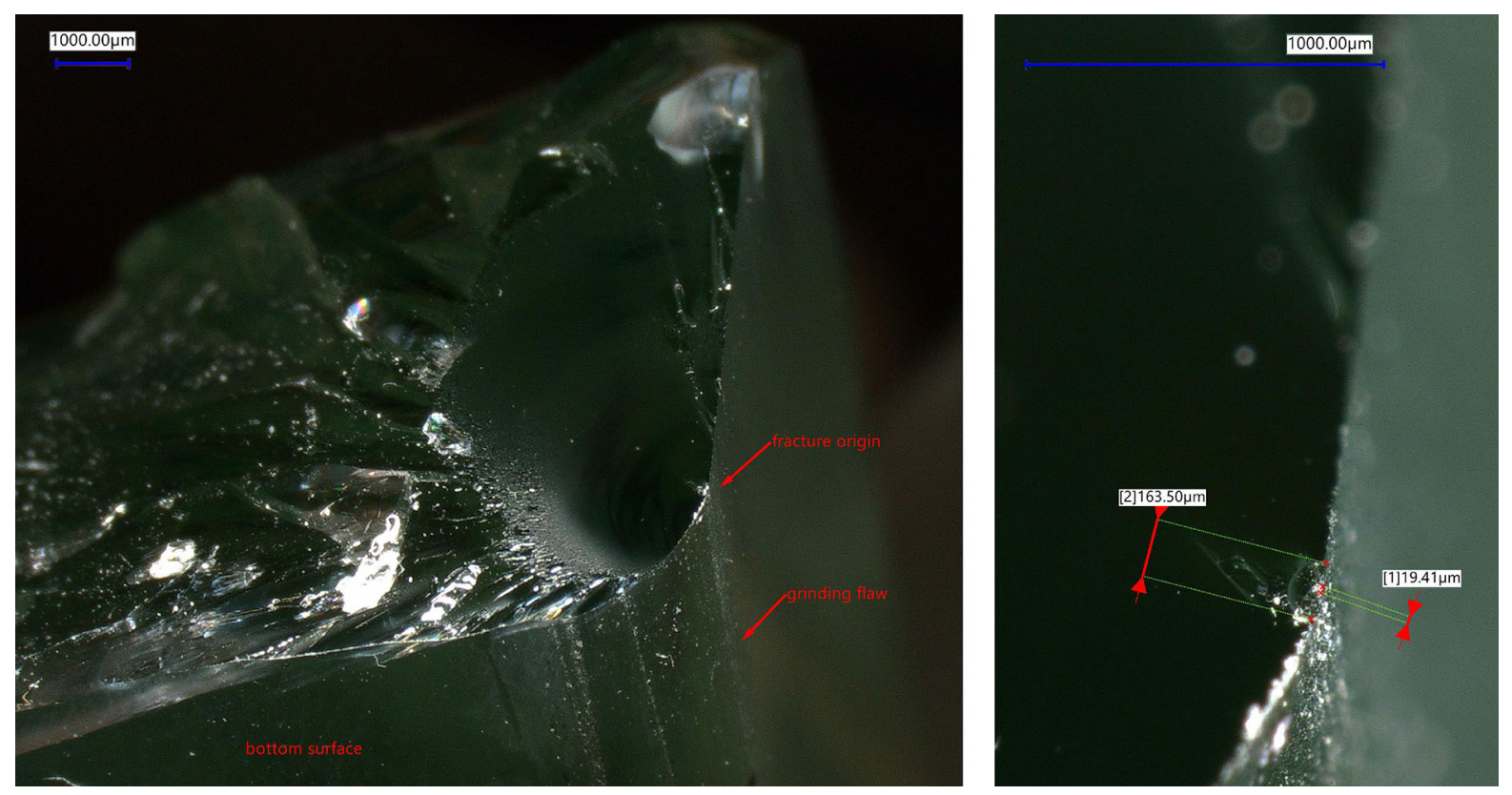

Fig. 35 The rough edge polishing/filleting of a Wertheim $1020{ }^{\circ} \mathrm{C}$ specimen acts as the fracture origin. The magnification of the critical flaw shows multiple striations arriving to that

\section{Discussion}

\subsection{Flexural strength comparison to shorter-span cast glass beams}

A comparison between the flexural strength and $\mathrm{E}$ modulus of the currently tested cast glass specimens $(20 * 30 * 350 \mathrm{~mm}, 140 / 280 \mathrm{~mm}$ span $)$ with values for shorter testing span specimens $(30 * 30 * 240 \mathrm{~mm}$, $100 / 200 \mathrm{~mm}$ span) previously reported by Bristogianni et al. (2020) is made (see Fig. 38, Table 6). It should be stressed that differences in the mechanical properties are not directly related to the "size factor", but are also at least partially linked to the differences between the bending fixtures (e.g. roller radius, free rollers vs. fixed ${ }^{29}$ ), stiffness of the beam shape (actively contributing to shear displacement or not), the post-processing quality of the specimens and even to minor variations in composition and contamination of the cullet (e.g. for Poesia or Car glass cullet).

\footnotetext{
${ }^{29}$ Fixtures that do not allow sideway rolling of the pins lead to a frictional constraint that positively influences the reported strength (Quinn et al. 2009).
}

point, together with a semi-elliptical fracture within the glass. This defect, observed in several samples that failed from machining damage, is believed to be created during grinding

In general, the measured stiffness by the DIC and IET methods is found in agreement with the DIC measurements of the prior study, apart from the case of the Poesia glass, where a lower E modulus by $5 \mathrm{GPa}$ is found. This change is more likely to be associated with an alteration in the cullet used. ${ }^{30}$ In terms of flexural strength, two trends were identified: the Poesia (standard and cast at $1070{ }^{\circ} \mathrm{C}$ ) and the contaminated Car glass specimens showed a reduced flexural strength by $11-24 \%$ and $27 \%$ respectively, while the cast at $1120{ }^{\circ} \mathrm{C}$ AGC Blue, Borosilicate Tubes and FT Float specimens showed a slight improvement in the flexural strength in the order of 1,8 and $9 \%$ accordingly. The increased improvement in the flexural strength $(+41 \%)$ of the Wertheim glass is linked to the by $200^{\circ} \mathrm{C}$ increased forming temperature, which led to the dissolution of crystalline interfaces and thus the creation of a more homogeneous glass.

\footnotetext{
30 Possible compositional changes/improvements in the batch may occur during the years in medium-sized foundries such as Poesia. Given the uncertainty of the XRF analysis which cannot detect Boron, such minor changes cannot be easily detected in this study. Determination of the $\mathrm{B}_{2} \mathrm{O}_{3}$ content in the Poesia cullet resulting from different production periods should be conducted employing Electron Probe Micro Analysis (EPMA).
} 


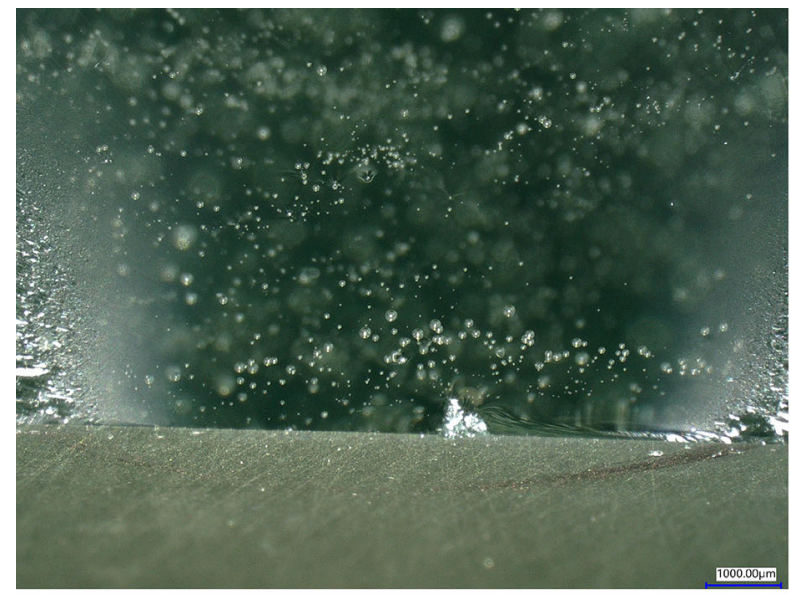

(a)

Fig. 36 a The fracture surface of an "FT Float $1120{ }^{\circ} \mathrm{C}, 2 \mathrm{~h}$ $-50{ }^{\circ} \mathrm{C} / \mathrm{h}$ " specimen forms a characteristic example of multiple flaws acting around a location, such as grinding damage,

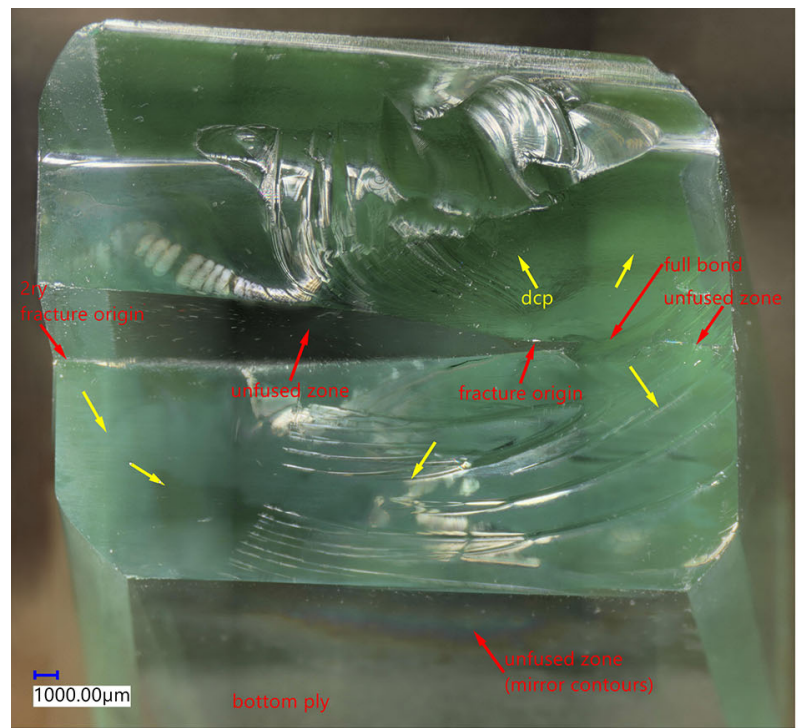

(a)

Fig. 37 Fracture surfaces of tack-fused Float glass beams $\left(650{ }^{\circ} \mathrm{C}, 1 \mathrm{~h}\right)$. a Typical failure observed in this series, with the fracture origin originating at the middle of the beam's height, at the interface between the two float glass planes. The yellow arrows show the direction of crack propagation (dcp). Zones of insufficient fusion are also marked at the image. b Single exam-

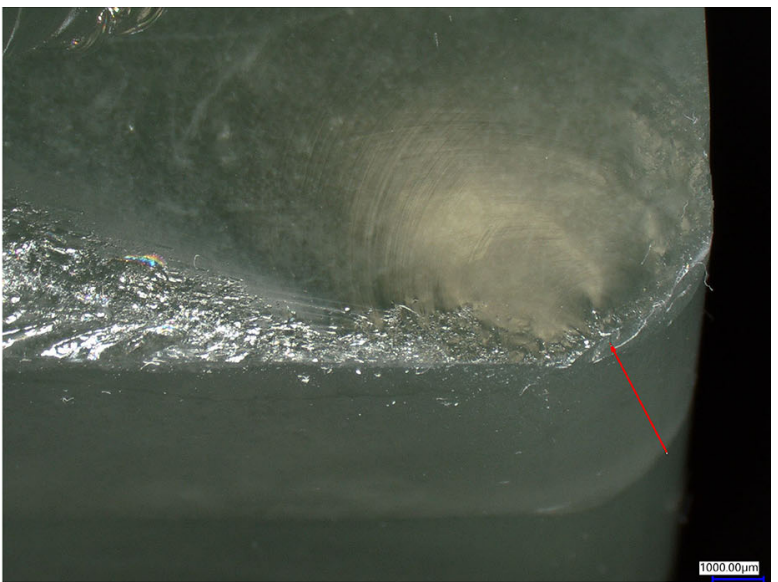

(b)

bubble veils, and stone inclusion. b Fracture mirror of a "Float $10 \mathrm{~mm} * 35,970{ }^{\circ} \mathrm{C} "$ specimen, which failed at the crystallineglass interface

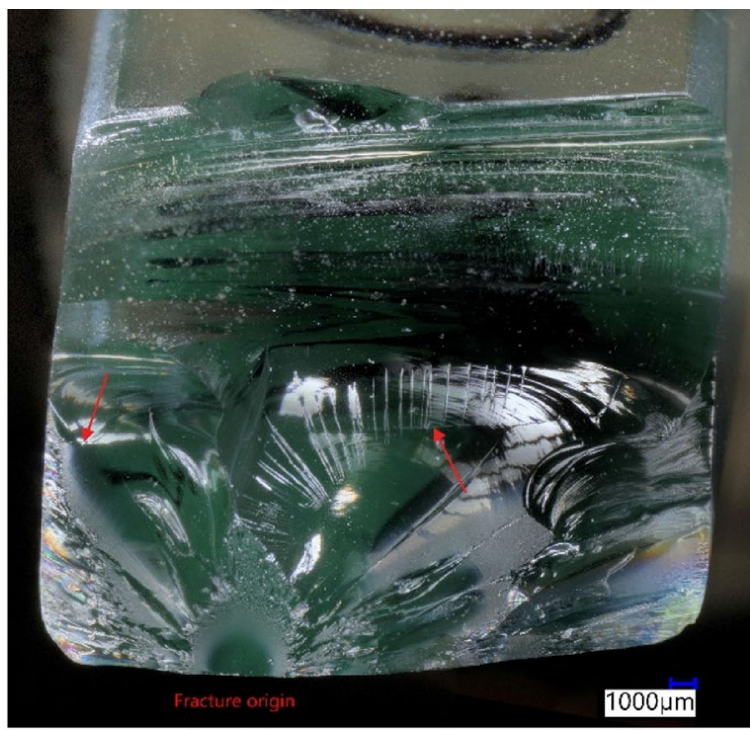

(b)

ple of a standard flexural fracture, originating from the bottom surface. Despite the visible traces of the fusion interface (red arrows), the bonding of the two float layers was sufficient at this location, leading to the monolithic behaviour of the beam and to a higher flexural strength 


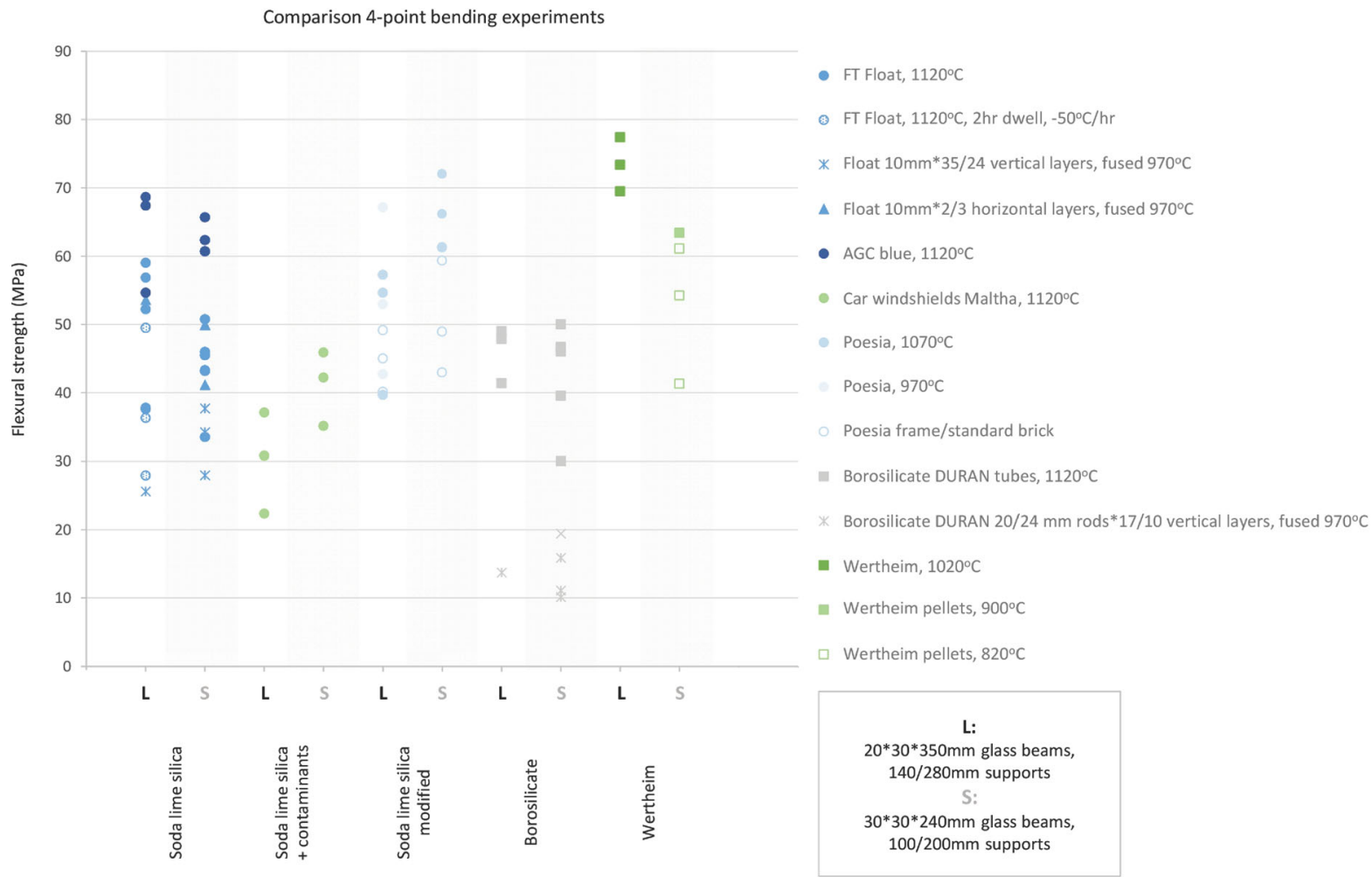

Fig. 38 Comparison of flexural strength between current and prior four point bending experiments

Table 6 Comparison of the average Flexural strength and E modulus between current and prior four point bending experiments

\begin{tabular}{|c|c|c|c|c|c|c|c|c|c|c|c|c|}
\hline \multirow{2}{*}{$\begin{array}{l}\text { Glass type } \\
\text { Experiment* }\end{array}$} & \multicolumn{2}{|c|}{$\begin{array}{l}\text { FT float } \\
1120^{\circ} \mathrm{C}\end{array}$} & \multicolumn{2}{|c|}{$\begin{array}{l}\text { AGC blue } \\
1120^{\circ} \mathrm{C}\end{array}$} & \multicolumn{2}{|c|}{$\begin{array}{l}\text { Car glass } \\
\text { Maltha } \\
1120^{\circ} \mathrm{C}\end{array}$} & \multicolumn{2}{|c|}{$\begin{array}{l}\text { Poesia } \\
1070{ }^{\circ} \mathrm{C}\end{array}$} & \multicolumn{2}{|c|}{$\begin{array}{l}\text { Poesia } \\
\text { stan- } \\
\text { dard** }\end{array}$} & \multicolumn{2}{|c|}{$\begin{array}{l}\text { Borosilicate } \\
\text { DURAN } \\
\text { Tubes } \\
1120{ }^{\circ} \mathrm{C}\end{array}$} \\
\hline & $\mathrm{L}$ & S & $\mathrm{L}$ & $\mathrm{S}$ & $\mathrm{L}$ & $\mathrm{S}$ & $\mathrm{L}$ & $\mathrm{S}$ & $\mathrm{L}$ & $\mathrm{S}$ & $\mathrm{L}$ & S \\
\hline $\begin{array}{l}\text { Average } \\
\text { flexural } \\
\text { strength } \\
(\mathrm{MPa})\end{array}$ & 47.7 & 43.7 & 63.6 & 62.9 & 30.1 & 41.1 & 50.5 & 66.5 & 44.8 & 50.4 & 46.1 & 42.5 \\
\hline $\begin{array}{l}\text { Average } \\
\text { Young's } \\
\text { modulus } \\
(\mathrm{GPa}) \text { by } \\
\mathrm{DIC}\end{array}$ & 75.3 & 72.7 & 76.1 & 76.5 & 74 & - & 70.4 & 75.8 & 68.7 & - & 62.4 & 66.8 \\
\hline
\end{tabular}

* "L" refers to the current 4-point bending experiments $(20 * 30 * 350 \mathrm{~mm}$ beam size, $140 / 280 \mathrm{~mm}$ load/support span) while "S" to prior testing $(30 * 30 * 240 \mathrm{~mm}$ beam size, $100 / 200 \mathrm{~mm}$ load/support span, see Bristogianni et al. 2020)

**The Poesia reference beams in this study (L) are cut out from larger cast glass pieces $(65 * 150 * 790 \mathrm{~mm})$, than in the previous study (S), where $65 * 105 * 210 \mathrm{~mm}$ cast glass bricks were used. Although the compositional differences between L and S beams should be neglegible, the thermal history of the components could differ 
Considering the larger maximum stress area of the longer span beams $\left(4200 \mathrm{~mm}^{2}\right.$ vs $\left.3000 \mathrm{~mm}^{2}\right)$, lower strength values would have been expected for all specimens. This is because in general larger specimens have a higher chance of a larger, more critical flaw (Quinn 2003). However, in cases of concurrent flaw populations-such as the studied cast glasseschanging the specimen size may alter the significance of one type of flaw over another (Quinn and Morrell 1991).

The explanation between the two observed trends is that the purer specimens seem to predominantly fail from machining flaws, which are of the same character and magnitude in both series of experiments. Therefore, similar strengths should can be expected. On the other hand, in the case of the more contaminated samples (Car glass Maltha), indeed larger stones are traced in the larger specimens, leading to a significant reduction of the strength (as anticipated), when such stones are exposed at the area of maximum stress.

Also, when comparing the two tests, it is important to take into account the change in the tested cross section $(30 * 20 \mathrm{~mm}$ vs $30 * 30 \mathrm{~mm}$ ). In the current study where the beam height is shorter, proportionally a higher zone above the surface is subjected to high tensile stresses. As a result, 4 out 57 (tack-fused excluded) specimens failed from an inclusion above the bottom surface in comparison to 1 out of 58 in the smaller span testing.

Lastly, it should be noted that the casting itself of two different shapes can lead to small variations between specimens of the same glass (due to different heat-flow for example), apart from the alterations that can occur due to randomness in the consistency of the cullet (e.g. Car glass) or unexpected changes in the ratio of the batch materials (e.g. Poesia glass).

The limited number of samples per glass type in both four-point bending tests does not allow for deriving strength scaling ratios using the Weibull size scaling approach. It pinpoints however the complexity arising in strength prediction, when failure is governed by more than one flaw type, and the glass quality is affected both by changes in the geometry and minor variations in composition as well as in the casting parameters.
4.2 Role of the different flaw types and uncertainties in predicting the critical flaw

The previously identified defect categories are crystalline inclusions (and interfaces), infolds, bubbles, cord and machining damage. Considering the prevailing failure due to inclusions and infolds in the case of Car glass Maltha or FT Float glass, compared to the failures from machining damage in more pure specimens, in theory predictions could be made based on the most critical from a pool of flaws at the bottom beam surface. In addition, when studying the relationship of flexural strength to flaw width in each glass series, usually a direct inverse relationship exists between the two values (see fracture mirror surfaces in Figs. 39, 40, 41, 42). However, by studying the bottom surface of the specimens upon fracture, it is often observed that failure occurred at a much less prominent flaw, than the ones situated in its surrounding (see Fig. 43a). Such phenomena rank on the one hand the criticality of each different type of flaw, but on the other hand draw the attention to three facts (i) stress gradients due to the loading conditions (flaw location in/outside of maximum stress zone, unevenness in the sample leading to asymmetric loading) will expose some flaws more than others, (ii) more than one type of flaw may be acting in combination (e.g. machining damage together with bubble veil), weakening a specific spot, and (iii) the criticalness of a flaw depends on its orientation in respect to the stress field.

In that sense, although in several cord-containing specimens failure does not occur at the cord (Figs. 42, $43 \mathrm{~b}, 44)$, the presence of cord could intensify a flaw that by first sight looked less critical than its adjacent (Fig. 43a). The presence of such a glass inhomogeneity implies a minor local change in the mechanical properties of the beam (e.g. change hardness or fracture toughness) that could alter the way the glass beam responds to a flaw situated in this specific location. Similarly, although bubbles in the bulk will not have a serious impact on the strength, a bubble or bubble veil just above the bottom surface will weaken this part of the surface. Figure $43 \mathrm{a}$ also suggests that infolds, despite their size, remain cavities that cause stress concentrations around them during loading, but will not induce stress themselves, as stone inclusions would do. In the occasion of the simultaneous presence of similar size infolds and stones at a surface, failure from a stone is more probable. 

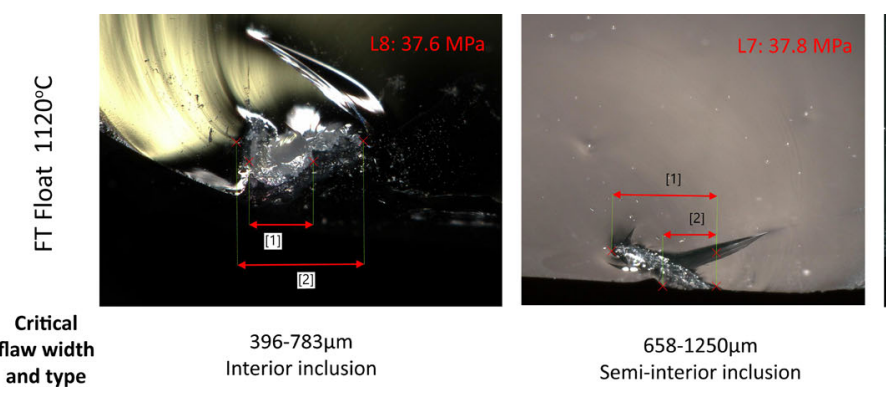

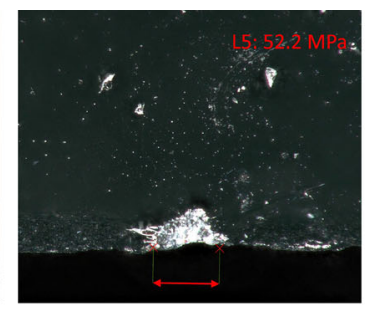

$253 \mu \mathrm{m}$
nfold/inclusion

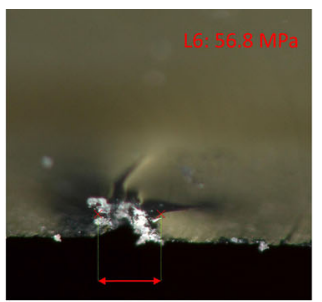

$195 \mu \mathrm{m}$ Infold/inclusion

Fig. 39 Critical flaw (crystalline inclusion) leading to failure in the "FT Float $1120{ }^{\circ} \mathrm{C}$ series. The flexural strength increases with the decrease of the flaw width

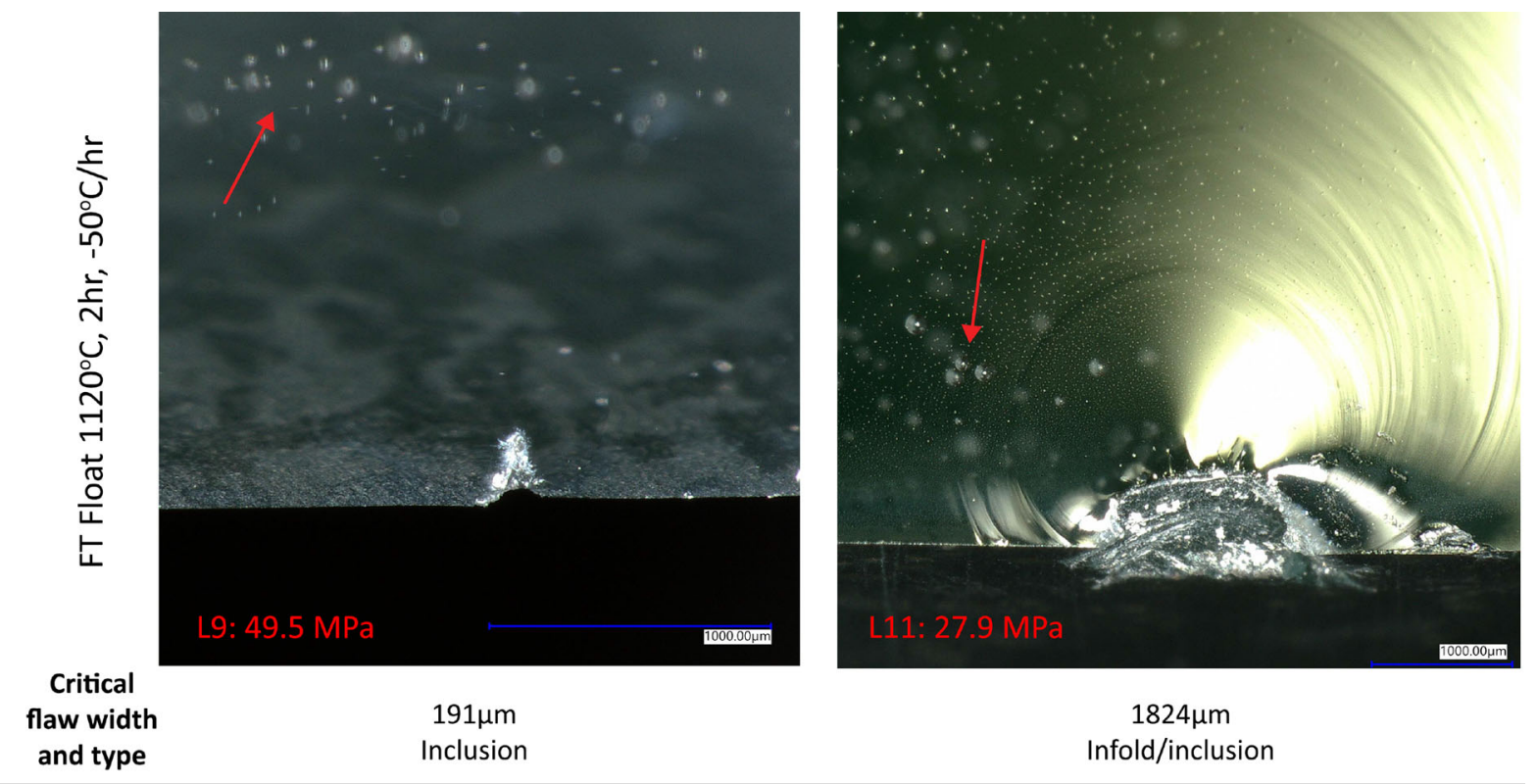

\section{Other bottom surface flaws}

Increased amount of bubbles, infolds, machining damage

Fig. 40 Critical flaw at the mirror surface of "FT Float $1120^{\circ} \mathrm{C}$, $2 \mathrm{~h},-50^{\circ} \mathrm{C} / \mathrm{h}$ " specimens. The increased width of the inclusion in L11 is responsible for the reduction of flexural strength by

Although grinding damage occurs in all specimens, some glasses with lower hardness will develop deeper scratches (as seen in Sect. 3.1). Moreover, specific locations will be more prone to parallel transverse grinding scratches due to the grinding process in relation to the beam geometry. This is particularly the case with the fillet edges of the beams, which proved to be a critical failure zone (Fig. 45).

Apart from large ( $>1 \mathrm{~mm})$ CSP inclusions located at the maximum stress zone (in the case of Car glass- - see Fig. 46), or exposed crystalline interfaces (in the case of more than $20 \mathrm{MPa}$. The surface quality is further weakened by the proximity of bubble clusters

the fused samples at $970{ }^{\circ} \mathrm{C}$ ) that can be characterized as high risk, all the rest of the flaws seem to have a versatile role that depends on the population of surrounding flaws and the exact loading condition (e.g. uneven load introduction). This complex interaction highlights the complexity of failure predictions and quality control for real-world applications of cast glass components. The subjection of such components to dynamic loading and thus a variable stress field, leads to a continuous shift of flaw activation, rendering a higher percentage 


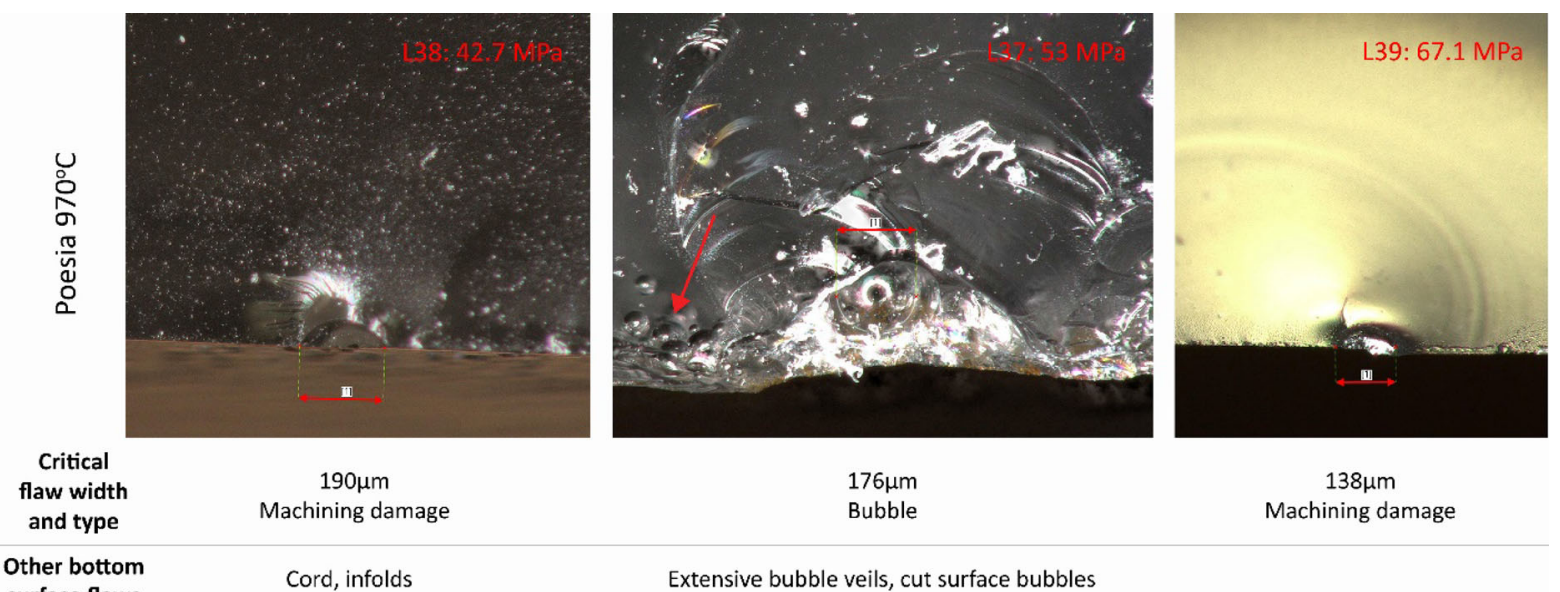

Fig. 41 Critical flaw at the "Poesia $970{ }^{\circ} \mathrm{C}$ " series. Several defects (e.g. cord, bubble veils) act upon the grinding surface damage, leading to a $15 \mathrm{MPa}$ range in the flexural strength

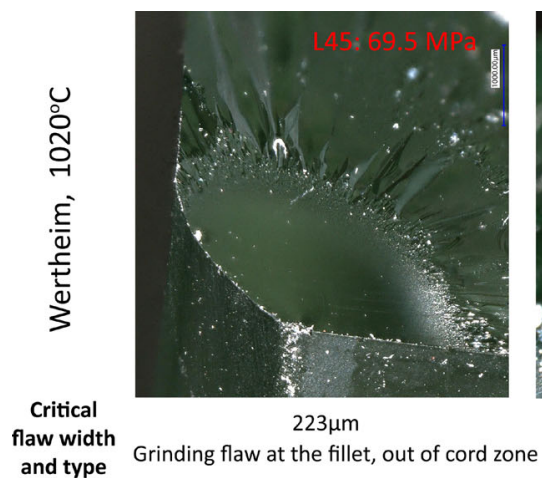

Fig. 42 Mirror surface of Wertheim series. All specimens failed due to grinding damage (rough fillet edge). Despite the presence of cord, the variations in the flexural strength $(8 \mathrm{MPa})$ are

of flaws as dangerous than expected in an evaluation with a static stress field in mind.

\subsection{Observations on the stiffness and structure of cast glass}

The study showed that even in cases with an increased density of flaws in the bulk (e.g. Car glass Matlha) such as bubbles, coating residues and cord, the global stiffness of the specimen will not be affected. On the contrary, higher values were reported for kiln-cast SLS glass specimens than for the original float glass cullet. Even in the case of extended discontinuations, such as in the tack fused $\left(650{ }^{\circ} \mathrm{C}\right)$ specimens, the $\mathrm{E}$ modulus was not reduced but stayed constant. This fact combined with the results of the IET damping values and the DSC tests suggests that the complete kiln-casting process - including the prolonged homogenization dwell at top temperature, the slower cooling rate down to the glass transition range and the prolonged annealing until below the strain pointcontribute to a structural change in the glass network. This densification seems to be increasing the Emodulus, but could also simultaneously be increasing the hardness of kiln-cast components-an hypothesis that requires further investigation, as the thermal history could thus be increasing the brittleness. This information will shed light to how the glass network around 


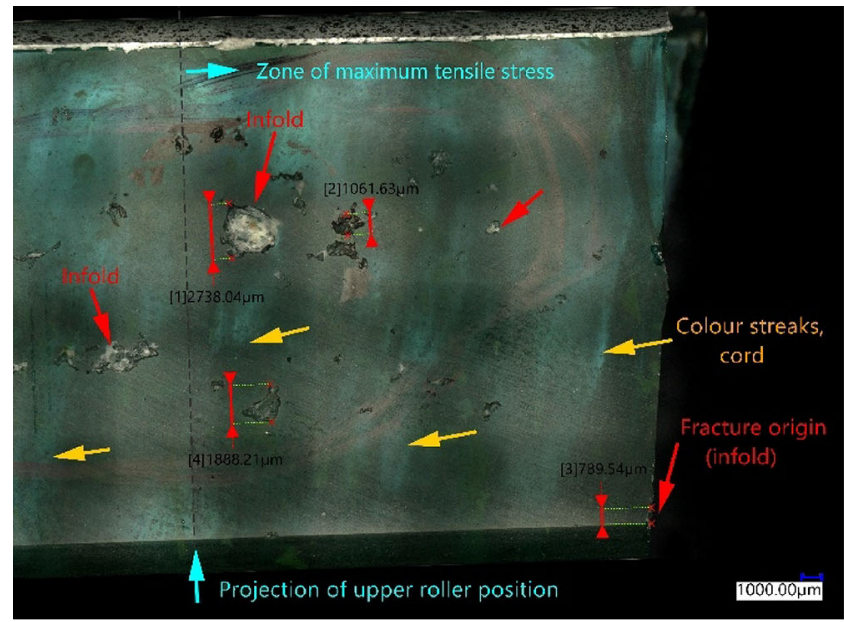

(a)

Fig. 43 a Bottom surface of an "AGC Clear \& Car glass" composite specimen, depicting the population of defects surrounding the fracture origin. The cord originating from the mixing of the two glasses is shown with yellow arrows. The specimen failed from a much smaller flaw than its surrounding, either due to

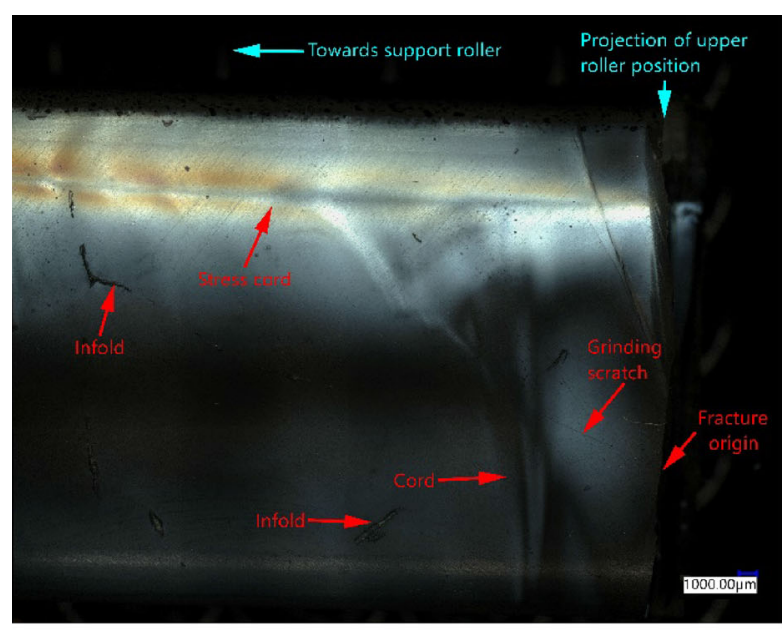

(a)

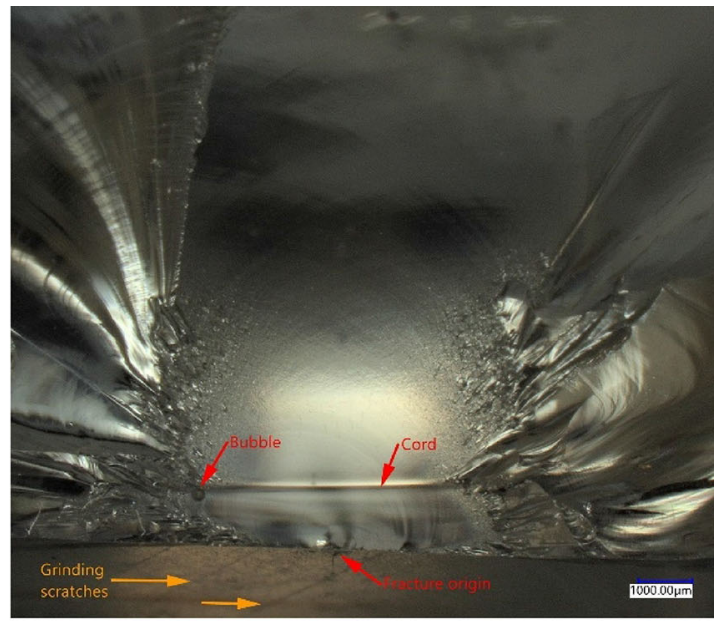

(b) accidental asymmetrical loading, or due to the influence of the repeated transverse cord. b Mirror surface of a "Poesia $970{ }^{\circ} \mathrm{C}$ " specimen that failed due to grinding damage. It is uncertain if the presence of cord influenced the strength

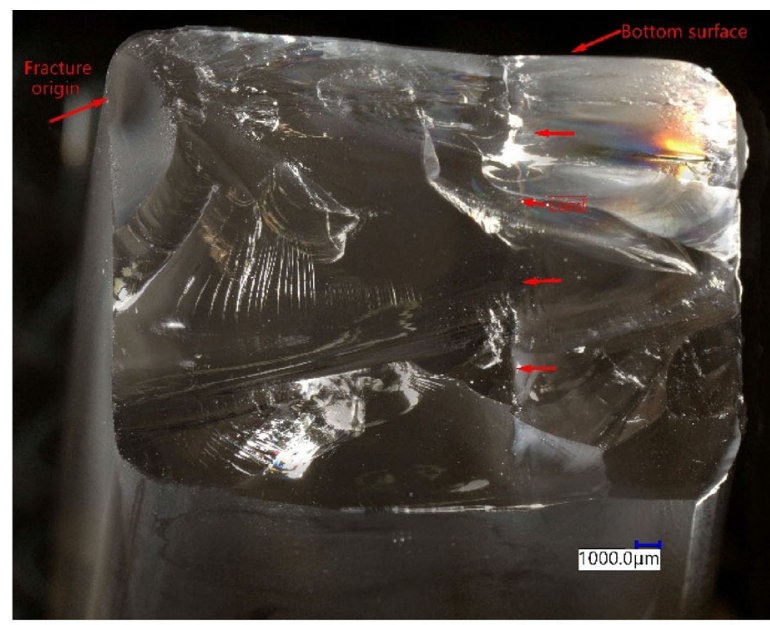

(b)

Fig. 44 Fracture origin in a a Poesia $970{ }^{\circ} \mathrm{C}$ and b Poesia $1070{ }^{\circ} \mathrm{C}$ specimen, showing that the occurring cord was not the cause of failure

a flaw will respond once a tensile stress is applied. The thermal history thus can counteract upon the chemical composition. ${ }^{31}$ Given the multiple casting parameters

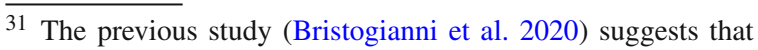
some compositions are more favorable (e.g. Poesia, Wertheim) than others, as they tend to deform more around a flaw due to a higher ratio of alkali oxides over calcium oxide and small
}

and variables applicable from one casting foundry to another, once more the issue of quality control of cast glass is raised, including the impact of the imposed ther-

Footnote 31 continued

percentage of boron. This ability of micro-deformation leads to the relaxation of the stress field and to a higher flexural strength. 


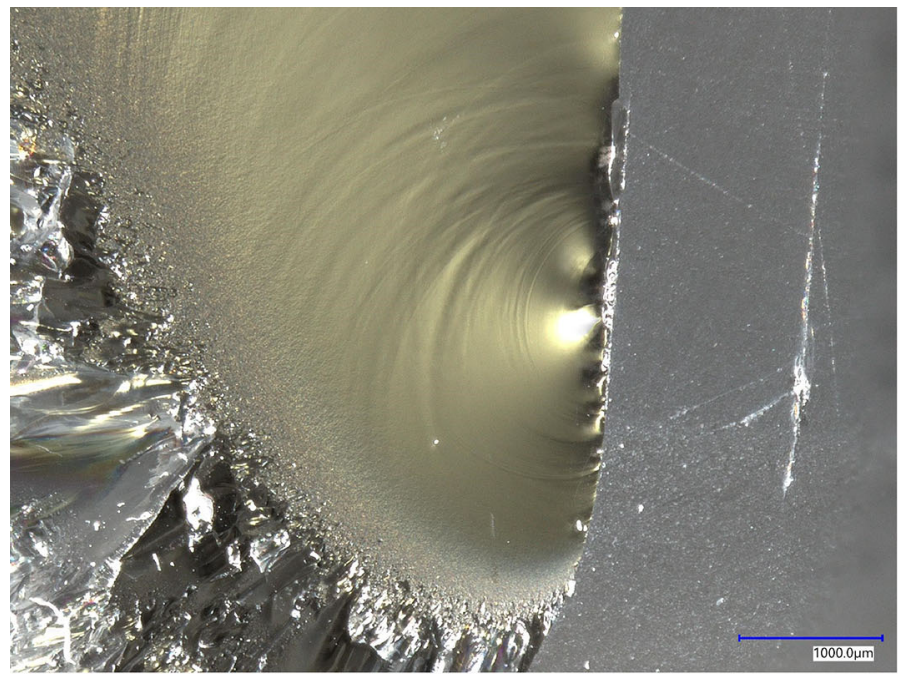

(a)

Fig. 45 Examples of transverse surface damage such as repetitive scratches in a Poesia $1070{ }^{\circ} \mathrm{C}$ specimen (a) or continuous parallel grinding scratches during the filleting of an AGC Blue

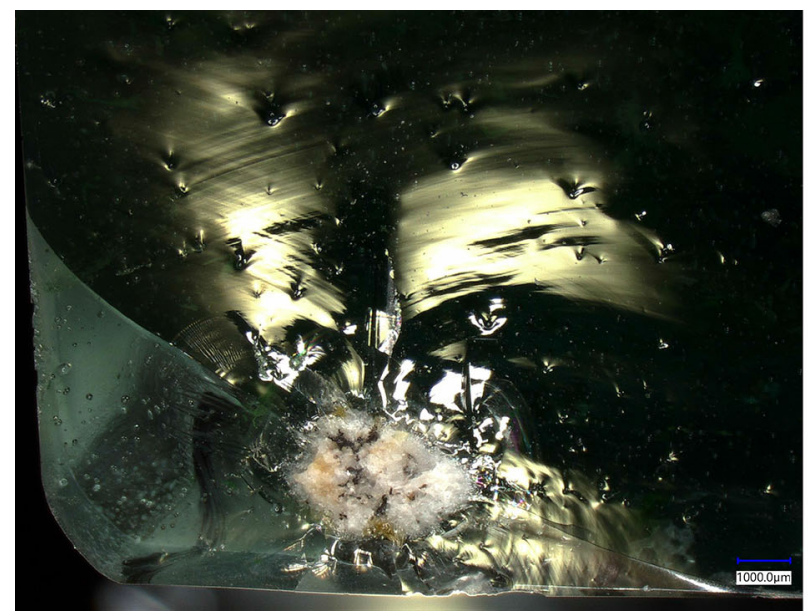

Fig. 46 Large crystalline inclusion ( $3.6 \mathrm{~mm}$ wide) in a Car Glass Maltha specimen, possibly originating from CSP contamination in the cullet. Traces of metal and colour streak can be found in

mal history (beyond the study of internal stress) to other obvious variations such as the chemical composition.

Nonetheless, the thermal history will affect both the microscopic and the macroscopic properties of the cast glass. At a macroscopic level, different types or more flaws may appear due to alterations in the firing schedule. As a direct example, the faster homogenization

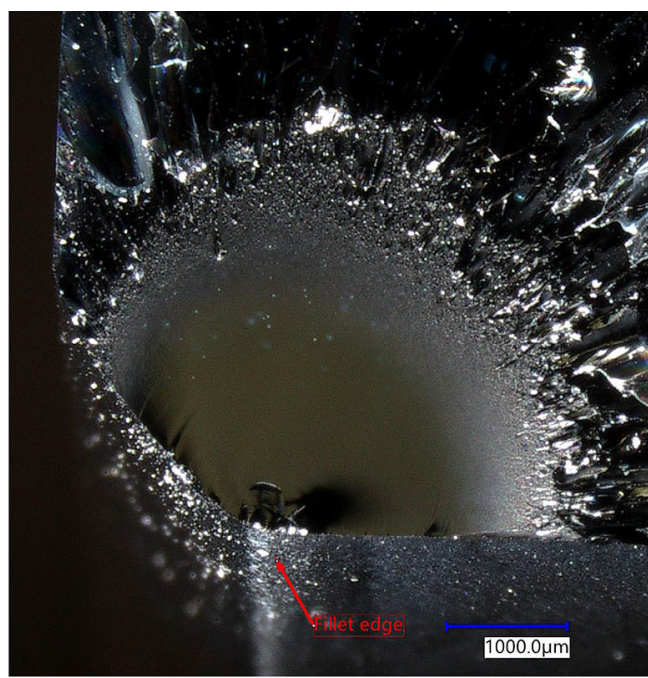

(b)

$1120^{\circ} \mathrm{C}$ specimen (b). Transverse flaws have a bigger impact in the strength than longitudinal flaws of the same sort, as in the first case, a wider flaw zone is exposed to tensile stress

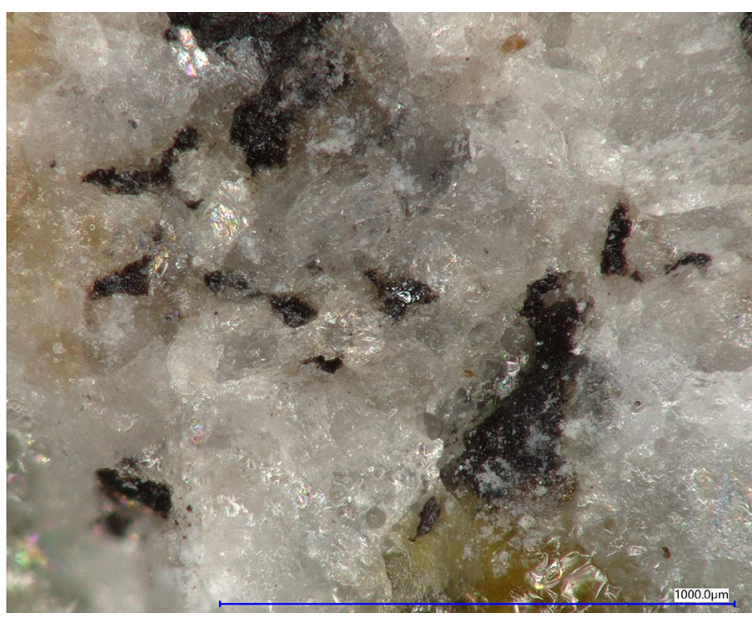

the stone. The fracture originated from the stone and not from the bottom surface

at top temperature and the slower cooling imposed on the FT Float glass, led to an increased amount of miniscule bubbles in the material. The fractographic analysis suggests that the occurring flaws contributed to a lower strength (by 20\%) in a more significant manner than any changes in the nanostructure of the network did. 


\section{Conclusions}

A total of 64 silicate based glass specimens were prepared by kiln-casting at relatively high viscosities $\left(10^{6}-\right.$ $10^{3.5} \mathrm{dPa} \mathrm{s}$ ) or by modifying industrial glass products into $20 * 30 * 350 \mathrm{~mm}$ beam size, to be tested in fourpoint bending (140-280 $\mathrm{mm}$ roller spans). Prior to testing, the defects of the kiln-cast samples were documented. These are grouped in casting-related defects that occur both in the bulk and surfaces (crystalline inclusions, glassy inhomogeneities and air bubbles) and post-processing defects (e.g. machining, impact). From the occurring defects, the CSP stones and cord were identified as stress inducing.

A low number of specimens (1-5) was tested per glass category, providing an indication on the flexural strength and stiffness of each glass type, but not sufficient data for deriving to statistical predictions. The four-point bending experiments of kiln-cast glass specimens showed a flexural strength range of 30-73 MPa, according to the level of contamination and the chemical composition of the glass. The measured E moduli by the IET and DIC/4PB were in close agreement, and ranged from 60 to $62 \mathrm{GPa}$ for Borosilicate samples, 69-72 GPa for Poesia, 70-76 GPa for SLS glasses, to $79 \mathrm{GPa}$ for the Wertheim glass. The "Wertheim $1020^{\circ} \mathrm{C}$ " specimens, had the highest flexural strength as, in terms of structure, the small addition of $\mathrm{Al}_{2} \mathrm{O}_{3}$ and $\mathrm{B}_{2} \mathrm{O}_{3}$ and the higher $\mathrm{Na}_{2} \mathrm{O} / \mathrm{CaO}$ ratio contribute to a higher bond strength yet more flexibility in comparison to a conventional SLS glass, while its fluidity at the forming temperatures contributed to a smooth surface without infolds or stones. The heavily contaminated Car glass Maltha cullet rendered the lowest strength results, when cast at $1120{ }^{\circ} \mathrm{C}$, due to the presence of even $3 \mathrm{~mm}$ wide CSP stones. However, by adding $\approx$ $30 \%$ of a pure compatible SLS cullet to the original car glass cullet, the strength improved by $29 \%$. Improvement by $19 \%$ in the flexural strength was also observed in the FT Float composite beams, which showed an equivalent strength to the industrially produced single float glass panes $(\approx 56 \mathrm{MPa})$. Thus the engineering of composite glasses can lead to the improvement of contaminated cullet, provided that no significant stress is developed between the mixed glasses.

The fused $\left(970^{\circ} \mathrm{C}\right)$ and tack-fused $\left(650^{\circ} \mathrm{C}\right)$ specimens had a reduced failure stress, either due to the exposure of the crystalline interface at the bottom surface or due to the insufficient bonding at the tack-fused interface respectively. In the first case however, if the crystalline interface was situated in the bulk (parallel to the bottom surface), the strength was unaffected. On the contrary, the majority of the tack-fused samples failed at the interface due to high stress concentration developing due to the improper bonding. Regarding the kiln-cast specimens produced at higher temperatures and the industrially produced glass specimens, the majority failed from a flaw situated at the bottom surface, at the zone of maximum tensile stress. Only four cases showed failure from a flaw just above the surface, at a maximum distance of $1 \mathrm{~mm}$. Other flaws situated in the bulk were not activated, showing the increased capacity of voluminous cast glass specimens to tolerate defects situated in the bulk, as long as the inclusions' thermal expansion coefficient and size do not introduce stresses to the parent glass.

The main causes of failure identified were crystalline inclusions (and interfaces), infolds, bubbles, and machining damage. Machining damage was the prevailing cause of failure in the case of more pure specimens and industrially produced reference specimens, while contaminated or fused specimens failed from crystalline inclusions. This pattern explains the double trend observed when comparing the previously tested kiln-cast specimens $(30 * 30 * 240 \mathrm{~mm})$ of smaller fixture span $(100-200 \mathrm{~mm})$ with the current tested specimens. Despite the expectation that scaling up the specimens would lead to a general reduction in strength, this effect was only occurring in the case of the contaminated samples. Given that the purer samples would fail in both cases from similar grinding or impact flaws, no significant differences would appear in the flexural strength.

Regarding the degree of criticality of the different flaws, it was observed that fracture will not always initiate from the most defect populated zone or from the most suspicious singularity. This is linked either to the presence of a stress gradient (e.g. asymmetric loading due to surface unevenness of the beam at the rollers) or to the simultaneous acting of more than one flaws on the same spot. This fact reflects an engineering challenge for real-world applications of cast glass, as the subjection of the components to dynamic loading can turn an initially negligible defect (including defects in the bulk) to the weakest link. Quality control and defect inspection therefore becomes a multi-dimensional (6D) problem, where the defect profile is determined by the type, size, shape, location, orientation and the strength of the 
glass. Upon this matrix, two parameters are imposed: the local stress field (combination of loading scheme, component geometry and internal stresses) and the general population of flaws. This highlights the complications involved in any attempt to do size scaling and develop statistical predictions.

Adding to the above complexity due to the macroscopic defects originating from the casting and postprocessing of glass, microscopic alterations take place in the glass structure as well, in relation to the imposed thermal history. Both DIC/4PB and the IET measurements showed an increase of the E modulus upon kilncasting, in the order of 2-3 GPa. In addition, the DSC curves of selected samples showed an increase of the $T_{g}$ by $7-17^{\circ} \mathrm{C}$ and a lower fictive temperature for the kilncast glass. Moreover, a lower damping was reported for kiln-cast SLS glasses in comparison to the industrialized float glass. All the above information suggests increased compacting of the glass network due to the imposed slower cooling rates and the prolonged annealing schedule. This slower cooling could also be associated with an increase in hardness and thus with more brittle behavior of the glass. Further research is required to verify these microscopic changes and to identify the extent to which each individual factor (stiffness, hardness) affects the overall structural performance. Still, the effect the thermal history may have on the creation of macroscopic defects (e.g. larger or higher content of bubbles, extended crystallization) will have a greater impact on the flexural strength than the changes that the thermal history will impose to the glass network.

\section{Recommendations}

Several recommendations arise from this study concerning the engineering, production, testing, and quality control of cast glass components for building applications. Regarding the glass selection and engineering, the design of composite glasses is a promising idea worth exploring. Further experimentation with a broader range of glass combinations of different qualities is required, together with trials on the transition interface between the two glasses (abrupt vs. diffuse). Better grinding and polishing of the component surface is advised to improve the strength of the specimens.

Regarding the mechanical testing, in general a larger number of specimens ( $\approx 30$ per category) is required to derive statistically valid conclusions and safe engineer- ing data. Particularly meaningful would be the testing in large numbers of not only laboratory-produced, but also industrially cast specimens by different manufacturers. In this manner, the effect of the casting process (and thus of the thermal history and occurring defects) on the strength of the components can be properly studied. The reliability of the four-point bending test can be increased by introducing soft aluminum strips between the fixture pins and the glass specimens, to reassure complete contact of the beam and the rollers, and thus increased symmetry in the load distribution. Moreover, the use of a universal testing machine of smaller load capacity, closer to the expected failure load, can increase the accuracy of the results. In addition, it is advised to perform four-point bending experiments at different loading speeds, to investigate the influence of the sub-critical crack growth on the failure stress. Higher accuracy in the IET measurements can be achieved if completely rectangular beams with sharp edges (no filleting) are used. Measurement of the internal friction of the kiln-cast glasses should be performed in a temperature range from room temperature to annealing point in order to reveal structural modifications occurring due to thermal history. This information should be linked with repeated DSC testing to investigate possible transitions in the $\mathrm{T}_{\mathrm{g}}$ and fictive temperatures, and Knoop hardness experiments to see to what extent densification takes place. The investigation of hardness variations along the glass specimens is important for understanding the gradient of critical stress levels per flaw type and location along an inhomogeneous glass component.

In addition, the physio-chemical characterization of the most common casting-related defects by Scanning Electron Microscopy (SEM) is required, together with the development of automated defect mapping methodologies for the produced components. The development of a digital scanning system that documents the type, shape and orientation of surface and bulk flaws should be combined with repeated mechanical testing and fracture analysis, to lead to a reliable mathematical prediction model. For more pure cast glass components, the relationship between flaws and strength may be straight-forward and quality control will be a more simple process to follow. However, in the case of more contaminated components, produced from recycled cullet, defining the defect-strength relationship is a complex, multidimensional problem. Machine learning 
techniques could potentially be employed to reach safe strength predictions and aid the quality control process.

Acknowledgements The authors are very grateful to Georgos Stamoulis and Fred Schilperoort for their dedicated support in setting up the four-point bending experiment, and to Rong Yu and Mariska van der Velden for their valuable assistance with the preparation of the glass specimens. This research has been greatly supported by Professor Rob Nijsse, to whom we express our sincere gratitude. The authors would also like to acknowledge Nicky Slootmans and Theo Bollen (IMCE NV) for conducting the IET measurements and providing insights into the relevant theory, John van den Berg for his guidance with the DSC tests, and Ruud Hendrikx for his important contribution with the XRF characterization. We are very thankful to George Quinn (NIST), Mauro Overend, Bert Sluijs and Clarissa Justino de Lima (AGR Delft) for their scientific advice and insightful suggestions. Finally, we are very grateful to Danny Timmers (Maltha Glasrecycling Nederland), Marco Zaccaria and François Boland (AGC Belgium), and Klaas Roelfsema (Schott), for their important contribution in glass cullet.

\section{Declarations}

Conflict of interest On behalf of all authors, the corresponding author states that there is no conflict of interest.

Open Access This article is licensed under a Creative Commons Attribution 4.0 International License, which permits use, sharing, adaptation, distribution and reproduction in any medium or format, as long as you give appropriate credit to the original author(s) and the source, provide a link to the Creative Commons licence, and indicate if changes were made. The images or other third party material in this article are included in the article's Creative Commons licence, unless indicated otherwise in a credit line to the material. If material is not included in the article's Creative Commons licence and your intended use is not permitted by statutory regulation or exceeds the permitted use, you will need to obtain permission directly from the copyright holder. To view a copy of this licence, visit http://creativecommons.org/licenses/by/4.0/.

\section{References}

Aldinger, B.S., Collins, B.K.: Color Atlas of Stones in Glass. American Glass Research, Butler (2016)

Aldinger, B.S., de Haan, P.W.: Color Atlas of Glass Container Defects. American Glass Research, Butler (2019)

ASTM: E 1876-01: Standard Test Method for Dynamic Young's Modulus, Shear Modulus, and Poisson's Ratio by Impulse Excitation of Vibration. In: United States (2002)

Bartuška, M.: Glass Defects. Glass Service Inc., Prague (2008)

Biscoe, J., Warren, B.E.: X-ray diffraction study of soda-boric oxide glass. J. Am. Ceram. Soc. 21(8), 287-293 (1938). https://doi.org/10.1111/j.1151-2916.1938.tb15777.x

Boehm, L., Ingram, M.D., Angell, C.A.: Test of a year-annealed glass for the Cohen-Grest percolation transition. J. Non-
Cryst. Solids 44(2), 305-313 (1981). https://doi.org/10. 1016/0022-3093(81)90033-8

Bray, P.J., Xiao, S., Guo, Q.: Nuclear magnetic resonance investigations of the structure of alkali borate glasses. Phys. Chem. Glasses 4, 37-47 (1963)

Bristogianni, T., Oikonomopoulou, F., Justino de Lima, C.L., Veer, F.A., Nijsse, R.: Structural Cast Glass Components Manufactured from Waste Glass: Diverting Everyday Discarded Glass from the Landfill to the Building Industry. Heron 63 (1/2 Special issue: Structural Glass) (2018)

Bristogianni, T., Oikonomopoulou, F., Veer, F.A., Nijsse, R.: The effect of manufacturing flaws in the meso-structure of cast glass on the structural performance. In: Zingoni, A. (ed.) Advances in Engineering Materials, Structures and Systems: Innovations, Mechanics and Applications, pp. 1703-1708. CRC Press, Leiden (2019)

Bristogianni, T., Oikonomopoulou, F., Yu, R., Veer, F.A., Nijsse, R.: Investigating the flexural strength of recycled cast glass. Glass Struct. Eng. (2020). https://doi.org/10.1007/ s40940-020-00138-2

Campbell, D.E., Hagy, H.E.: Glasses and glass-ceramics. In: Lynch, C.T. (ed.) CRC Handbook of Materials Science, Volume II: Material Composites and Refractory Materials. CRC Press, Boca Raton (1975)

Duan, R.G., Roebben, G., Van der Biest, O., Liang, K.M., Gu, S.R.: Microstructure research of glasses by impulse excitation technique (IET). J. Non-Cryst. Solids 281(1), 213-220 (2001). https://doi.org/10.1016/S0022-3093(00)00397-5

Duan, R.G., Roebben, G., Van der Biest, O.: Glass microstructure evaluations using high temperature mechanical spectroscopy measurements. J. Non-Cryst. Solids 316(1), 138-145 (2003). https://doi.org/10.1016/ S0022-3093(02)01946-4

EUROGLAS: Products and data, 4th edn. Haldensleben (2016)

Fluegel, A.: Glass viscosity calculation based on a global statistical modeling approach. Glass Technol. Eur. J. Glass Sci. Technol. A 48, 13-30 (2007)

Gardon, R.: Modelling annealing lehrs for flat. Glass 65(8), 372-379 (1982). https://doi.org/10.1111/j.1151-2916. 1982.tb10487.x

Glass For Europe: The status of Flat Soda Lime Silicate Glass and its raw materials under REACH (Regulation (EC) No 1907/2006) (2015)

Gold Star: Investment Casting Powder Safety Data Sheet. www. goldstarpowders.com (2019)

Goodwin Refractory Services Ltd: Crystalcast (M248). www. grscastingpowders.com (2003)

Gross, T.M., Tomozawa, M.: Fictive temperature-independent density and minimum indentation size effect in calcium aluminosilicate glass. J. Appl. Phys. 104(6), 063529 (2008). https://doi.org/10.1063/1.2985907

Heimerl, W.: Chemical resistance and corrosion, and ion release. In: Bach, H., Krause, D. (eds.) Analysis of the Composition and Structure of Glass and Glass Ceramics. Springer, Berlin (1999)

Hodge, I.M.: Enthalpy relaxation and recovery in amorphous materials. J. Non-Cryst. Solids 169(3), 211-266 (1994). https://doi.org/10.1016/0022-3093(94)90321-2

Hulínský, V.: Glassy inhomogeneities-cords and layers. In: Bartuška, M. (ed.) Glass Defects. Práh, Prague (2008) 
Ito, S., Taniguchi, T.: Effect of cooling rate on structure and mechanical behavior of glass by MD simulation. J. NonCryst. Solids 349, 173-179 (2004). https://doi.org/10. 1016/j.jnoncrysol.2004.08.180

Li, H., Agarwal, A., Tomozawa, M.: Effect of fictive temperature on dynamic fatigue behavior of silica and soda-lime glasses. J. Am. Ceram.Soc. 78(3), 1393-1396 (1995). https://doi. org/10.1111/j.1151-2916.1995.tb08502.x

Lord, J.D., Morrell, R.: Elastic modulus measurement. In: A National Measurement Good Practice Guide, vol. 98. NMS (2006)

Milberg, M.E., O’Keefe, J.G., Verhelst, R.A., Hooper, H.O.: Boron coordination in sodium borosilicate glasses. Phys. Chem. Glasses 13(3), 79-84 (1972)

Moynihan, C.T., Easteal, A.J., De Bolt, M.A., Tucker, J.: Dependence of the fictive temperature of glass on cooling rate. J. Am. Ceram. Soc. 59(1-2), 12-16 (1976). https://doi.org/ 10.1111/j.1151-2916.1976.tb09376.x

Narayanaswamy, O.S.: Optimum schedule for annealing flat. Glass 64(2), 109-114 (1981). https://doi.org/10.1111/j. 1151-2916.1981.tb09586.x

Němec, L.: Gaseous inhomogeneities in the glass-bubbles. In: Bartuška, M. (ed.) Glass Defects. Práh, Prague (2008)

Oikonomopoulou, F., Bristogianni, T., Barou, L., Veer, F.A., Nijsse, R.: The potential of cast glass in structural applications. Lessons learned from large-scale castings and state-of-the art load-bearing cast glass in architecture. J. Build. Eng. 20, 213-234 (2018). https://doi.org/10.1016/j. jobe.2018.07.014

Oikonomopoulou, F., Bristogianni, T., Veer, F.A., Nijsse, R.: The construction of the Crystal Houses façade: challenges and innovations. Glass Struct. Eng. 3(1), 87-108 (2018a). https://doi.org/10.1007/s40940-017-0039-4

Oikonomopoulou, F., Bristogianni, T., Barou, L., Jacobs, E., Frigo, G., Veer, F.A., Nijsse, R.: Interlocking cast glass components, exploring a demountable dry-assembly structural glass system. Heron 63, 103-138 (2018c)

Paech, C., Göppert, K.: Innovative Glass Joints-The 11 March Memorial in Madrid. Paper presented at the Challenging Glass, Conference on Architectural and Structural Applications of Glass, Delft (2008)

Quinn, G.D.: Weibull strength scaling for standardized rectangular flexure specimens. J. Am. Ceram. Soc. 86(3), 508-510 (2003). https://doi.org/10.1111/j.1151-2916. 2003.tb03329.x

Quinn, G., Morrell, R.: Design data for engineering ceramics: a review of the flexure test. J. Am. Ceram. Soc. 74, 20372066 (1991). https://doi.org/10.1111/j.1151-2916.1991. tb08259.x

Quinn, G.D., Ives, L.K., Jahanmir, S.: On the nature of machining cracks in ground ceramics: part II-comparison to other silicon nitrides and damage maps. Mach. Sci. Technol. 9, 211-237 (2005). https://doi.org/10.1081/MST-200059051

Quinn, G.D., Sparenberg, B.T., Koshy, P., Ives, L.K., Jahanmir, S., Arola, D.D.: Flexural strength of ceramic and glass rods. J. Test. Eval. 37, 222-244 (2009). https://doi.org/10. 1520/JTE101649
Radovic, M., Lara-Curzio, E., Riester, L.: Comparison of different experimental techniques for determination of elastic properties of solids. Mater. Sci. Eng.: A 368(1), 56-70 (2004). https://doi.org/10.1016/j.msea.2003.09.080

Roebben, G., Bollen, B., Brebels, A., Humbeeck, J., Van der Biest, O.: Impulse excitation apparatus to measure resonant frequencies, elastic moduli, and internal friction at room and high temperature. Rev. Sci. Instrum. 68, 4511-4515 (1997). https://doi.org/10.1063/1.1148422

Roebben, G., Donzel, L., Stemmer, S., Steen, M., Schaller, R., Van der Biest, O.: Viscous energy dissipation at high temperatures in silicon nitride. Acta Mater. 46(13), 4711-4723 (1998). https://doi.org/10.1016/S1359-6454(98)00131-1

Schott: DURAN Technical Data (2017)

Shelby, J.E.: Introduction to Glass Science and Technology. The Royal Society of Chemistry, London (2005)

Shelby, J.E.J., Day, D.E.: Mechanical relaxations in mixed-alkali silicate glasses: I. Results 52(2), 169-173 (1969). https:// doi.org/10.1111/j.1151-2916.1969.tb13358.x

Sheybany, H.A.: De La Structure Des Verres Alkalinosilicates Mixtes. Verres et Refractaires 2, 127-145 (1948)

Smedskjaer, M.M., Jensen, M., Yue, Y.: Effect of thermal history and chemical composition on hardness of silicate glasses. J. Non-Cryst. Solids 356(18), 893-897 (2010). https://doi. org/10.1016/j.jnoncrysol.2009.12.030

Stevels, J.M.: The structure and physical properties of glass. In: Flügge, S. (ed.) Handbuch der Physik. Thermodynamics of Liquids and Solids, vol. 13, pp. 511-643. Springer, Berlin (1962)

Striepe, S., Potuzak, M., Smedskjaer, M.M., Deubener, J.: Relaxation kinetics of the mechanical properties of an aluminosilicate glass. J. Non-Cryst. Solids 362, 40-46 (2013). https://doi.org/10.1016/j.jnoncrysol.2012.11.017

van Dam, S.: Experimental Analysis of the Post-Fracture Response of Laminated Glass Under Impact and Blast Loading. Ghent University, Ghent (2017)

van Limpt, J.A.C.: Modeling of evaporation processes in glass melting furnaces. Technische Universiteit Eindhoven (2007)

Varshneya, A.K.: Fundamentals of Inorganic Glasses, 2nd edn. Society of Glass Technology, Sheffield (2013)

Varughese, B., Lee, Y.K., Tomozawa, M.: Effect of fictive temperature on mechanical strength of soda-lime glasses. J. Non-Cryst. Solids 241(2), 134-139 (1998). https://doi. org/10.1016/S0022-3093(98)00762-5

Zheng, Q., Zhang, Y., Montazerian, M., Gulbiten, O., Mauro, J.C., Zanotto, E.D., Yue, Y.: Understanding glass through differential scanning calorimetry. Chem. Rev. 119(13), $7848-7939$ (2019). https://doi.org/10.1021/acs.chemrev. $8 \mathrm{~b} 00510$

Publisher's Note Springer Nature remains neutral with regard to jurisdictional claims in published maps and institutional affiliations. 